University of Tennessee Health Science Center UTHSC Digital Commons

\title{
The Role of BiP Nucleotide Exchange Factor Sil1 in Immunoglobulin Biosynthesis
}

Tyler Sanford

University of Tennessee Health Science Center

Follow this and additional works at: https://dc.uthsc.edu/dissertations

Part of the Medical Cell Biology Commons, and the Medical Immunology Commons

\section{Recommended Citation}

Sanford, Tyler, "The Role of BiP Nucleotide Exchange Factor Sil1 in Immunoglobulin Biosynthesis" (2012). Theses and Dissertations (ETD). Paper 255. http://dx.doi.org/10.21007/etd.cghs.2012.0275. 


\title{
The Role of BiP Nucleotide Exchange Factor Sil1 in Immunoglobulin Biosynthesis
}

\begin{abstract}
$\mathrm{BiP}$ is an essential endoplasmic reticulum resident molecular chaperone of the HSP70 family that binds exposed hydrophobic regions of unfolded proteins. Substrates bound by BiP are protected from dangerous non-specific interaction with other unfolded proteins via their aggregation prone exposed hydrophobic regions, which are normally buried in the native state, and act as BiP binding targets. For these substrates to mature into the native state, BiP must be released. Like all HSP70 family members, cycles of BiP binding and release are nucleotide dependent and facilitated by two genres of cochaperones, HSP40s, and nucleotide exchange factors (NEFs). HSP40s function in stimulating the hydrolysis of ATP, which causes a conformational change that induces tight binding of BiP to substrate, whereas, NEFs stimulate the escape of ADP that allows BiP to release substrate so that it can progress toward its final native state.
\end{abstract}

In 2002, we identified a mammalian BiP associated protein, Sil1, with nucleotide exchange activity. In 2005, Sil1 became the first molecular cochaperone known to cause disease upon discovery of mutations that lead to Marinesco-Sjögren Syndrome (MSS), a debilitating recessive disease characterized by severe cerebellar atrophy and a wide range of systemic defects. Now, many Sil1 mutations in MSS are known to result in interrupted BiP binding or Sil1 instability. We have attained an animal model of MSS with a Sil1 mutation that results in loss of a major BiP interaction site. This model, known as the Woozy mouse due to its striking ataxic phenotype, closely phenocopies many aspects of human MSS yet has been the spotlight of very few studies.

For the first time, we have performed a detailed examination on the effects of Sil1 loss on a specific BiP substrate, immunoglobulin (Ig) heavy chain. This is a highly relevant target to study for two main reasons. First, because Ig is the best characterized BiP substrate and is readily tractable by several wellestablished methods. Second, because production of $\mathrm{Ig}$ is an essential part of primary and secondary immune responses that have not been examined in MSS patients, or anywhere in terms of Sil1 function. We examined levels of total IgM, IgG2b and IgG1 as well as antigen-specific levels of these same antibodies in the serum of woozy mice by ELISA before and after immunization. We discovered significantly lower levels of total IgM in Woozy mice but, surprisingly, did not observe any defects in total production of other Ig isotypes. We were also surprised to find no differences in concentration of antigenspecific Ig in serum after immunization, including IgM levels. Neither did we observe any defects in IgM production by western blotting or ELISA of cell supernatant from cultured primary B cells subjected to LPS stimulation. Furthermore, although we hypothesized that Sil1 null cells may have higher levels of some chaperones or cofactors as part of an ER stress induced compensatory mechanism for Sil1 loss (this has been shown to be the case in Purkinje cells of the neurodegeneration prone cerebellum in Sil1 $\mathrm{KO}$ mice), this was not our observation in B cells or activated plasmablasts.

Based on our data from Woozy mice and also from primary cultured B cells, we hypothesize that individuals affected with MSS will produce normal levels of Ig in response to antigen, which is necessary for healthy primary and secondary immune responses. We also have additional preliminary data to suggest that there may be some age related defects in the Woozy mouse model that have not been previously reported. However, these studies are ongoing and solicit further investigation.

\section{Document Type}

Thesis

\section{Degree Name}

Master of Science (MS) 


\section{Program}

Biomedical Sciences

Research Advisor

Linda Hendershot, Ph.D.

\section{Keywords}

BiP, Sil1, Grp170, MSS, Marinesco-Sjögren Syndrome, Nucleotide exchage factor

\section{Subject Categories}

Medical Cell Biology | Medical Immunology | Medical Sciences | Medicine and Health Sciences 
The Role of BiP Nucleotide Exchange Factor Sil1 in Immunoglobulin Biosynthesis

\author{
A Thesis \\ Presented for \\ The Graduate Studies Council \\ The University of Tennessee \\ Health Science Center \\ In Partial Fulfillment \\ Of the Requirements for the Degree \\ Master of Science \\ From The University of Tennessee
}

By

Tyler Sanford

December 2012 
Copyright (C) 2012 by Tyler Sanford. All rights reserved. 


\section{ACKNOWLEDGEMENTS}

I would like to thank Dr. Linda Hendershot for being a wonderful mentor, and for all of her guidance on this project. I sincerely hope that my career positively reflects the leadership I observed during my time as your student. You have been a genuine, kind, helpful director and friend through one of the greatest learning experiences of my life. I will never forget your inspiring example.

My committee members also deserve a special thank-you for all of their advice and support - Dr. Tony Marion, Dr. Terry Geiger, Dr. Mike Whitt, and Dr. John Cox. You have each contributed much-appreciated time and effort that has helped drive the success of this project. I am very grateful for all of your help.

I would also like to thank all of the Hendershot lab members, past and present, who were a part of this journey. Dr. Amanda Preston, Dr. Beata Lizak, Dr. Cliff Toleman, Dr. Ethel Pereira, Dr. Joel Otero, Julia Behnke, Dr. Kyung Tae Chung, Dr. Matthias Feige, Melissa Mann, Dr. Moritz Marcinowski, Viraj Ichhaporia, Walid Awad, and Dr. Yuichiro Shimizu. I could write a book on the experiences and fun times we've had, I hope I never forget all the laughs - good and bad. We have journeyed far together. Many hilarious photoshopped pictures, unforgettable late night trips downtown, wonderful cookouts, and awesome trips to Jessieville and Clarksdale will forever standout among my favorite memories. I will never forget you, thanks for making my time in Memphis so enjoyable! Please keep in touch!

I must briefly mention my Memphis friends who have helped me keep my sanity through all of this. Mike Wainscott, Adam Langley, Bo and Rachel Franklin, Will Ireland, David and Hillary Butler, Kevin Tompkins, Matt Kiefer, Josh Hughes, Ken Busby - y'all are the best!

Lastly, I would like to thank my family. You are my inspiration and the source of any good that I am capable of accomplishing. Mom and Dad, I feel very blessed to have the parents that every son was intended to have. Shea, my best friend and brother - words cannot express how much I value our friendship. My wonderful grandparents - Papa Eime, Nannie, Papa Gary, and Meme, I am eternally grateful for every way that you have shown your love and support both large and small.

Whatever good may come in my life - it is because of you all. Issac Newton realized that our accomplishments are rarely our own, and I wholeheartedly agree with his timeless words - "If I have seen further, it is because I have stood on the shoulders of giants." There are no words, or sufficient actions, to express how much I appreciate each of you. Thank you.

\section{Uva uvam vivendo varia fit.}




\begin{abstract}
$\mathrm{BiP}$ is an essential endoplasmic reticulum resident molecular chaperone of the HSP70 family that binds exposed hydrophobic regions of unfolded proteins. Substrates bound by BiP are protected from dangerous non-specific interaction with other unfolded proteins via their aggregation prone exposed hydrophobic regions, which are normally buried in the native state, and act as BiP binding targets. For these substrates to mature into the native state, BiP must be released. Like all HSP70 family members, cycles of BiP binding and release are nucleotide dependent and facilitated by two genres of cochaperones, HSP40s, and nucleotide exchange factors (NEFs). HSP40s function in stimulating the hydrolysis of ATP, which causes a conformational change that induces tight binding of BiP to substrate, whereas, NEFs stimulate the escape of ADP that allows $\mathrm{BiP}$ to release substrate so that it can progress toward its final native state.
\end{abstract}

In 2002, we identified a mammalian BiP associated protein, Sil1, with nucleotide exchange activity. In 2005, Sill became the first molecular cochaperone known to cause disease upon discovery of mutations that lead to Marinesco-Sjögren Syndrome (MSS), a debilitating recessive disease characterized by severe cerebellar atrophy and a wide range of systemic defects. Now, many Sill mutations in MSS are known to result in interrupted BiP binding or Sill instability. We have attained an animal model of MSS with a Sill mutation that results in loss of a major BiP interaction site. This model, known as the Woozy mouse due to its striking ataxic phenotype, closely phenocopies many aspects of human MSS yet has been the spotlight of very few studies.

For the first time, we have performed a detailed examination on the effects of Sill loss on a specific BiP substrate, immunoglobulin (Ig) heavy chain. This is a highly relevant target to study for two main reasons. First, because Ig is the best characterized BiP substrate and is readily tractable by several well-established methods. Second, because production of Ig is an essential part of primary and secondary immune responses that have not been examined in MSS patients, or anywhere in terms of Sill function. We examined levels of total $\operatorname{IgM}, \operatorname{IgG} 2 \mathrm{~b}$ and $\mathrm{IgG} 1$ as well as antigen-specific levels of these same antibodies in the serum of woozy mice by ELISA before and after immunization. We discovered significantly lower levels of total IgM in Woozy mice but, surprisingly, did not observe any defects in total production of other Ig isotypes. We were also surprised to find no differences in concentration of antigen-specific Ig in serum after immunization, including IgM levels. Neither did we observe any defects in IgM production by western blotting or ELISA of cell supernatant from cultured primary B cells subjected to LPS stimulation. Furthermore, although we hypothesized that Sill null cells may have higher levels of some chaperones or cofactors as part of an ER stress induced compensatory mechanism for Sill loss (this has been shown to be the case in Purkinje cells of the neurodegeneration prone cerebellum in Sill KO mice), this was not our observation in B cells or activated plasmablasts.

Based on our data from Woozy mice and also from primary cultured B cells, we hypothesize that individuals affected with MSS will produce normal levels of Ig in 
response to antigen, which is necessary for healthy primary and secondary immune responses. We also have additional preliminary data to suggest that there may be some age related defects in the Woozy mouse model that have not been previously reported. However, these studies are ongoing and solicit further investigation. 


\section{TABLE OF CONTENTS}

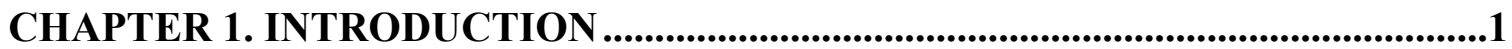

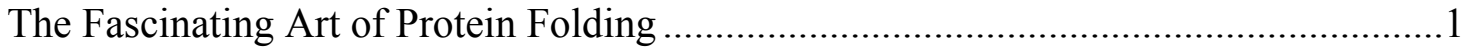

A Brief History of Studies That Shed Light on Protein Folding ..................................

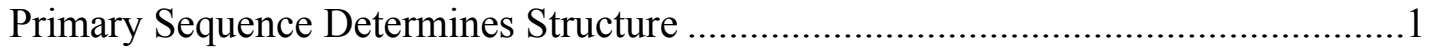

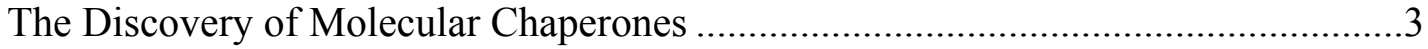

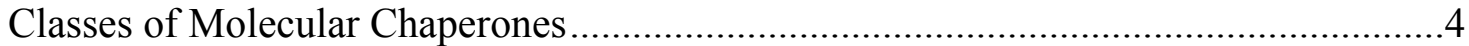

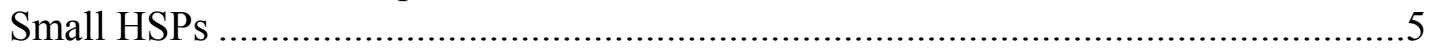

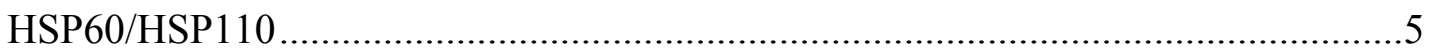

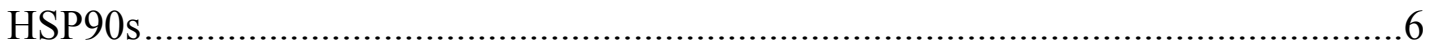

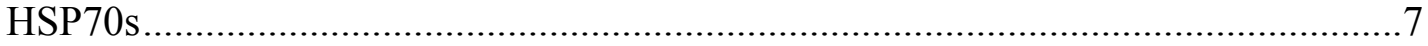

Endoplasmic Reticulum Resident HSP70 Chaperone BiP ................................ 10

Immunoglobulin Is a Model Substrate for BiP Mediated Protein Folding ........... 10

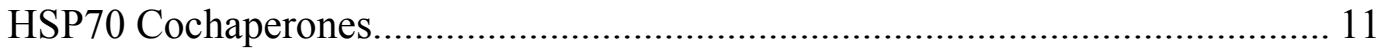

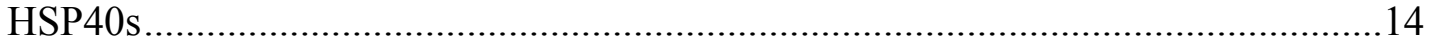

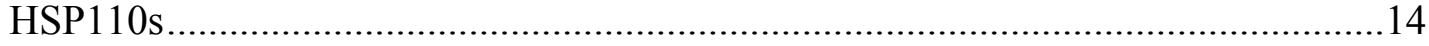

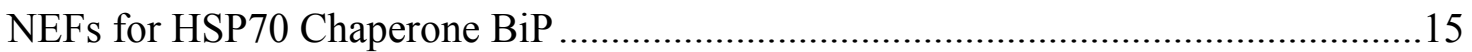

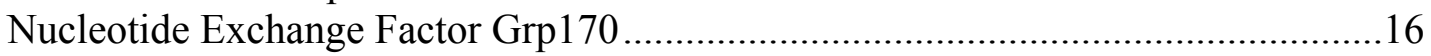

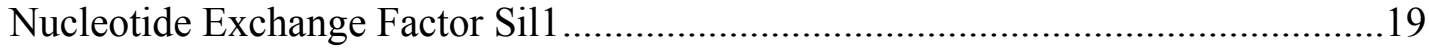

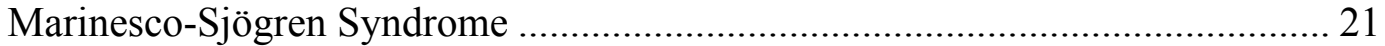

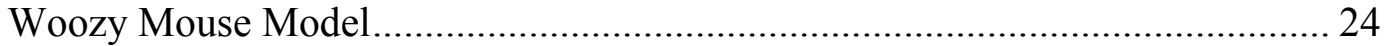

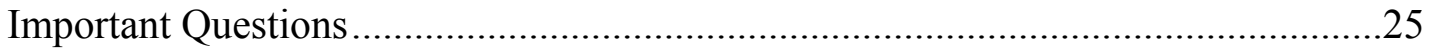

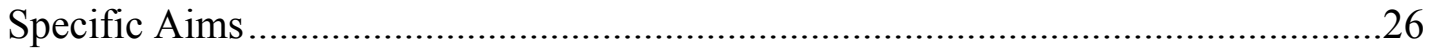

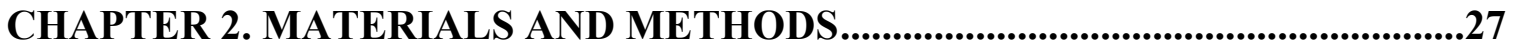

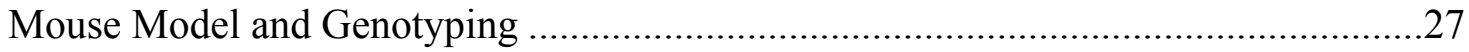

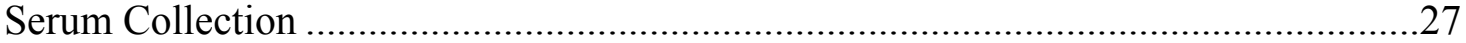

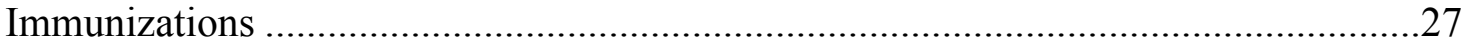

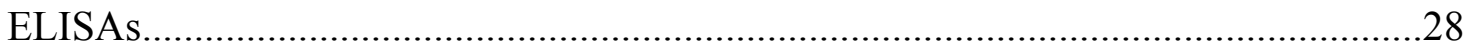

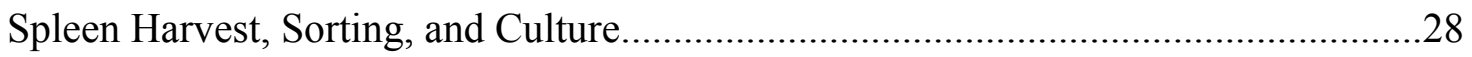

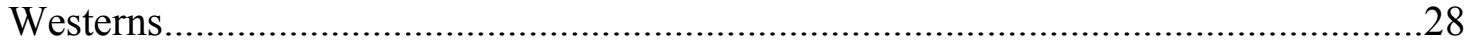

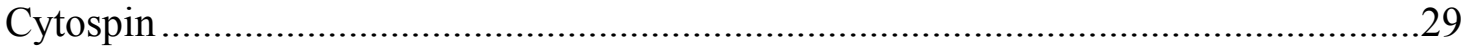

CHAPTER 3. THE EFFECTS OF SIL1 LOSS ON IMMUNOGLOBULIN

BIOSYNTHESIS AT THE ORGANISMAL LEVEL ..........................................30

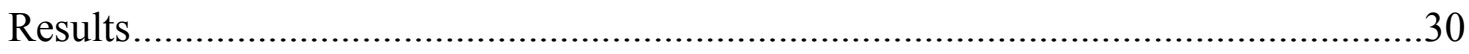

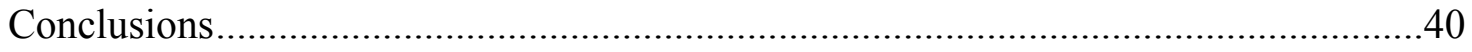

\section{CHAPTER 4. THE EFFECTS OF SIL1 LOSS ON IMMUNOGLOBULIN} BIOSYNTHESIS AT THE CELLULAR LEVEL ...............................................41

Results

Conclusions 
CHAPTER 5. ADDITIONAL STUDIES ON THE PHENOTYPE OF AGED

SIL1 KO MICE ................................................................................................................47

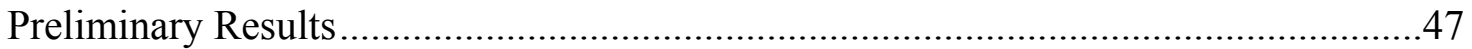

Preliminary Conclusions and Future Direction ..........................................................53

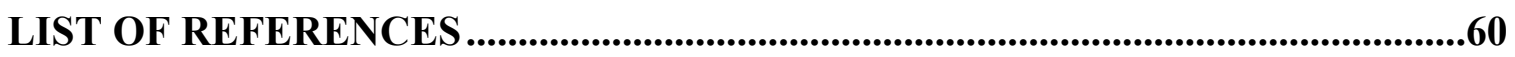

VITA 


\section{LIST OF TABLES}

Table 1-1. Nomenclature of Heat Shock Family Members..........................................5

Table 1-2. Relevant HSP70 Chaperone Cofactors .....................................................13

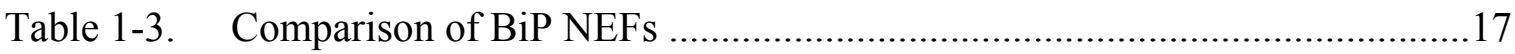

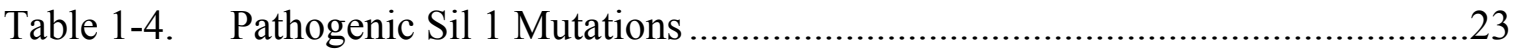

Table 3-1. Primers Used in Genotyping Sil1 Null Mice .............................................31

Table 4-1. Strategy for Isolating Purified Splenic B Cells ........................................42

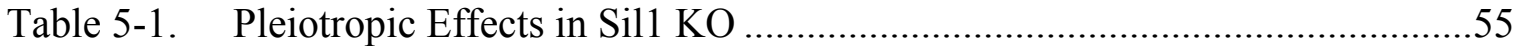

Table 5-2. Additional Phenotypes of Aged Will KO Mice ........................................56 


\section{LIST OF FIGURES}

Figure 1-1. Protein Folding Schematic ..................................................................

Figure 1-2. Structure of an HSP70 Family Member......................................................

Figure 1-3. Nucleotide-Dependent Chaperoning Cycle of HSP70s ..............................

Figure 1-4. BiP Association with Assembling Ig Precursors but Not the Completely Assembled Protein ................................................................................ 12

Figure 1-5. Plasma Cell Function Is Dependent on Expansion of the ER and Its

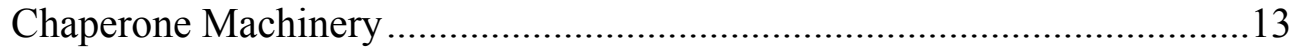

Figure 1-6. Tissue Expression of ER Chaperone Machinery ........................................18

Figure 1-7. Stress Induction of ER Chaperone Machinery......................................20

Figure 1-8. Sill Crystal Structure and Mechanism ....................................................22

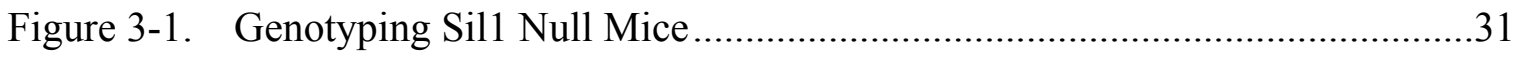

Figure 3-2. Basal Serum Concentrations of IgM, IgG2b, and IgG1 in WT and Sill

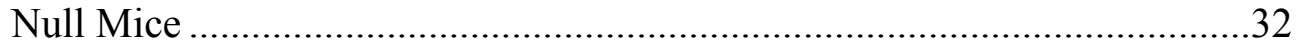

Figure 3-3. Time Course of Immunizations and Serum Collection...............................34

Figure 3-4. Antigen-Specific IgM, IgG2b, and IgG1 Production Measured over 24 Days Post Immunization ...........................................................................36

Figure 3-5. Total Non-Antigen-Specific Igm, IgG2b, and IgG1 Production over 24 Days Post Immunization

Figure 4-1. Sill Null Mice Respond to LPS Stimulation by Producing IgM Positive Plasmablasts.

Figure 4-2. Ex Vivo IgM Secretion of Activated Plasma Cells from WT and Sill KO Mice in Response to LPS Stimulation

Figure 4-3. Ig Mu Heavy Chain and Kappa Light Chain Production in Response to LPS Stimulation

Figure 4-4. Wild Type and Sil1 Null Plasma Cells Upregulate BiP Cofactors Erdj3 and Grp170 in Response to LPS Stimulation

Figure 5-1. Sil1 Null Mice Have Higher Basal Levels of Grp170 Expression in a Heterogeneous Population of Non-B Cell Splenocytes That Is Not Further Upregulated in Culture. 
Figure 5-2. Identification of Splenic Cell Populations in Aged WT and Sill KO Mice

Figure 5-3. Distribution of Pooled Splenocytes from 3 WT and 3 Sill KO Aged Mice

Figure 5-4. Electron Micrograph of Mac1+/Gr1+ Sorted Cells

Figure 5-5. Gross Anatomical Comparison of Aged WT Female vs. Sill KO Female with Retained Mummified Fetuses and Large Pasteurella pneumotropica Infection.

Figure 5-6. Size Comparison of Organs in WT vs. Sil1 Null Mouse with Mummified Fetuses and Pasteurella pneumotropica Infection.

Figure 5-7. Number and Relative Percentages of Non-Red Cells Present in Blood of Aged Matched WT Control and Sill KO Female with Retained Mummified Fetuses and Large Pasteurella pneumotropica Infection

Figure 5-8. Quantitation of Hematocrit, Red Blood Cells, and Hemoglobin in Blood of Aged Matched WT Control and Sill KO Female with Retained Mummified Fetuses and Large Pasteurella pneumotropica Infection 


\section{CHAPTER 1. INTRODUCTION}

\section{The Fascinating Art of Protein Folding}

The process of protein folding is a fascinating art. Unfolded proteins are essentially inactive and ultimately destructive to cells, however, properly folded tertiary protein structures are essential for all life forms to exist. The spectrum of influence exerted by the delicate process of protein folding is almost unfathomable. Properly folded proteins are estimated to comprise over half the dry biomass on earth, estimated at over 500 billion metric tons apart from bacteria [1], yet catastrophic diseases can result from even the slightest protein conformational variations. Protein folding is an intriguing cellular process that is essential to every aspect of life, nonetheless this phenomenon is still incompletely understood and a very active area of research that is relevant to the highest degree.

\section{A Brief History of Studies That Shed Light on Protein Folding}

Over the past half-century, many scientists have stimulated our fascination of the awe-inspiring elegance of nature represented in the process protein folding. A brief historical review of some of the major scientists and their experiments in this light helps show how far the field of molecular biology has come and serves as a relevant and interesting introduction to the context behind aims set forth in this project. Although there are innumerable contributors to the field of protein folding knowledge I have chosen to focus this brief historical review on two major paradigm-shifting discoveries that are essential to our understanding of how proteins fold - the discovery that primary amino acid sequence determines protein structure and the discovery of molecular chaperones.

\section{Primary Sequence Determines Structure}

Protein folding is an essential step required for the expression of genetic material. The DNA/RNA code specifies the linear sequence of amino acids in a given protein, but these amino acids must form secondary structures that interact, or "fold", to form tertiary and in some cases quaternary structures which enable their biological function (Figure 1-1). The problem of folding proteins at the cellular level is enormously complex, yet one that is solved with clever simplicity. In 1972 Christian Anfinsen was awarded the Nobel Prize in chemistry for shedding the first light on how cells handle this problem. He discovered that primary amino acid sequences intrinsically encode information that drives the transformation of linear amino acid sequences into complex structures. Anfinsen's paradigm- shifting experiments on pancreatic ribonuclease are still revered among the most enlightening experiments in the history of cell biology [2].

Ribonuclease, in its native state, contains four intramolecular disulfide bonds created from eight sulfhydryl-containing cysteine residues. Anfinsen showed that, after 


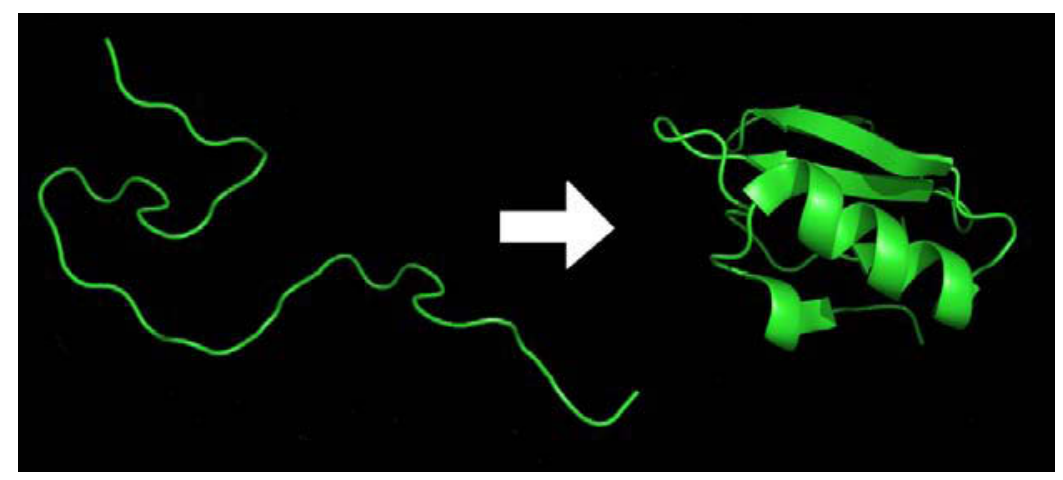

Figure 1-1. Protein Folding Schematic. The central dogma of molecular biology specifies that the flow of information within organisms eventually results in the genetic code being trapped in a final proteinaceous state. The mechanism by which a linear strand of amino acids is transformed into a functional molecule with a definite threedimensional structure is the process of protein folding. The arrow shows the protein before and after folding. (Reprinted with permission from Wikipedia. The Free Encyclopedia. http://www.en.wikipedia.org/wiki/Protein_folding. Accessed April 3, 2012.)

denaturation by reductive cleavage of these disulfide bonds, renaturation of ribonuclease requires that only 1 of 105 possible pairings of the sulfyhydryl groups must occur. The process of protein folding is the furthest thing from a random event.

When fully reduced ribonuclease is allowed to reoxidize under denaturing conditions (e.g. $8 \mathrm{M}$ urea, which diminishes the hydrophobic effect), a mixture of products containing all 105 disulfide bond combinations is produced, almost all of which are biologically inactive. However, Anfinsen observed that if the denaturant is removed and this mixture of 'scrambled' proteins with randomly formed disulfide bonds is exposed to reagent with a small amount of sulfhydryls (e.g. 2-Mercaptoethanol, which cleaves or reduces disulfide bonds), disulfide interchange occurs to form the correct disulfide bonds and a homogenous solution of native enzyme with full biological activity is reproduced. This energetically favorable and highly reproducible native structure is initiated and stabilized through non-covalent interactions such as hydrophobic packing, ionic interaction, hydrogen bonding, Van Der Waals forces and disulfide bonds that radiate from the primary sequence of the protein. These same chemical interactions serve to limit "off pathway" intermediates that would not lead to a biologically active protein. This is what is meant by Anfinsen's bold claim that primary sequence determines native structure.

Once secondary structures consisting of $\alpha$-helices, $\beta$-sheets, and random coils have formed, a large repertoire of intramolecular interactions occur that further enable the process of protein folding and synergistically drive and stabilize secondary, tertiary, and quaternary protein structures. For example, hydrophilic amino acid residues are more stable on the exterior surface of proteins where they energetically favor interaction with 
water molecules and maintain solubility. Conversely, amino acids with hydrophobic nonpolar side chains are most commonly found in the core of proteins where they are shielded from the aqueous hydrophilic exterior. In addition, interactions between positively and negatively charged amino acids lead to the formation of salt bridges that can stabilize regions of a protein, whereas interactions between like charges serve to prevent mis-interaction between inappropriate regions. All of these interactions emanate from the primary sequence of translated amino acids and their unique side chain residues. The sum of these interactions leads to the production of the biologically active conformation of the protein.

Anfinsen's dogma is fundamental yet incomplete in understanding the principles that enable protein folding in a cell. The shortcoming of Anfinsen's experiments is that they were performed under alien circumstances. The very dilute solution containing a single purified protein that was optimized to allow spontaneous refolding in his experiments is worlds different than the crowded, molecularly diverse intracellular environment in which proteins are actually synthesized and folded. Also, the bovine ribonuclease Anfinsen used as a model is a relatively small, monomeric, single domain protein of 124 amino acids; whereas the genome-wide average of eukaryotic proteins is between 300-400 amino acids [3] many of these also contain multiple domains assembled from a number of distinct protein subunits and are therefore much more complicated to fold and assemble. In addition, unlike Anfinsen's experiments where a full-length protein was denatured and allowed to refold, many proteins begin to fold co-translationally in vivo or before the entire polypeptide chains have been synthesized. So, there are broad ranges of variables hazardous to protein folding in the intracellular environment that must be dealt with in vivo that are not accounted for by Anfinsen's explanation alone. Not surprisingly, another elegant solution to a complex question of cell biology was found by evolution in the discovery of molecular "chaperones".

\section{The Discovery of Molecular Chaperones}

In the early 1980's, Ron Laskey was interested in the rapid formation of nucleosomes that occurs in amphibian embryos after fertilization. He sought to determine if nucleosomes (i.e., histones + DNA) that were dissociated by high salt concentrations would reassociate spontaneously as the salt concentrations were lowered back to intracellular levels. These experiments proved to be a spectacular failure, and even worse, resulted in the formation of large nonspecific aggregates rather than reconstructed nucleosomes [4]. Eventually, Laskey isolated a factor from a nuclear homogenate, now called nucleoplasmin, which allowed nucleosomes to reform and simultaneously prevented the formation of nonspecific aggregates. This previously unknown protein was found to successfully promote nucleosome reformation by binding histones and reducing their strong positive charge, thereby preventing improper association with other proteins in the crowded cellular extract, but was not a component of the final structure of nucleosomes. Following this exciting discovery, Laskey coined the term "molecular chaperone" in 1978 to describe the function of what would soon become representative of a new class of proteins. Laskey concluded, "The role of the protein we have purified is 
that of a 'molecular chaperone' which prevents incorrect ionic interactions between histones and DNA". However, unlike nucleoplasmin, which serves to "chaperone" a very specific client, the majority of molecular chaperones are generalist and have a vast number of client proteins that they can help to fold.

\section{Classes of Molecular Chaperones}

Today, the definition of molecular chaperone has been extended to include any protein that interacts with, stabilizes or helps another protein to acquire its functionally active conformation, without being present in its final structure [5]. Also important to the modern concept of chaperone function is the understanding that chaperones are not limited by the job description of "protein folding". Proteostasis depends on continual chaperone maintenance in many ways, including de novo folding, refolding, multimeric assembly, trafficking, and degradation, as well as maintaining proteins (e.g. kinases and transcription factors) in a state that can be readily activated. The repertoire of chaperones produced by evolution includes an interesting variety of proteins and mechanisms to carry out these functions.

The majority of molecular chaperones are induced by excessive temperatures, which adversely affects protein folding, and as such are classified as heat shock proteins (HSPs). Collectively, this family of proteins constitutes an ancient cytoprotective mechanism known as the heat shock response, which was discovered by fortuitous encounter in 1962 when Ferruccio Ritossa's incubator overheated [6]. This fast-acting and intense emergency response is among the most highly conserved genetic systems ever studied, being found in every organism examined. Importantly however, HSPs play a role not only during stress, but are also constitutively expressed as house keeping proteins. Furthermore, HSPs are induced in a wide variety of cellular stresses other than elevated temperature. Unfolded proteins, hypoxia, low glucose, alcohol, radiation, $\mathrm{Ca}^{2+}$ fluctuations, heavy metal ions, cold shock, bacterial toxins, infection and almost any conceivable stress that disturbs proteostasis can cause an increase in HSP production [7, $8]$.

Keeping up-to-date with the increasing number chaperones and their varying roles in proteostasis is an intimidating endeavor. In an attempt to lessen the semantic difficulty of this task, the scientific community organized a system of conventional nomenclature for HSPs in 2009 [9]. Many proteins were given new systematic names at this time. The new naming system is based on the highly consistent HUGO Gene Nomenclature Committee and used in the National Center of Biotechnology Information Entrez Gene database for heat shock genes. This scheme organizes human HSP chaperones into six sub-categories by gene family and approximate molecular weights; Table 1-1 summarizes the highlights of this literature review. Currently, however, much of the older nomenclature still predominates in the literature. 
Table 1-1. Nomenclature of Heat Shock Family Members.

\begin{tabular}{cccc}
\hline $\begin{array}{c}\text { Heat Shock } \\
\text { Protein Family }\end{array}$ & $\begin{array}{c}\text { Heat Shock } \\
\text { Gene Family }\end{array}$ & $\begin{array}{c}\text { Human Family } \\
\text { Members }\end{array}$ & $\begin{array}{c}\text { Mouse Family } \\
\text { Orthologs }\end{array}$ \\
\hline Small HSPs & HSPB & 11 & 11 \\
HSP40s & DNAJ & 50 & 50 \\
HSP60/HSP10 & HSPD/HSPE & $1 / 1$ & $1 / 1$ \\
HSP70s & HSPA & 13 & 11 \\
HSP90s & HSPC & 5 & 4 \\
HSP110s & HSPH & 4 & 4 \\
\hline
\end{tabular}

\section{Small HSPs}

Members of the small HSP family (HSPB) are generally confined to the cytoplasm of prokaryotes and eukaryotes. Although these diminutive chaperones are the least of their class by size ranging from $\sim 15-30 \mathrm{kD}$, many small HSPs may combine to form large oligomeric complexes between $\sim 400-500 \mathrm{kD}$, which provide high diversity in chaperone specificity. A conserved crystallin domain flanked by variable $\mathrm{N}$ - and $\mathrm{C}$ termini characterizes all 11 human small HSPs [9]. The most studied small HSPs in humans are the $\alpha / \beta$ crystallins (HSPB4-5). These characteristic small HSPs are involved in an extremely wide range of proteome maintenance specializing in prevention of aggregate formation. In the vertebrate eye, up to $\sim 90 \%$ of all proteins in the lens are crystallins. The low protein turnover of this environment makes the eye extremely sensitive to aggregation, which can destroy the refractive index required for vision. Impressively, crystallin chaperone activity maintains this dynamic and delicate environment over the course of an entire lifetime by maintaining the solubility of client proteins.

\section{HSP60/HSP110}

The HSP60/HSP10 (HSPD/HSPE) complex is a fascinating molecular machine. With no other known HSP family members, this is a truly unique chaperone with an elegant protein folding mechanism. In prokaryotes the single HSP60/HSP10 orthologs, GroEL and GroES, are present in the cytosol. In eukaryotes, HSP60/HSP10 are expressed in organelles of endosymbiotic origin, such as the mitochondria of animal cells and chloroplasts in plants (Cpn60) [10]. Specifically in humans, these chaperones are essential for maturation of a subset of mitochondrial proteins and are also known by their specialized name, chaperonins. A distantly related chaperone family known as the CCTs (also known as chaperonins) have been discovered in the cytosol of human cells and share $\sim 30 \%$ sequence identity with HSP60. Curiously however, CCTs do not exist as a complex with any HSP10-like factor because they have evolved to encode the HSP10like cap, utilizing one polypeptide chain instead of two [11]! 
In vivo, HSP60 family members exist as large double ring oligomeric structures consisting of 14 subunits and ranging in total size from $\sim 800-900 \mathrm{kD}$. This tetra-decamer complex contains a large central cavity, which acts as a protein folding cage that is essential to their ATP dependent chaperoning ability [12]. This unique structure-function relationship has led this complex to be known as "Anfinsen's cage" - due to the isolated microenvironment provided by its encapsulating mechanism. This confining mechanism dramatically emphasizes the dogma set by Christian Anfinsen's experiments, which proved that nascent proteins can fold spontaneously given the proper environment. After the hydrophobic central cavity of HSP60 preferentially binds partially folded proteins, HSP10 binds to the large HSP60 complex in a lid-like manner to provide a sealed enclosure where clients are allowed to fold while simultaneously being protected from aggregation within the crowded intracellular environment. This sophisticated mechanism of protein folding was discovered by a series of elegant experiments in the 1990s. In appreciation for their fascinating discovery of the HSP60/HSP110 complex and great contribution to the field of protein folding knowledge, Franz Hartl and Arthur Horwich have won numerous scientific awards, including the 2011 Lasker Prize for basic medical research .

\section{HSP90s}

HSP90s are another particularly interesting example of chaperone biology. There are 5 members of the HSP90 family in the cytosol of human cells, and Hsp90 is the most abundant protein of all HSPs. HSP90s are essential for viability in mice, however their bacterial homologs, the HtpG family, are nonessential in unstressed conditions [13]. The HSP90s are somewhat less promiscuous than other chaperone families and have a selective group of around 100 known clients to date, most of which are kinases and transcription factors [14]. An interesting role of HSP90s in evolution has also been hypothesized. These chaperones may play a specialized role in the acquisition of new protein traits over time by buffering the effects of mutations that may otherwise have been destructive. Regrettably however, this double-edged sword may also promote the formation of mutations that drive oncogenesis.

Structurally, HSP90s consist of 3 domains, (1) an N-terminal nucleotide binding domain, (2) a so-called "middle" domain that recognizes and tightly binds substrate after dimerization and ATP hydrolysis, and (3) a C-terminal domain which initiates dimerization. The mechanism of HSP90s requires C-terminal initiated dimerization. Upon ATP binding the N-terminal NBDs 6dimerize and allow monomers to twist around one another securely binding substrate in between. In this ATP-bound and completely dimerized state HSP90s acts as a molecular clamp able to hold substrate in its inactive form. Upon ATP hydrolysis, N-terminal NBDs separate and chaperone recycling can occur.

HSP90 substrates comprise a fascinating group of medically relevant targets that are commonly known to be deregulated in tumorogenesis, including tumor suppressor p53, several MAP kinases, Src family kinases, telomerase, and even the HSF 
transcription factor which regulates the expression of all HSPs[15]. Numerous HSP90 cochaperones regulate HSP90 function, many of which utilize tetratricopeptide (TPR) motifs to dock with HSP90 and even facilitate substrate transfer. With help from of a host of cochaperones, HSP90s regulate conformational control of clients and hold them in a state that can be readily activated by the appropriate signal. For this reason, HSP90s are on the cutting-edge of tumor signaling research and are promising targets for some cancer treatments [5].

\section{HSP70s}

HSP70s (HSPA) were the first heat shock chaperones discovered by Ferruccio Ritossa in the 1960s and among the largest chaperone families in humans with 13 members. These ubiquitous chaperones are found in the cytosol of prokaryotes and widely distributed throughout all cellular compartments in eukaryotic cells, including the nucleus, cytosol, mitochondria and endoplasmic reticulum (ER). The single prokaryotic HSP70 ortholog, DnaK, is highly conserved and its chaperone function is a wellunderstood model of chaperone mediated protein folding.

All HSP70s are characterized by the presence of 3 structural domains (Figure 1-2). The chaperone cycle of HSP70s depends on allosteric coupling of each of these domains, which include (1) an N-terminal ATPase domain that drives conformational changes in the other domains via ATP hydrolysis, (2) a peptide binding domain that recruits client proteins by their exposed hydrophobic residues, and (3) a C-terminal lid domain that holds clients in a tightly bound high affinity state post nucleotide hydrolysis.

In vivo, HSP70s are involved in a host of chaperone functions including protein folding, refolding, assembly, trafficking, targeting misfolded substrates for degradation, and maintaining some signaling molecules in a quickly available state that can be activated during times of intracellular stress. All of these functions are dependent on the ATP-dependent cycling of BiP depicted in Figure 1-3.

HSP70s in the various compartments have been shown to bind a large repertoire of substrates cotranslationally so that these substrates are bound before they are completely synthesized, which reduces their propensity to aggregate. However, it also adds additional complexity to the folding process, since in some cases $\mathrm{N}$-terminal regions of the protein must interact with more C-terminal regions in the final structure. HSP70s have also gained interest in some clinical applications. Several members of the HSP70 family are currently being investigated as diagnostic indicators or potential treatments for numerous disorders with protein malfolding pathologies. Neurodegenerative disorders have been a major focus of HSP70 in clinical applications since the affected tissue types in these disorders are often susceptible to aggregation and formation of amyloid plaques, which are normally prevented by chaperones during proteostasis. Creutzfeldt-Jakob's disease, Parkinson's disease, Huntington's disease, and Alzheimer's disease are among the focus of these studies. 


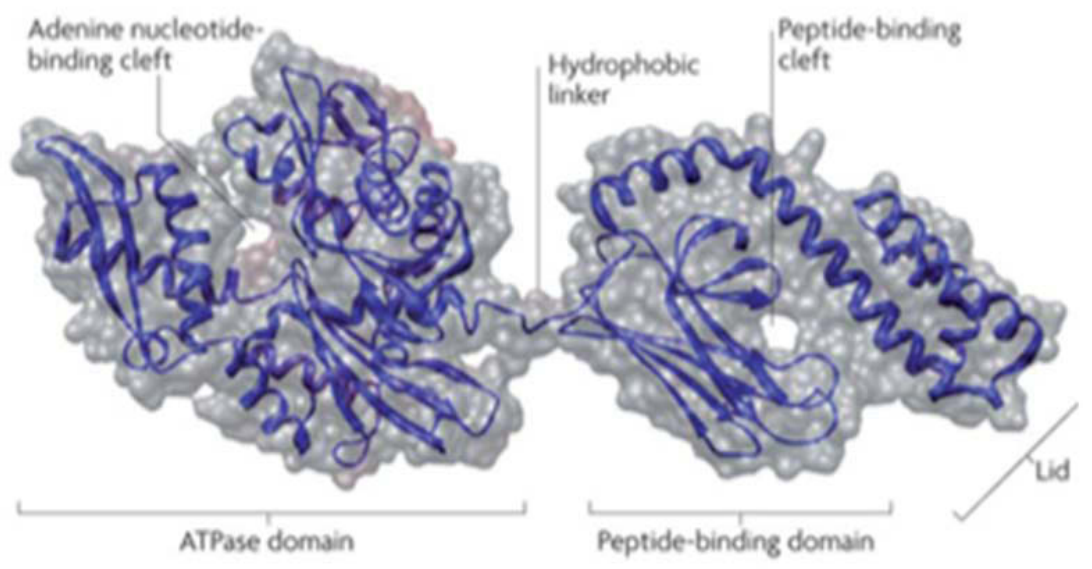

Figure 1-2. Structure of an HSP70 Family Member. The structure of an HSP70 member was solved for DnaK, the E.coli HSP70, in an ADP bound state (protein data bank code $2 \mathrm{KHO}$ ). The ATPase domain and peptide-binding domain are indicated as shown and connected by a short, flexible, hydrophobic linker. Each of these domains are allosterically coupled and driven by the binding, hydrolysis, and release of ATP/ADP. (Reprinted with permission from Kampinga, H.H. and E.A. Craig, The HSP70 chaperone machinery: J proteins as drivers of functional specificity. Nat Rev Mol Cell Biol, 2010. 11(8): p. 579-92. [16].) 


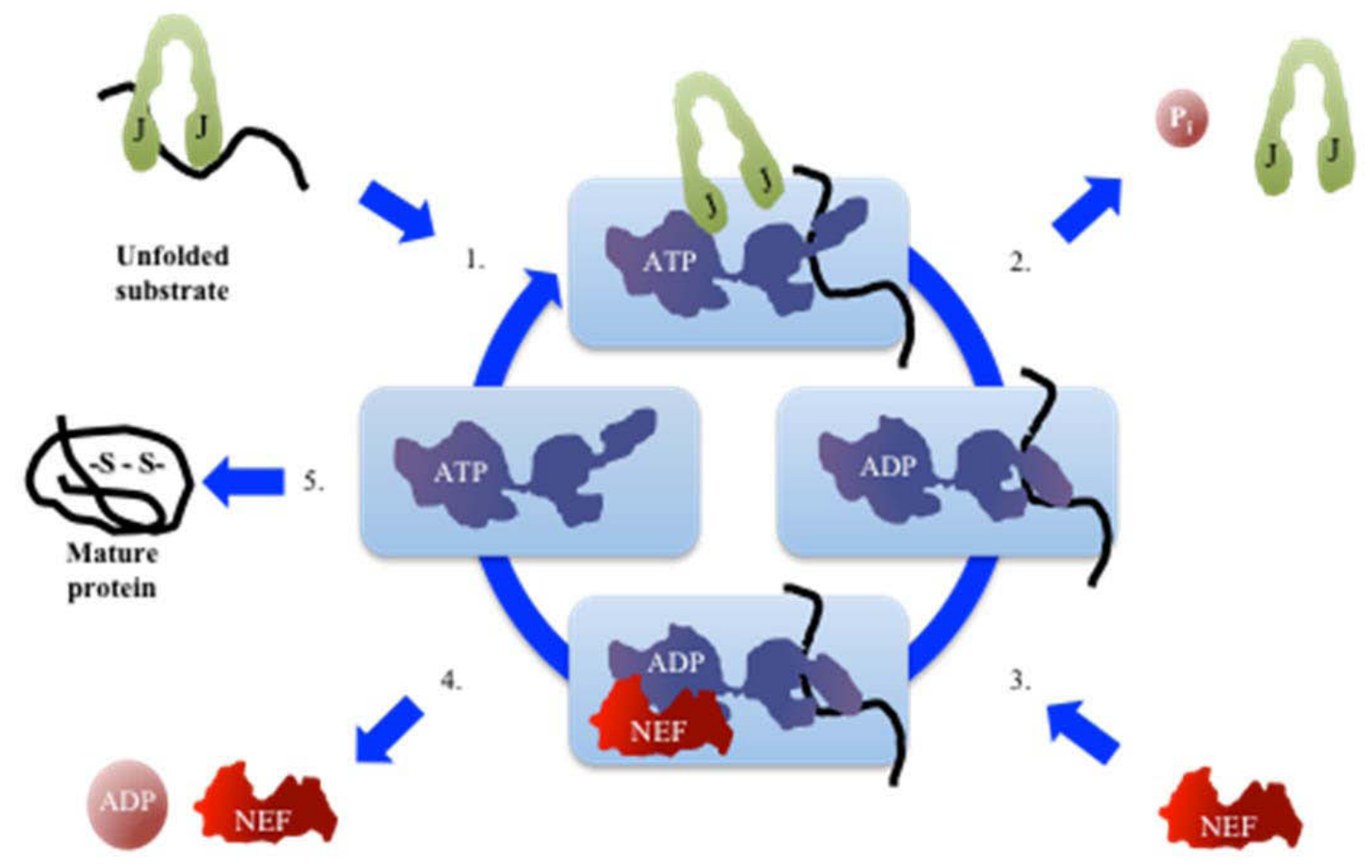

Figure 1-3. Nucleotide-Dependent Chaperoning Cycle of HSP70s. The chaperoning mechanism of HSP70 (Purple) is dependent on its nucleotide bound state, which regulates the conformation of its substrate binding domain via assistance from two cochaperone families, J-domain containing HSP40s (Green) and nucleotide exchange factors (Red). (1) HSP40 members function in the delivery of unfolded substrates to HSP70, however HSP70 can also bind substrate independently. (2) HSP40s stimulate ATP hydrolysis by the HSP70s upon substrate transfer allowing release of inorganic phosphate. This stimulates a conformational change in the substrate binding domain of HSP70 that results in tight binding to substrate and release of HSP40. (3) NEFs preferentially bind to ADP bound HSP70. (4) Nucleotide exchange factors stimulate a conformational change in the HSP70 nucleotide binding domain that induces ADP release. (5) The passive rebinding of ATP "reopens" the substrate binding domain, allowing the substrate to release and fold. The ATP bound form of HSP70 is now primed to interact with an HSP40 and another chaperoned cycle is ready to begin. 


\section{Endoplasmic Reticulum Resident HSP70 Chaperone BiP}

Of the many HSP70 chaperones, BiP (HSPA5, also known as Grp78) is particularly interesting and of central importance to this thesis. It was the first ER molecular chaperone to be identified in any organism and was originally termed "immunoglobulin heavy chain binding protein" for its association with unassembled immunoglobulin (Ig) heavy chain molecules in pre-B lymphocytes [17]. BiP is now known to be expressed in all cell types, with a few exceptions in archea, and has a vast number of substrates in the ER.

BiP's activity is centralized in the ER - a unique and highly specialized protein folding environment that is responsible for the production of about $1 / 3$ of all cellular proteins. In eukaryotes, ribosomes bind to the ER membrane and proteins are translocated into the ER cotranslationally. This binding of ribosomes causes the appearance of a hallmark 'rough ER'. Although the general principles of folding are the same in the ER and cytosol, there are fundamental differences between these compartments [18]. The ER has a more oxidizing environment than the cytosol, which promotes the formation of disulfide bonds. This can serve to stabilize proteins once they have folded, but great care must be taken to prevent the formation of incorrect disulfide bonds, as occurred in Anfinsen's experiments with Ribonuclease A. In addition, posttranslational addition of $\mathrm{N}$-linked glycans in the ER can drive proper folding and limit potential off pathway folding due to their hydrophilic nature. Lastly, the ER represents a particularly crowded environment that has been estimated to contain over $100 \mathrm{mg} / \mathrm{mL}$ of nascent polypeptide chains, a large percent of which are unfolded proteins. This large concentration of unfolded, aggregation prone intermediates (many of which are BiP substrates) provides yet another hurdle to the already complex process of protein folding.

Although there are several HSPs present in the mammalian ER, BiP is the master regulator of ER function and the only ER-localized HSP70 member. Similar to other conventional HSP70 chaperones, BiP has an expansive job description. These functions include folding and refolding of nascent peptides within the ER lumen, trafficking of secretory proteins into and out of the ER, targeting misfolded substrates for ERassociated-degradation (ERAD), regulating intralumenal $\mathrm{Ca} 2+$ concentrations and maintaining the ER-localized transducers of the UPR in an inactive state that can be readily activated in response to alterations in ER that adversely affect protein folding or simply the increased demands found in secretory tissues. The presence of this organelle specific stress-signaling pathway speaks to the evolutionary need to maintain ER homeostasis in order to sustain the proper maturation of secretory pathway proteins. The lengthy job description of $\mathrm{BiP}$ emphasizes its broad role in maintaining proteostasis. This observation is further affirmed by the finding that BiP deficient mice embryos do not develop past the pre-implantation stage resulting in embryonic lethality at day E3.5 [21].

\section{Immunoglobulin Is a Model Substrate for BiP Mediated Protein Folding}

Dedicated secretory cells, such as Ig secreting plasma cells (i.e., terminally differentiated B cells that have been stimulated by exposure to antigen), are particularly 
reliant on $\mathrm{BiP}$ and have impressive protein folding capabilities far beyond that of average cell types. Amazingly, the expanded ER of plasma cells enables secretion of up to 10,000 Ig molecules/second [19]. In the case of an IgM pentamer, this requires the assembly of 21 subunits and the formation of $\sim$ one hundred disulfide bonds per molecule! Within the ER of plasma cells, BiP binds and retains immature Ig heavy chain molecules $(\mathrm{H})$ until they are paired with Ig light chains (L) (Figure 1-4). In order to form a functional effector molecule, BiP must release $\mathrm{H}$ upon encounter with $\mathrm{L}$ to allow formation of a mature $\mathrm{H}_{2} \mathrm{~L}_{2}$ Ig heterodimer. This was demonstrated in experiments using BiP mutants that are defective in the ATPase cycle. These mutants bind to heavy chains but cannot be released from them, which prevents assembly with light chains and prohibits secretion of incompletely assembled molecules. In the cell, BiP release is regulated by nucleotide exchange factors (NEFs), which are presumed to be key players of all BiP mediated protein folding, although this has not been directly examined.

The robust secretory function of plasma cells and other professional secretory cell types is enabled by a hugely expanded ER (Figure 1-5) and upregulation of molecular chaperones and their co-factors by the Unfolded Protein Response (UPR), a cytoprotective signaling cascade that is activated by the accumulation of unfolded proteins in this organelle. A host of ER quality control machinery, including BiP, closely monitors this extremely stressful cellular environment to protect cells from the dangers of aberrant protein folding. Proteins that are incompletely or improperly folded are recognized by chaperone machinery, such as BiP, and selectively retained to ensure fidelity of all proteins that exit the ER and protect fitness of the organism.

\section{HSP70 Cochaperones}

All HSP70s depend on cochaperones for efficient function (Table 1-2). Accordingly, there two classes of cochaperones that interact with BIP in the ER, (1) HSP40s, or Dnaj-like proteins, and (2) nucleotide exchange factors. Currently, 7 known HSP40s have been identified with J domains oriented into the lumen of the ER (Erdjs 1-7), all of which have been shown to interact with BiP and stimulate its ATP hydrolysis. Many of these bind substrates directly and function in delivering them to BiP. The presence of multiple HSP40s that can bind substrates directly is likely to also play a critical role in allowing $\mathrm{BiP}$ to have so many different functions. In addition two NEFs have been identified in the mammalian ER (Sil1 and Grp170). The importance of these BiP cofactors is primarily due to the fact that, similar to other HSP70s, BiP has a very weak intrinsic ATPase activity, with one cycle being on the order of several minutes [22, 23]. So, it is not surprising that BiP requires assistance from NEFs and HSP40 cofactors to expedite this process. In prokaryotes, the combination of DnaK plus DnaJ and GrpE cofactors increases cycling by $50 \mathrm{x}$ - or even up to many thousand-fold if GrpE is saturating [24]. In eukaryotes, the presence of HSP40 and NEFs likewise dramatically increase cycling efficiency of HSP70. 


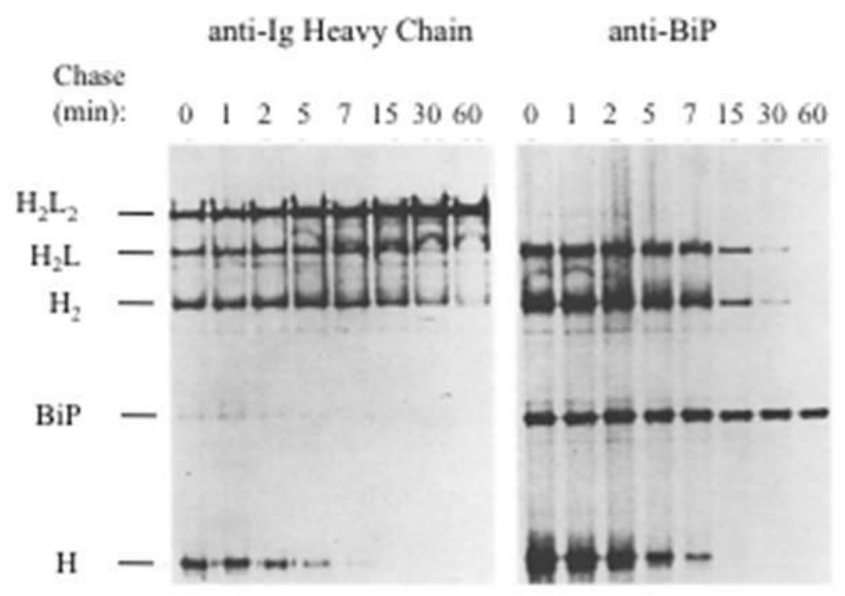

Figure 1-4. BiP Association with Assembling Ig Precursors but Not the

Completely Assembled Protein. Cells from a mouse plasmacytoma line producing IgG1 antibodies were pulse-labeled for 10 minutes with $35 \mathrm{~S}$ methionine then chased in media containing excess cold methionine for the indicated times. Lysates from each time point were split and immunoprecipitated separately with either anti-mouse gamma 1 heavy chain antibody and protein A-sepharose or with monoclonal anti-BiP coupled to sepharose. Assembling Ig precursors were then run on non-reducing SDS PAGE gels and bands were visualized by autoradiography. (Reprinted with permission from Bole, D.G., L.M. Hendershot, and J.F. Kearney, Posttranslational association of immunoglobulin heavy chain binding protein with nascent heavy chains in nonsecreting and secreting hybridomas. J Cell Biol, 1986. 102(5): p. 1558-66. [20]). 


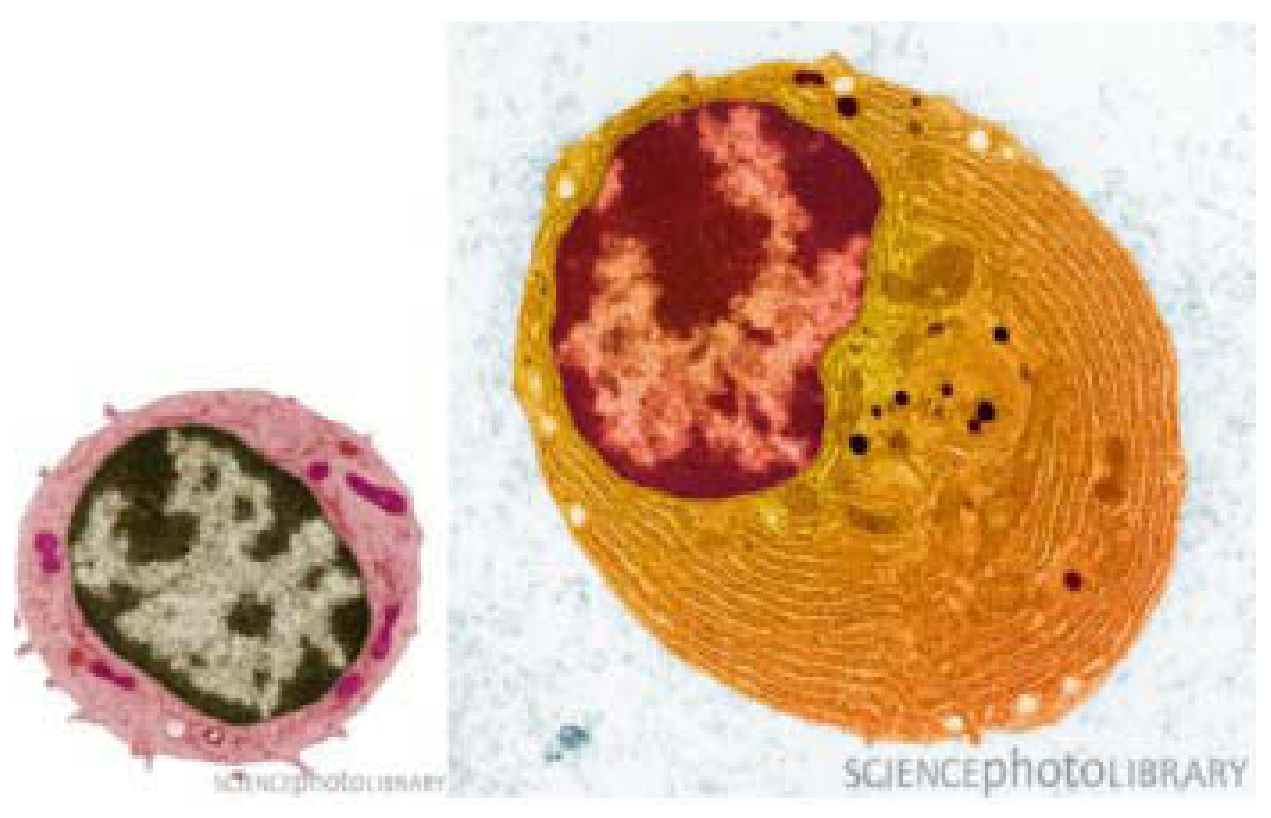

Figure 1-5. Plasma Cell Function Is Dependent on Expansion of the ER and Its Chaperone Machinery. Plasma cells are professional antibody secreting factories that undergo a dramatic cellular change from B cells (left) to terminally differentiated plasma cells (right) upon exposure to antigen. This process is driven by a partial UPR that upregulates the cellular chaperone machinery and hugely expands the ER so that cells are able to handle such high stress secretory demands. (Reprinted with permission from Science Photo Library, http://www.SciencePhoto.com. Accessed April 3, 2012.)

Table 1-2. Relevant HSP70 Chaperone Cofactors.

\begin{tabular}{|c|c|c|c|}
\hline Organism (Chaperone Localization) & HSP70 & HSP40 & NEF \\
\hline Bacteria (Cytosol) & DnaK & DNAJ & GrpE \\
\hline Yeast (ER) & $\operatorname{Kar} 2 p$ & $\begin{array}{l}\text { Sec63p, JEM, } \\
\text { Scj1p }\end{array}$ & $\begin{array}{l}\text { Lhs 1p, } \\
\text { Sillp }\end{array}$ \\
\hline Mammals (ER) & $\mathrm{BiP}$ & ERDnaJ $1-7$ & $\begin{array}{l}\text { Grp } 170 \text {, } \\
\text { Sil1 }\end{array}$ \\
\hline
\end{tabular}




\section{HSP40s}

The HSP40s (DNAJ) constitute the largest family of human HSPs. This incredibly diverse family has members present in the cytosol of prokaryotes and in the cytosol, mitochondria and endoplasmic reticulum of eukaryotes. All HSP40 family members are characterized by the presence of a 70 amino acid J-domain that allows binding to HSP70s and simultaneously stimulates HSP70 ATPase activity. As previously mentioned, HSP70s have weak intrinsic ATPase activity and therefore limited cycling ability. With help from HSP40s and nucleotide exchange factors, HSP70 cycling can be tightly regulated. In one sense, HSP40s function primarily as co-chaperones that assist the chaperoning abilities of HSP70. However, HSP40s are known to bind client proteins and prevent aggregation independently while concurrently shuttling clientele to HSP70.

Three subfamilies of HSP40s exist based on their similarity to the single DnaJ protein present in E. coli. Amusingly, DnaJ was so named for the alphabetical reasoning that it was the $10^{\text {th }}$ gene identified in a genetic screen for proteins that assist in the replication of bacteria phage DNA. It was found to genetically interact with another member of this screen, DnaK (the $11^{\text {th }}$ gene identified), and subsequent experiments revealed that DnaJ served to stimulate the ATPase activity of DnaK.

The three subfamilies are named (1) DNAJA, (2) DNAJB and (3) DNAJC. An Nterminal J-domain, Gly/Phe rich region, Cys rich region, and a variable C-terminus characterize DNAJA (1) members, which are most similar to bacterial DnaJ. An Nterminal J-domain and an adjacent Gly/Phe rich region identify DNAJB (2) members. While only a J-domain, which can occur anywhere in the proteins, characterizes DNAJC (3) members. Kampinga et al classified a total of 50 DNAJ family members in humans, which is continuing to expand [9]. This number is much larger than the HSP70 family (13 in humans) because many HSP40s can assist a single HSP70. For example, in human cells there is a single known HSP70 in the endoplasmic reticulum that is assisted by 7 known interacting HSP40s, this trend occurs in other cellular compartments also. This extremely diverse family of HSP40s has an enormous range of interactions both with unfolded client proteins and HSP70s as cochaperones that is incompletely understood and a strong focus of research in the protein folding community.

\section{HSP110s}

The HSP110 family has 4 known members in humans, three of which are cytosolic (HSP105, APG1, APG2/Hsp110) and a single ER resident member (Grp170). Similar to many other chaperone families, these so-called "large HSPs" are responsible for a diverse set of functions within cells. Interestingly, HSP110s have been found to function in chaperoning polypeptide clients, as all HSP family members, and also to uniquely chaperone RNA messages as well [25]. In addition to their intrinsic chaperoning ability HSP110 family members also act as auxiliary cochaperones by stimulating nucleotide exchange of HSP70s. Furthermore, HSP110s have also been shown to play a role in determining the fate of clients in the HSP70-HSP90 chaperone complex. Thus, the 
complex mechanism of HSP110 family members is a combination of chaperone and NEF. However, it should be noted that there are many mechanistic details of the large HSPs that have not been worked out, especially regarding their intrinsic nucleotide binding and hydrolysis activity.

The HSP110 family was historically overlooked until the 1990s when discovery of their relationship to the HSP70s first came as a surprise. The HSP110s are members of the HSP70 superfamily and exhibit both similarities and differences in structure and function to the HSP70s. The structural organization of HSP70s and HSP110s is very similar, each sharing an $\mathrm{N}$-terminal nucleotide binding domain, a substrate binding domain and a C-terminal "lid" domain. The major structural distinctions of the HSP110s are their highly divergent ATPase domains and extended C-terminal "lid" domains that carry insertions of varying lengths [26]. Importantly, this enlarged C-terminal domain is the source of their ability to tightly hold non-native substrates.

Recent studies suggest that HSP110 family members have different requirements for nucleotide binding and hydrolysis [27]. The HSP110 yeast cytosolic homologs, Sse1p and $\mathrm{Sse} 2 \mathrm{p}$, are relatively well-characterized chaperones. Interestingly, Sse $1 \mathrm{p}$ is stress inducible while Sse2p is constitutively expressed [28]. Sse1p has been shown to bind and hydrolyze ATP, but this function is non-essential to its NEF function. However, the NEF function of Lhs1p (ER lumenal Grp170 homolog in yeast) has been suggested to be dependent on ATP binding, but this remains to be conclusively proven. ATP-bound Lhs $1 p$ preferentially binds ADP- bound Kar2p (ER lumenal BiP homolog in yeast), which is consistent with the known NEF activity of Lhs1p and Grp170 [27]. This conclusion is also in agreement with data that shows mutations inhibiting Sse1 ATP binding reduce the efficiency of its ability to function as a NEF [26] to its HSP70 partner Ssalp.

The future of HSP110 research looks to be very exciting. A growing body of evidence suggests the role of large HSPs in host immunity, particularly in cancer immunology. The immunogenic strength of tumor antigens is increased when presented by HSP110s. Vaccination with Hsp110 or Grp170 derived from tumors has been shown to induce complete regression of fibrosarcoma in mouse models and also to significantly extend the life expectancy of colon cancer models [29]. The development of vaccines that utilize HSP110s, and other chaperone classes, as adjuvant for cancer immunotherapy is an inspiring endeavor and very active area of research.

\section{NEFs for HSP70 Chaperone BiP}

NEFs are essential to release unfolded substrates from so they can properly fold. Without NEFs, HSP70 chaperones would bind to substrates, but release them at a dangerously slow rate or possibly even remain bound to a single substrate indefinitely. Two resident ER NEFs have been identified, Sill and Grp170. In vitro experiments demonstrate that they facilitate efficient cycling by promoting concomitant release of ADP and rebinding of ATP to the nucleotide-binding cleft. This in turn opens the lid on 
the substrate-binding domain (SBD) allowing the substrate to be released. Currently, little is known about the level of control these NEFs exert on BiP in vivo, although all functions of BiP require the activity of its ATPase cycle, with the exception of its role in regulating calcium stores.

Although GrpE, the NEF to prokaryotic HSP70 homolog DnaK, was discovered in 1978 [30], the eukaryotic HSP70 NEFs were discovered much more recently. Sls1p and Sillp were first discovered in two yeast genera in $2000[31,32]$ and the mammalian BAP protein (more commonly known as Sil1), a homolog of the two yeast proteins was discovered in 2002 [33]. These ER proteins are orthologues of the cytosolic localized NEFs, Fes $1 p$ in yeast and HspBP1 in mammals, respectively. The yeast ER HSP110 homolog, termed Lhs1p, was discovered in 1996 [34] while the mammalian homologue, Grp170, was first identified in 1993 bound to immunoglobulin chains [35]. The classification of Grp170 as a large "HSP70" family member and its ability to bind immunoglobulin led investigators to conclude that it was likely to be a new ER chaperone. However, Steel et al demonstrated the surprising finding that Lhs1p, the yeast ER large HSP70, had NEF activity for Kar2p in 2004 [36].

In yeast, loss of either Sillp or Lhs1p (mammalian Sil1 and Grp170 homologues) individually results in a viable phenotype with varying levels of UPR induction. Loss of Lhs $1 p$ results in constitutive and considerably stronger UPR induction than Sill loss. However, loss of both Sillp and Lhs1p simultaneously results in synthetic lethality, which is the same phenotype observed with loss of Kar2p (mammalian BiP homolog). Furthermore, Lhs $1 p$ mutant cells have a translocation defect that is significantly relieved by multicopy Sil1p expression, although loss of Sillp is not associated with a translocation phenotype. In contrast, neither Kar2p nor Scj1 (Yeast HSP40 member) over-expression are able to suppress the translocation phenotype of Lhs1p mutant yeast [32]. The ability of Sillp to compensate for loss of Lhs1p suggests that there is a least some redundancy in function of these NEFs, although their different phenotypes suggest that they have some distinct functions.

In mice, loss of Grp170, the Lhs1p homolog, is embryonic lethal, whereas loss of Sill results in viable mice that have multisystem defects. The difference in the magnitude of the relative phenotypes is consistent with the stronger UPR induction caused by Lhs1p loss as compared to Sillp loss in yeast. This suggests that Grp170 may have an additional role, which is in keeping with recent data showing that the HSP110 family may also possess chaperone functions. Other than their shared ability to stimulate nucleotide release from $\mathrm{BiP}$, these proteins are dramatically different in numerous ways (Table 1-3, Figure 1-6).

\section{Nucleotide Exchange Factor Grp170}

Grp170, also known as Orp150, (named for its membership in the Glucose Responsive Protein and Oxygen Responsive Protein families, respectively) is a member of the HSP110 family, which shares strong structural similarities to the HSP70 family. 
Table 1-3. Comparison of BiP NEFs.

\begin{tabular}{lll}
\hline \multicolumn{1}{c}{ NEF } & \multicolumn{1}{c}{ Grp170 } & \multicolumn{1}{c}{ Sil1 } \\
\hline Additional names & Lhs1p (Yeast), Orp150, HYOU1 & Sil1p (yeast), SLS1p (yeast), \\
& & BAP \\
Molecular weight & $150-170 \mathrm{kD}$ & $52-54 \mathrm{kD}$ \\
Post translational modification & 9 potential glycosylation sites & 2 potential glycosylation sites \\
Direct interaction with substrate & Yes & No \\
Independent nucleotide hydrolysis & Possibly & No \\
Translocation defect (S. cereviseae) & Yes & No \\
Known crystal structure & No (S. cereviseae cytosolic & Yes (S. cereviseae), 2.3 \\
& ortholog Sse1, yes) & resolution) \\
Important BiP interaction site(s) & Unknown, may include multiple & His ${ }^{163}$, Glu \\
& regions & (S. cereviseae), \\
& & $9,10)$ \\
ER retention sequence & KNDEL & None \\
Related cytosolic proteins & HSP110, HSP70 superfamily & HspBP1 \\
Induced by ER stress & Yes & No \\
Mammalian expression pattern & Unknown & Ubiquitous, highest in \\
& & secretory tissues \\
Deficiency & Embryonic lethal (mice) & Marinesco-Sjögren Syndrome \\
\hline
\end{tabular}



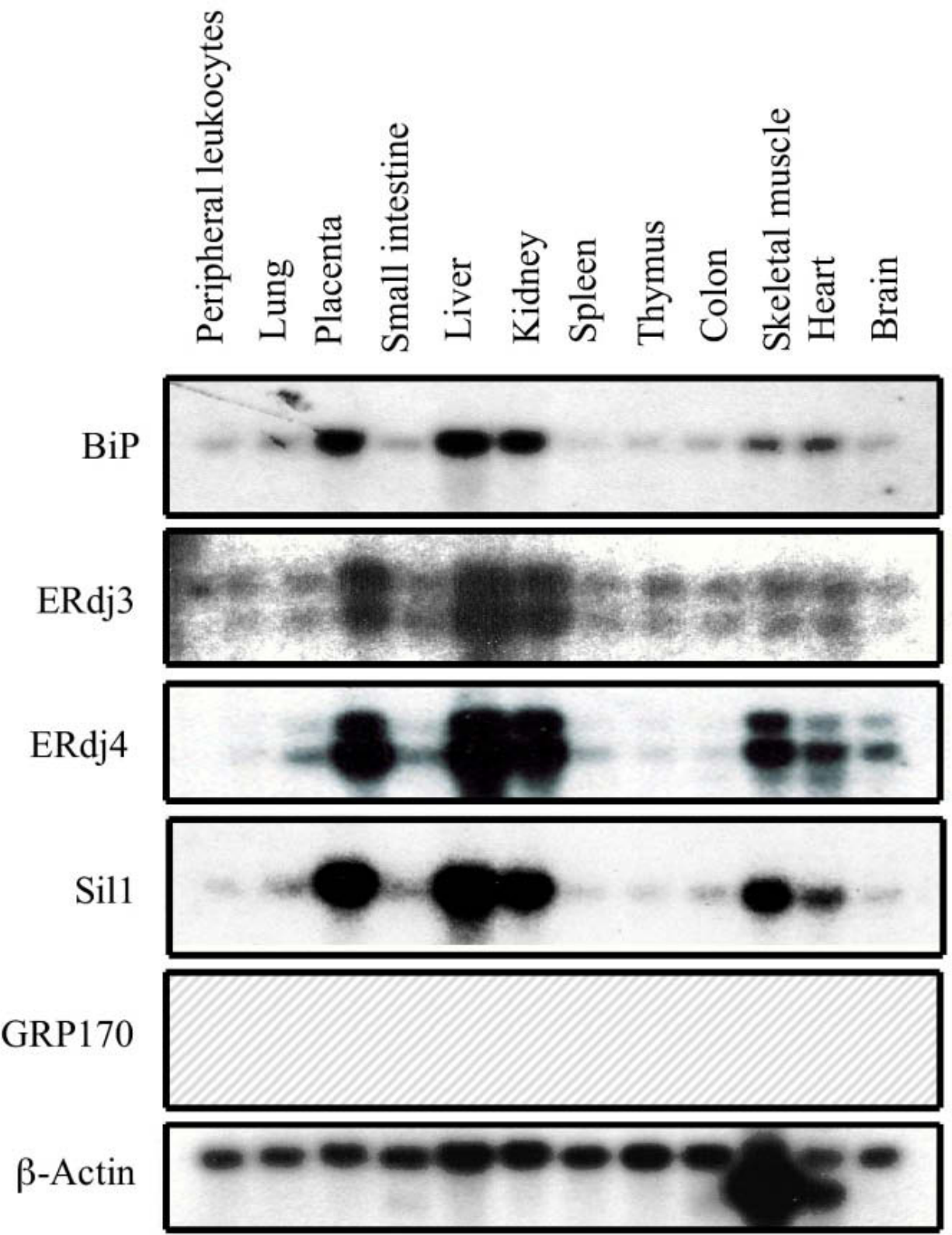

Figure 1-6. Tissue Expression of ER Chaperone Machinery. Distribution of ER chaperone BiP components in human tissues by western blotting. Sil1, originally known as BAP, is most highly expressed in secretory tissues, like BiP. At the time of this experiment, reagents to measure Grp170 expression were not available. 
Interestingly there are 4 known mRNA variants and 3 known protein isoforms of Grp 170 [37], however the relevancy of these isoforms is unknown. Despite a recent increase in the number of reports in literature, the function of Grp170 remains poorly characterized.

Like all HSP110 family members, the structure of Grp170 is quite similar to that of BiP, including an N-terminal nucleotide binding domain, a linker region, and a possible substrate-binding domain. In keeping with the latter possibility, Grp170 was identified by its ability to bind to immunoglobulin, similar to BiP. However, it remains unclear whether or not Grp170 is capable of intrinsic nucleotide hydrolysis even though it contains a domain architecture that resembles the BiP NBD. It does not possess a specific highly conserved arginine residue, present on the surface of all HSP70 NBDs, and as a result is unable to interact with DnaJ family members which promote ATPase activity of HSP70s. The expression pattern of Grp170 in mammalian tissues has not been determined. As previously mentioned, loss of Grp170 in mice results in embryonic lethality, however it is not known if this is due to its NEF or putative chaperone activities. Unfortunately, the details of this phenotype are not yet present in literature, as it was only reported that no knockout pups were born in over 100 attempted breedings [38].

Studies on the yeast homolog of Grp170, Lhs1p (Lumenal Hsp Seventy), first shed light on the mechanism that induces nucleotide release from the yeast BiP homolog Kar2p [36]. This mechanism requires interaction with between lobe I of the Lhs1p NBD and lobe II of the Kar2p NBD [39]. This same mechanism was later shown to be shared by other HSP110 family members including yeast Sse1p, mammalian GRP170, and cytosolic HSP110.

\section{Nucleotide Exchange Factor Sil1}

Mammalian Sil1, originally known as BAP (BiP Associated Protein), is an ER localized BiP NEF. Sill has a molecular weight of 52-54kD, contains 2 potential $\mathrm{N}$-glycosylation sites, and does not possess a characteristic ER retention sequence as found on many ER resident proteins. Although Sill does not contain a characteristic ER retention sequence, it is selectively retained in the ER via its interaction with $\mathrm{BiP}$ [40].

ER stress inducer tunicamycin inhibits post-translational glycosylation within cells, which affects the proper folding of many secretory pathway proteins - causing ER stress. Thapsigargin, another ER stress inducer, causes ER stress by destabilizing intracellular calcium levels. The resulting accumulation of unfolded proteins in the ER after tunicamycin or thapsigargin treatment induces the UPR, which is well known to increase production of many chaperones and their cofactors. Unlike BiP and Grp170, Sill has not been shown to be regulated by ER stress (Figure 1-7). Tunicamycin-treated cells do not increase Sill production in yeast [32] or in human cell lines and interestingly, Sil1 may even be down-regulated by stress [33].

The Sil1-BiP complex structure, was solved for yeast Sillp and the Kar2p ATPase domain (yeast homologs of Sill and BiP, respectively), and contains amino 


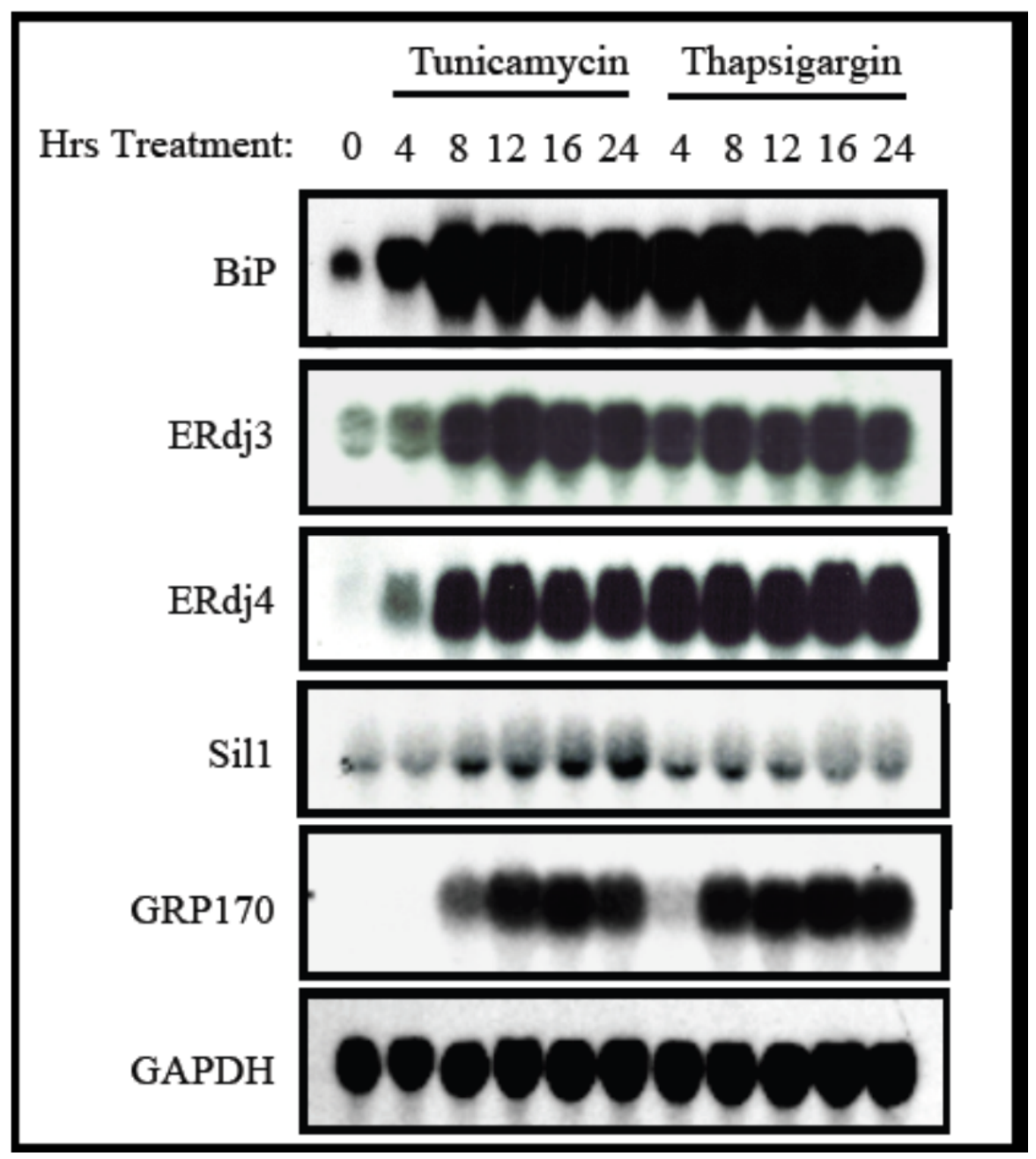

Figure 1-7. Stress Induction of ER Chaperone Machinery. RNA message induction of ER chaperone BiP components during tunicamycin or thapsigargin induce ER stress as shown by northern blotting. Interestingly, Sill expression is much less affected by ER stress than other BiP components. 
acids [46].125-406 of Sil1p and amino acids 47-426 of Kar2p (Figure 1-8). This crystal structure shows that Sill binds lobe IIb of BiP in a "clamp-like" manner. Sill binding induces rotation of $\mathrm{BiP}$ nucleotide binding domain lobe IIb $13.5^{\circ}$ away from the nucleotide binding pocket, causing release of bound nucleotide [42]. Since Sill prefers to interact with the ADP bound form of $\mathrm{BiP}$ and not the ATP bound form, the release of nucleotide will be confined to ADP [33]. Additionally, Sill also induces a slight $3.7^{\circ}$ shift in lobe Ib of BiP that further eases the escape of ADP. The secondary structure of Sill consists of $16 \alpha$-helicies and no $\beta$-sheets. Helices 3-14 form 4 distinct Armadillolike Repeat Motifs (ARM) and combine to form a gently curved and slightly elongated tertiary shape with a concave face that wraps around lobe Iib of the BiP NBD domain.

Studies have shown that full length Sill binds the BiP NBD with high affinity $(\mathrm{kd}=\sim 13 \mathrm{nM})$ [42]. Mutations H163A and E390A reduce Sil1-BiP binding to undetectable levels in yeast [42], but similar studies have not been done on mammalian Sil1. In Marinesco Sjögren Syndrome (MSS), most Sil1 mutations are nonsense or frame shift mutations predicted to truncate the protein product, although splice site mutations, missense mutations, and larger genomic deletions have also been described.

\section{Marinesco-Sjögren Syndrome}

MSS is a rare autosomal recessive disorder linked to Sill loss, and is characterized by vast multi-system defects. The most frequent symptoms associated with this disorder include cerebellar ataxia, early onset cataracts, progressive myopathy, and mild to severe intellectual disability. The fairly recent discovery of Sill as a cause of MSS, the pleotropic and variable symptoms associated with it, and the rarity of the disease are currently an obstacle in gathering epidemiological data on the exact prevalence of MSS. The first symptoms of MSS are usually evident at birth due to muscular hypotonia. Although individuals with MSS suffer from numerous symptoms throughout their life, the lifespan of these individuals appears to be normal [43]. A host of other sporadic pathologies have also been reported, including but not limited to, skeletal abnormalities, short stature, hypogandism, and elevated creatine kinase (CK) [41] [44]. In spite of this disease being linked to a component of the molecular chaperone machinery, a precise molecular explanation for this spectrum of affected tissues and organs has not been determined.

Mutations causing MSS were localized to human chromosome 5q31 in 2003 by homozygosity mapping [45]. In 2005, homozygous Sil1 mutations were found in this region of affected individuals that were present in single copies in their parents or unaffected siblings but not in the general population [44] [41]. To date, over 20 distinct Sill mutations have been described in MSS patients, and this number continues to grow as more genes in affected individuals are sequenced (Table 1-4). About 2/3 of patients with classic MSS symptoms have identified Sill mutations. Most of these mutations are nonsense or frameshift mutations predicted to truncate the protein product, however, splice site mutations, missense mutations, and a larger genomic deletion have also been 

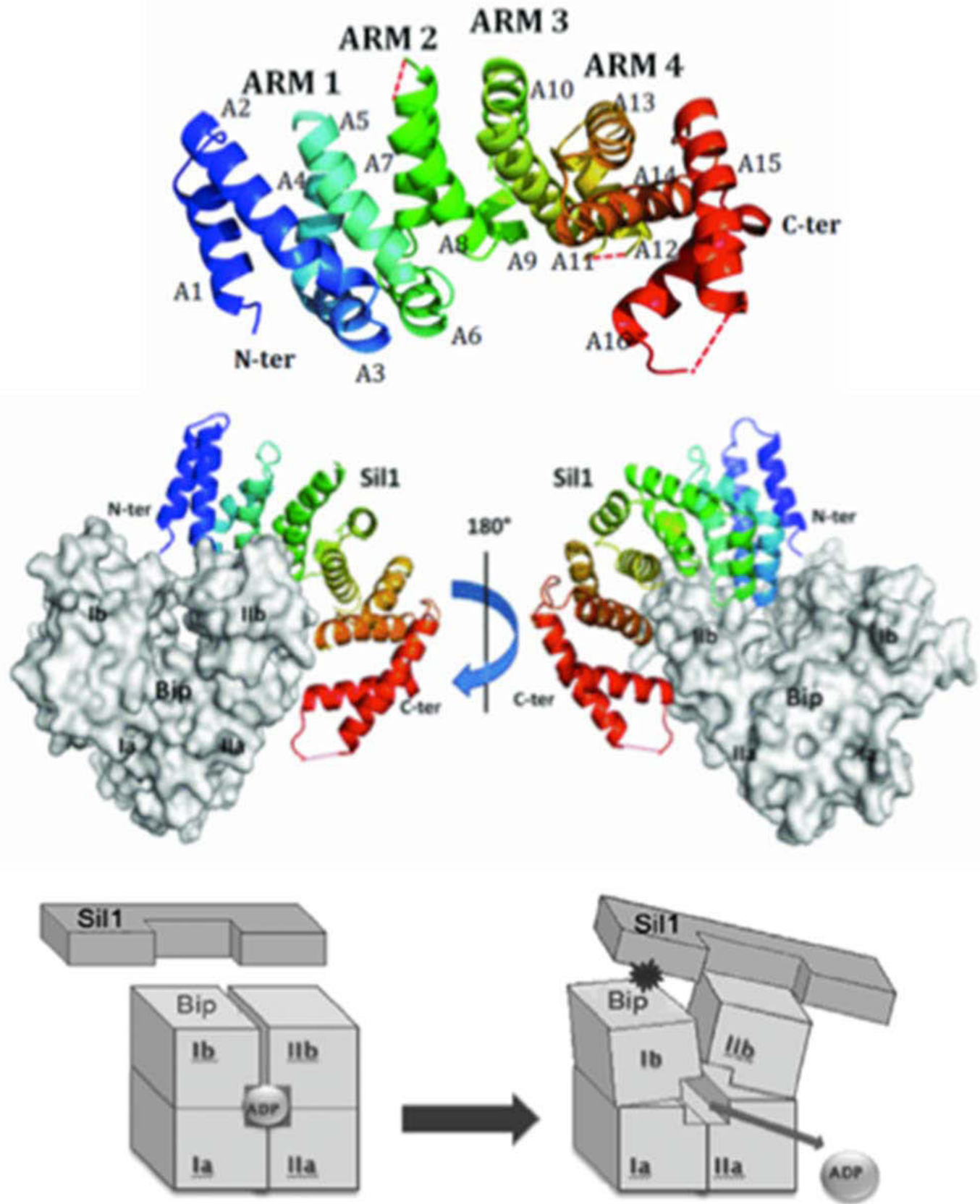

Figure 1-8. Sil1 Crystal Structure and Mechanism. Sill contains 16 alpha-helices including 4 armadillo-like repeats which bind to BiP NBD domain Iib in a clamp-like manner. This binding induces a conformational change that swings lobe Iib, and lobe $\mathrm{Ib}$ to a lesser extent, away from the nucleotide-binding cleft of BiP and drives nucleotide exchange.(Reprinted with permission from Yan, M., J. Li, and B. Sha, Structural analysis of the Sil1-Bip complex reveals the mechanism for Sill to function as a nucleotideexchange factor. Biochem J, 2011. 438(3): p. 447-55 [42].) 
Table 1-4. Pathogenic Sil1 Mutations.

\begin{tabular}{|c|c|c|c|}
\hline Exon & Nucleotide Change & Amino Acid Change & Reference \\
\hline 3 & $178 \mathrm{C}>\mathrm{T}$ & E60X & Senderek et al 2005 \\
\hline 3 & 212dupA & H71QfsX5 & Anttonen et al 2005 \\
\hline 4 & $274 \mathrm{C}>\mathrm{T}$ & R92W & Riazuddin et al 2009 \\
\hline 4 & $331 \mathrm{C}>\mathrm{T}$ & R111X & $\begin{array}{l}\text { Anttonen et al } 2005 \\
\text { Senderek et al } 2005 \\
\text { Annesi et al } 2007\end{array}$ \\
\hline 4 & 346delG & G116fs & Senderek et al 2005 \\
\hline $6-7$ & 454-?_767+? del & $58 \mathrm{~Kb}$ deletion & Takahata et al 2010 \\
\hline 6 & 506-509dupAAGA & D170E fsX4 & Anttonen et al 2005 \\
\hline 6 & 603_607delGAAGA & E200DfsX6 & Takahata et al 2010 \\
\hline Intron 6 & $645+1 \mathrm{G}>\mathrm{A}$ & Skipping of Exon 6 & Senderek et al 2005 \\
\hline Intron 6 & $645+2 \mathrm{~T}>\mathrm{C}$ & $\begin{array}{l}\text { V186_Q215del } \\
\text { A152_Q215del }\end{array}$ & Anttonen et al 2005 \\
\hline 9 & 936dupG & L313ĀfsX39 & $\begin{array}{l}\text { Anttonen et al } 2008 \\
\text { Eriguchi et al } 2008\end{array}$ \\
\hline 9 & 947_948insT & L316fs & Senderek et al 2005 \\
\hline 9 & $102 \overline{9}+1 \mathrm{G}>\mathrm{A}$ & Skipping of Exon 9 & Senderek et al 2005 \\
\hline 9 & $1030-18 \mathrm{G}>\mathrm{A}$ & L344fs & Senderek et al 2005 \\
\hline 9 & $1030-9 \mathrm{G}>\mathrm{A}$ & F345AfsX9 & Anttonen et al 2005 \\
\hline 10 & $1240 \mathrm{C}>\mathrm{T}$ & Q414X & Riazuddin et al 2009 \\
\hline 10 & $1249 \mathrm{C}>\mathrm{T}$ & Q417X & Senderek et al 2005 \\
\hline 10 & $1312 \mathrm{C}>\mathrm{T}$ & Q438X & Kaeim et al 2006 \\
\hline 10 & 1366delT & L456fs & Senderek et al 2005 \\
\hline 10 & $1367 \mathrm{~T}>\mathrm{A}$ & L456X & Senderek et at 2005 \\
\hline 10 & $1370 \mathrm{~T}>\mathrm{C}$ & L457P & Anttonen et al 2008 \\
\hline
\end{tabular}

(Reprinted with permission from Anna-Kaisa Antonnen. "The Molecular Basis of Marinesco-Sjogren Syndrome." Academic Dissertation, Helsinki Biomedical Graduate School, 2008 [47]). 
described [39]. In addition, three distinct mutations that only affect the last 5-6 amino acids of Sil1 have been identified [36]. In this region, many ER localized proteins contain an ER retention sequence, and it was originally hypothesized that these mutations caused MSS by allowing the secretion of Sil1, thereby depleting it from the ER. The WT Sill C-terminus sequence is KELR, whereas the most common ER retention sequence is KDEL. In light of this fact, it was originally hypothesized that the C-terminal Sill KELR sequence was a divergent ER localization motif. Recently, Howes et al performed an indepth analysis of mutations that affect the last 5-6 amino acids of the Sill C-terminus [40]. Interestingly, however it was found that the C-terminal KELR sequence of Sill was not an ER retention sequence but rather that this C-terminal KELR sequence is essential to maintaining stability of Sill. Proteins with mutations in this region form large aggregates or are quickly degraded. Although WT Sill does not contain a characteristic ER localization sequence, such as KDEL, it is retained in the ER via its association with BiP.

Major predicted BiP interaction sites on Sill are translated from exons 6 and 9, and a minor interaction site from exon 10 . The recently published crystal structure of yeast Sill identified 7 residues which make up these major BiP interaction sites and 2 residues involved in the minor interaction site [42]. Not surprisingly, the majority of pathogenic MSS mutations affect these sites. The woozy mouse model of MSS contains a mutation that results in a truncated protein product with an early stop codon in exon 7 [46]. In the absence of a good reagent to detect mouse Sill it has been difficult to determine how this truncating mutation affects endogenous Sill levels. However, an epitope tagged version of the truncated Sill has been expressed and shown to colocalize with $\mathrm{BiP}$ in the ER of transfected COS cells and to have a reduced ability to bind BiP

\section{Woozy Mouse Model}

A mouse model which closely phenocopies human MSS was discovered in 2005. A spontaneous recessive mutation on mouse chromosome 18 was found to truncate the Sill message after exon 7 due to insertion of a 96-nucleotide retrotransposon element followed by a premature stop codon [46]. This mutation disrupts a major BiP interaction site in exon 9 and a minor BiP interaction site in exon 10. Immunoprecipitation experiments with transfected, epitope-tagged and truncated Sill have shown that it has a reduced ability to interact with $\mathrm{BiP}$. However, it is unclear whether this mutation leads to the expression of significant amount of the truncated protein in the woozy mouse due to the lack of Sill specific mouse antiserum. It is also unclear if this truncated protein possesses nucleotide exchange activity.

Sill is widely expressed in mice and humans, but not all cell types are equally affected by its loss. Similar to patients with MSS, mice with the 'woozy' (wz) mutation develop significant neurodegeneration in the cerebellum. However adult onset ataxia develops in mice between 3-4 months of age, while humans already show a significant level of neurodegeneration and hypotonia at birth. This hallmark phenotype manifests in clearly visible instability of motor function in these mice, which has been quantified by treadmill gait analyses and is the etymology of the common model name "woozy mouse'. 
Woozy mice show severe Purkinje cell loss specifically in lobules I-VIII of the cerebellum, but caudal lobule IX and lobule X are mysteriously less affected. Electron micrographs show dense structures within the ER and nucleus of these Purkinje cells, suggesting protein aggregation, which is known to be highly toxic in neuronal cell types.

Due to UPR activation in the Sil1-deficient Purkinje cells of the woozy mouse, endogenous Grp170 and other ER chaperones are upregulated, but this is not sufficient to prevent severe neurodegeneration. However, introduction of a Grp170 transgene, which expresses protein levels $\sim 3$-fold higher than the already increased levels found in Sill deficient mice, is able to rescue neurodegeneration and ER stress symptoms observed in woozy mice, including Purkinje cell death, upregulation of ER stress markers BiP and CHOP, and ubiquitylated protein inclusions [46]. Furthermore, Grp170 heterozygous mice crossed to the woozy mice $\left(\mathrm{Sill}^{-/-} ; \mathrm{Hyou}^{+/-}\right.$) exhibit earlier onset neurodegeneration and ataxia, which is so severe that animals of this genotype cannot walk on a treadmill at 20 weeks of age. Purkinje cells of caudal lobule IX and lobule X, which are resistant to Sill loss, also die in this model.

In turn, the discovery that mice, which only have one copy of alternative BiP NEF Grp170 in addition to the Sill woozy mutation ( $\mathrm{Sil1}^{-/-} ; \mathrm{Hyou}^{+/-}$), suggested that an excess of the ADP-bound form of BiP could be the molecular etiology of these phenotypes. To investigate this hypothesis, Zhao et al crossed the woozy mouse with one that is null for ERdj6 [46]. In WT mice, ERdj6 transfers unfolded proteins to BiP and stimulates ATP hydrolysis, therefore increasing the prevalence of ADP-BiP-substrate bound complexes. Interestingly, these double-knockout (Sil1 ${ }^{-/} ;$Dnajc $3^{-/}$) mice do not show any signs of ataxia even up to 8 months of age. However, some signs of Purkinje cell degeneration are still present, though to a lesser degree than Sil1 ${ }^{-/-}$woozy mice. In addition to reducing the amount of $\mathrm{BiP}$ in the $\mathrm{ADP}$ bound form, decreasing one of its HSP40 co-factors could also result in a lower rate of substrate delivery and result in higher levels of free BiP, which may be the molecular etiology of rescuing the woozy phenotype.

To date, the similarity of other non-neurodegenerative phenotypes between this model and human MSS are less well-characterized. This gap in literature makes the woozy mouse model a prime subject for investigation of the molecular consequences of Sill loss and has strong potential benefit for the MSS community.

\section{Important Questions}

A molecular understanding of the complex pathologies associated with loss of Sill in man and mouse is currently unknown. However, there are several logical hypotheses that may explain the phenotypes following Sill loss. First, the failure of critical $\mathrm{BiP}$ substrates to mature properly due to their inability to be released from $\mathrm{BiP}$ could be responsible for at least some of the disease phenotypes. Second, the accumulation of unfolded proteins in the ER, leading to prolonged activation of the UPR, which can result in cell death, could lead to loss of affected cells. A third possibility is 
that loss of Sill and the resulting stabilization of BiP-substrate complexes could lead to decreases in free $\mathrm{BiP}$ levels that would be inadequate to chaperone new proteins entering the ER. Since free levels of BiP regulate UPR transducers, this could also lead to prolonged activation of the UPR and cell death. It is unknown which of these factors, or combination thereof, is responsible for the MSS phenotype seen in patients with mutations in Sill and the woozy mouse. Nor is it known whether the most affected tissues in MSS patients and woozy mice are those that are unable to express high enough levels of GRP170 to counteract the loss of Sill. To begin to better understand the cellular and molecular consequences of Sill loss, we have chosen to examine the effects on the biosynthesis and secretion of the best characterized BiP substrate, immunoglobulin (Ig) . A great deal is known about the biosynthetic pathways for the various Ig classes and subclasses, all of the necessary reagents and methodologies are available, and these proteins can be readily studied in whole animals and in isolated cells, utilizing the woozy mouse model.

\section{Specific Aims}

Aim 1: To examine the effect of Sill loss on immunoglobulin biosynthesis at the organismal level.

a. Determine if Sil1 KO mice are able to secrete Ig into the bloodstream.

b. Examine the kinetics and magnitude of total Ig secretion and antigen specific Ig secretion.

c. Compare secretion of Ig isotypes and subclasses that vary in their dependence on $\mathrm{BiP}$ for folding and assembly in wild-type and knock-out mice.

Aim 2. To examine the effects of Sill loss on immunoglobulin biosynthesis at the cellular level.

a. Examine the requirement of Sill for Ig secretion, in a controlled environment using primary splenic B cells and activated plasma cells ex vivo.

b. Investigate whether the loss of Sill causes ER stress in primary B cells or causes a more dramatic upregulation of the UPR in Sill-/- activated plasma cells as compared to wild-type littermates.

c. Determine if Grp170 is expressed at higher basal levels in primary splenocytes of Sil1-/- mice compared to WT littermates or is super induced during B cell differentiation to compensate for Sill loss. 


\section{CHAPTER 2. MATERIALS AND METHODS}

\section{Mouse Model and Genotyping}

C57/B16 Sil1 null mice were a generous gift from Dr. Susan Ackerman. Pups were weaned and tagged at 21 days old and tail samples were used for genotyping. Each animal was genotyped 3 times to ensure proper identification prior to any experiments.

Following were the primers used:

- Wild type: primers LZO134 and LZO135

$95^{\circ} \mathrm{C} 2 \mathrm{~min}, 95^{\circ} \mathrm{C} 30 \mathrm{~s}, 57^{\circ} \mathrm{C} 1 \mathrm{~min}, 68^{\circ} \mathrm{C} 1.5 \mathrm{~min}, 68^{\circ} \mathrm{C} 10 \mathrm{~min}, 4^{\circ} \mathrm{C}$ (40 cycles)

- Knockout: primers LZO136 and LZO137

$95^{\circ} \mathrm{C} 2 \mathrm{~min}, 95^{\circ} \mathrm{C} 30 \mathrm{~s}, 57^{\circ} \mathrm{C} 30 \mathrm{~s}, 68^{\circ} \mathrm{C} 1 \mathrm{~min}, 68^{\circ} \mathrm{C} 10 \mathrm{~min}, 4^{\circ} \mathrm{C}$ (40 cycles)

\section{Serum Collection}

Whole blood samples were taken from mice via standard retro-orbital or tail bleeding protocols at volumes $(75 \mu \mathrm{L})$ and times approved by St Jude Children's Research Hospital IACUC. For these procedures, mice may be lightly anesthetized with $3 \%$ isofluorane (required for retro orbital bleeding, optional for tail bleeding) to reduce pain and struggle, therefore increasing the consistency of sampling technique. After collecting samples, whole blood was allowed to clot at room temperature for 30-60 minutes and were then stored overnight at $4^{\circ} \mathrm{C}$. After centrifugation $\left(4^{\circ} \mathrm{C}, 3\right.$ minutes, $5 \mathrm{k}$ $\mathrm{rpm}$ ) serum was removed and carefully and thoroughly combined 1:1 with glycerol to prevent freeze-thaw degradation of serum components and allow repeated sampling while stored at $-20^{\circ} \mathrm{C}$.

\section{Immunizations}

Mice 8-12 weeks of age were immunized for experiments discussed in chapter 3. To initiate a T-dependent immune response we immunized these animals with $100 \mu \mathrm{g}$ NP(15)-KLH in $200 \mu \mathrm{L}$ complete Freund's adjuvant per mouse. Animals were immunized intraperitoneally with the stated volume divided between 2 injection sites (left and right). For immunizations, mice may be lightly anesthetized with $3 \%$ isofluorane to reduce pain and struggle, therefore increasing the consistency of the technique, and ensures that animals get equal volume of immunization. After the initial immunization, a second booster immunization was given in similar fashion. This booster immunization contained equal concentraion of antigen, but this time in incomplete Freund's adjuvant. 


\section{ELISAs}

Total immunoglobulin ELISA plates were coated with $2 \mu \mathrm{g} / \mathrm{mL}$ anti mouse Ig in borate-saline buffer (Southern Biotech goat-anti mouse $\mathrm{Ig}(\mathrm{H}+\mathrm{L})$ unlb $1 \mathrm{mg} / \mathrm{mL}$, cat\# 1010-01) and incubated overnight at $4^{\circ} \mathrm{C}$ and then blocked with $1 \%$ BSA in borate-saline buffer for 1 hour. Serum dilutions $(100 \mu \mathrm{L} /$ well), were pre-optimized for each type of ELISA and then incubated on plates for 4 hours at room temperature. Plates were then washed and the desired secondary antibody (Southern Biotech goat anti-mouse IgM-biotin, IgG1-biotin, or IgG2b-biotin; respective cat\#'s 1020-08,1070-08, 1090-08) was allowed to incubate overnight at $4^{\circ} \mathrm{C}$. The following day, Streptavidin-alkaline phosphatase (Jackson ImmunoResearch cat\# 016-050-084) in BSA (1:10k) was incubated for 1 hour at room temp. Plates were then washed and 100 $\mu 1$ of PNPP developing substrate in diethanolamine substrate buffer (Thermo Scientific respective cat\#'s 34047, 34064) was added until sufficient color development and samples were analyzed on a microplate reader at $410 \mathrm{nM}$. Developing times may vary widely depending on the immune response of the mice and the dilutions used, a ballpark time estimate for optimization is $\sim 30-40$ minutes, however, this should be determined each type of ELISA. Known concentrations of purified mouse IgM, IgG1, and IgG2b immunoglobulins were used as a standard for quantitation of samples (respective BD Pharminigen cat\#'s $553472,557273,557351)$.

The same protocol was used for antigen-specific ELISAs, except plates were coated with $2 \mu \mathrm{g} / \mathrm{mL} \mathrm{NP}(15)-\mathrm{KLH}$ in borate-saline buffer instead of anti-mouse Ig.

\section{Spleen Harvest, Sorting, and Culture}

Spleens were harvested and finely lacerated with a scalpel in complete RPMI and passed through a $40 \mu \mathrm{M}$ strainer to suspend single cells for sorting. This cell solution was then delivered to the St Jude flow cytometry and cell sorting shared resource center. After red blood cell lysis, these splenocytes were then positively or negatively sorted for the desired populations. B cells were grown in RPMI media containing $20 \%$ FBS, $2 \mathrm{mM} \mathrm{L-}$ glutamine, and a penicillin/streptomycin antibiotic solution, which was further supplemented with non essential amino acids, 2-mercapto ethanol and $5 \mu \mathrm{g} / \mathrm{mL}$ LPS and adjusted to $\sim 1 \times 10^{6}$ cells per $\mathrm{mL}$ each day. For future reference, we concluded that although these experiments were performed at cell densities of $1 \times 10^{6}$ cell $/ \mathrm{mL}, \mathrm{B}$ cell cultures perform better at densities between $3-5 \times 10^{6}$ cells $/ \mathrm{mL}$, which will be used in future experiments. Protocols for other culturing other cell populations within the spleen remain to be optimized.

\section{Westerns}

B cells cultured in the presence of LPS were harvested every 24 hours over the course of 4 days. Pellets from each day containing $5 \times 10^{6}$ cells were centrifuged down, washed twice with cold PBS and then stored at $-80^{\circ} \mathrm{C}$ until needed. Whole cell lysates 
were obtained by lysing cell pellets for 30 minutes at $4^{\circ} \mathrm{C}$ in $500 \mu \mathrm{L}$ RIPA buffer with complete protease inhibitor and PMSF. Cell lystates were clarified by centrifugation at $14,000 \mathrm{rpm}$ for 30 minutes. Before loading, lysates were diluted at a ratio of $2 \times 10^{4}$ cells $/ \mu \mathrm{L}$ in sample buffer and heat denatured at $90^{\circ} \mathrm{C}$ for 10 minutes. Cell lysates were then run on $10 \%$ polyacrylamide SDS PAGE gels at $5 \times 10^{5}$ cells per lane and transferred to PVDF membranes and probed with the indicated antibodies.

\section{Cytospin}

Slides of B cells were made using a Cytospin centrifuge. Each slide was prepared with $2.5 \times 10^{5}$ cells in $50 \mu \mathrm{L} 10 \%$ PBS + FBS. Samples were centrifuged onto the slide for 5 minutes at $500 \mathrm{rpm}$. Slides were then fixed in $95 \%$ ethanol and $5 \%$ acetic acid for 20 minutes and washed overnight in $10 \% \mathrm{PBS}+\mathrm{FBS}$ at $4^{\circ} \mathrm{C}$, do not rock or disturb the slides during this time. The following day slides were placed in a humidifying chamber to prevent drying out and $20 \mu \mathrm{L}$ goat anti mouse kappa-TRITC staining antibody was incubated on the slide for 20 minutes. Slides were then washed in 10\% PBS + FBS for 4 hours at room temperature. Lightly dry slides and add ProLong Gold mounting medium (contains DAPI nuclei stain) and coverslip. Dry overnight in dark at $4^{\circ} \mathrm{C}$ and visualize under fluorescent microscope. 


\section{CHAPTER 3. THE EFFECTS OF SIL1 LOSS ON IMMUNOGLOBULIN BIOSYNTHESIS AT THE ORGANISMAL LEVEL}

\section{Results}

BiP is known to be required for biosynthesis of all Ig molecules, but the role of NEFs in this process has never been examined in vivo. To determine if the loss of Sill would affect the ability of B cells to assemble and secrete antibodies, we obtained Sill wild-type and null mice from Dr. Susan Ackerman and established a breeding colony. When pups were weaned at 21 days they were identified with an ear tag and genotyped by tissue sampling. Using primer pairs LZO134-135 for the WT allele and primer pairs LZO136-137 for the interrupted allele (Table 3-1), we were able to identify WT mice, heterozygous mice, and mice that were null for Sill (Figure 3-1) which were born at normal Mendelian and sex ratios. All wild-type and null littermates used for the experiments were genotyped 3 times to ensure proper identification, and heterozygous pairs were bred to produce more offspring as needed.

When our mice reached 8-12 weeks of age, we first compared the basal levels of total serum immunoglobulin in unimmunized mice. We obtained sera from $10 \mathrm{WT}$ and 10 KO Sil1 mice. Due to the limiting average litter size of 4.9 pups (Jackson Laboratory resource manual), several litters were required to produce the desired sample size, however, all mice from each WT and KO cohort were strictly limited to an equal number of siblings. We examined serum immunoglobulin concentrations for three different isotypes and subclasses by ELISA. We chose IgM and IgG2b, because they assemble via an $\mathrm{H}>\underline{\mathrm{HL}}>\mathrm{H}_{2} \mathrm{~L}_{2}$ pathway (henceforth referred to as the HL path), and IgG1 because it assembles from $\mathrm{H}>\underline{\mathrm{H}}_{2}>\mathrm{H}_{2} \mathrm{~L}_{2}$ (henceforth referred to as the, $\mathrm{H}_{2}$ path) intermediates. Since BiP remains bound to immunoglobulin heavy chain intermediates $(\mathrm{H})$ until they are able to fold and assemble with immunoglobulin light chain intermediates (L), and eventually form a mature immunoglobulin heterodimer $\left(\mathrm{H}_{2} \mathrm{~L}_{2}\right)$ that meets the quality control requirements of the ER and are able to be secreted, the intermediates in the latter pathway remain $\mathrm{BiP}$ substrates until the very end of the maturation process. This led us to hypothesize that $\mathrm{H}_{2}$ intermediates might be more affected by the loss of a NEF. The individual Ig serum levels were quantified by generating standard curves with known concentrations of each Ig isotype and subclass examined.

Our data show that Sill mice were able to secrete immunoglobulin of all three types. However, we observed that Sill -deficient mice had slightly lower basal levels of IgM in serum than their WT littermates as visible by the median cohort values shown in Figure 3-2, which we calculated to be $\sim 1000 \mu \mathrm{g} / \mathrm{mL}$ for WT $\sim 300 \mu \mathrm{g} / \mathrm{mL}$ for $\mathrm{KO}$. However, there was some overlap between WT and KO ranges of serum IgM and some Sill null mice had serum levels that were as high or higher than some individual WT mice. We measured the significance of these data sets by an unpaired t-test and found that although there is a broad range in serum antibodies among the 20 mice examined, the calculated probability between WT and KO basal serum IgM was calculated to be $p=0.056$, which is near the accepted convention of statistical significance $(p \leq 0.05)$. 
Table 3-1. Primers Used in Genotyping Sil1 Null Mice.

\begin{tabular}{lllc}
\hline \multicolumn{1}{c}{ Gene Target } & Primer & \multicolumn{1}{c}{ Sequence } & Predicted Product \\
\hline WT & LZO134 & ctatagccegcctcaggagtgttgta & \multirow{2}{*}{$922 \mathrm{bp}$} \\
WT & LZO135 & attgccecatagagccatttgttgt & \\
Sill KO & LZO136 & caccggatgcagaaaagccacaat & \multirow{2}{*}{$774 \mathrm{bp}$} \\
Sill KO & LZO137 & gcaactcgccgcacatctgaactt & \\
\hline
\end{tabular}

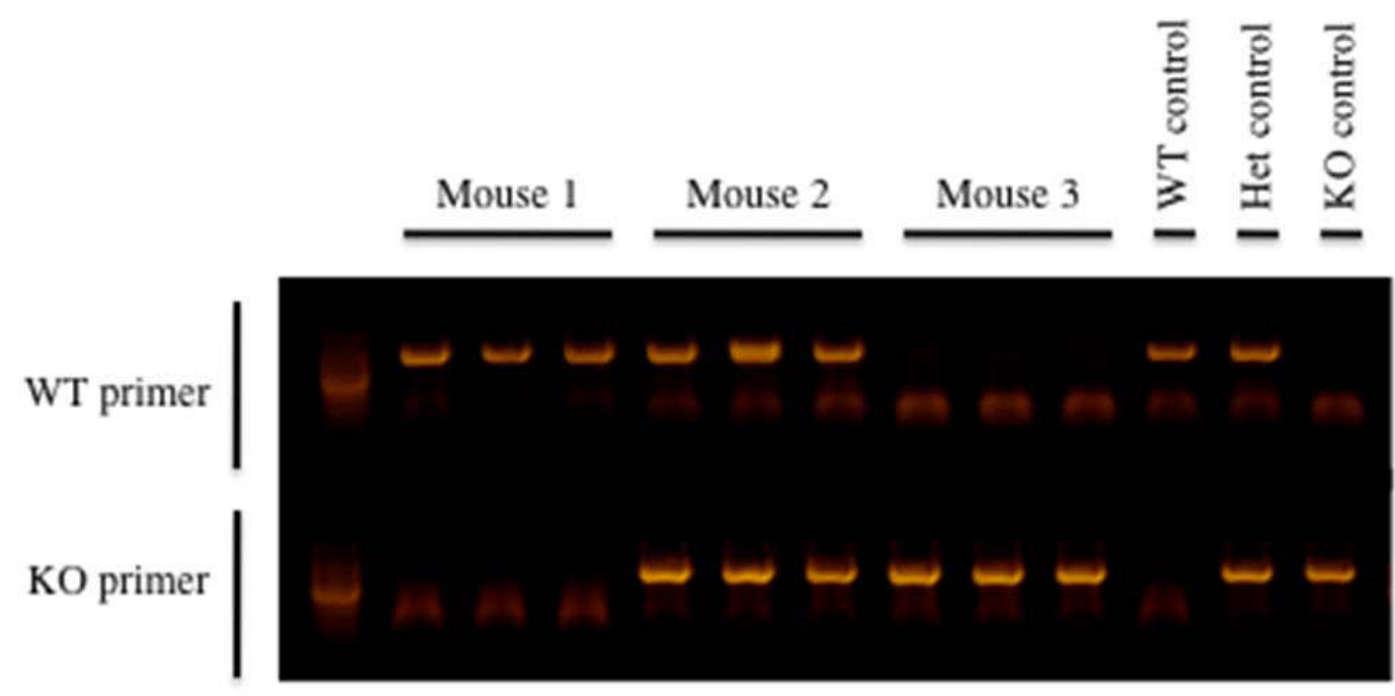

Figure 3-1. Genotyping Sil1 Null Mice. Mice were weaned at age 3 weeks and tissue samples were tested for their ability to produce a product using WT and KO primers to indicate the presence of a wild-type allele, knockout allele, or heterozygous combination. Mice used for serum sampling were genotyped 3 times as shown to ensure proper identification of WT and KO alleles. In this figure, mice 1, 2, and 3 are WT, Het, and KO examples, respectively. The specific primer pairs used are shown in accompanying Table $3-1$. 

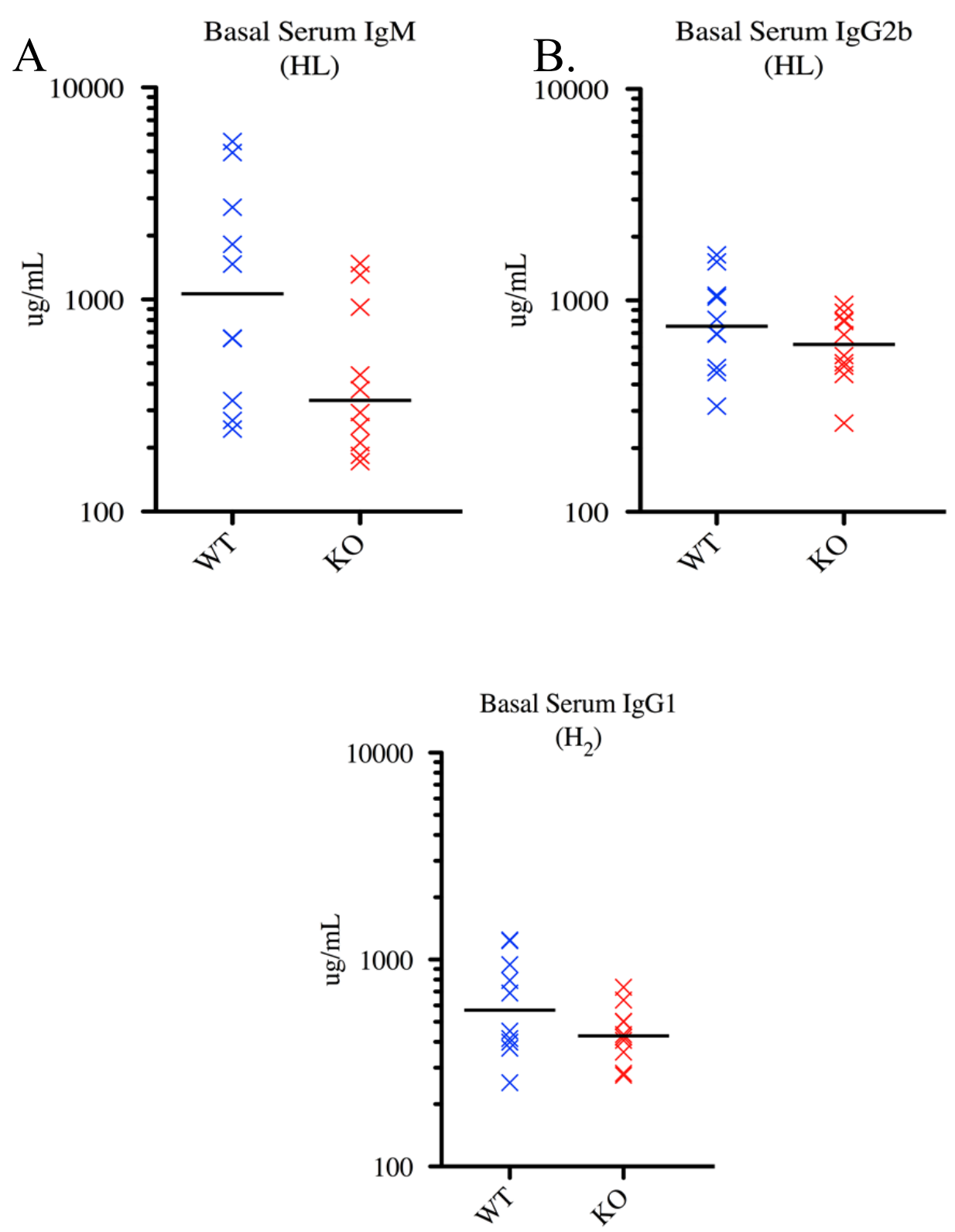

Figure 3-2. Basal Serum Concentrations of IgM, IgG2b, and IgG1 in WT and Sil1 Null Mice. Each point shows the triplicate-average calculated serum concentration from a single mouse analyzed by ELISA with coefficient of variation (CV) $<10 \%$ from each WT (blue) and KO (red) serum sample. Median cohort values are indicated by a black line. 
Interestingly, the range of total IgM was larger in both WT and KO mice than either of the other examined IgG subclasses in WT or KO mice; the reason for this is unclear but this observation was consistent throughout all experiments.

Although the most striking trend from these data is the difference in basal serum IgM concentrations, there was an observed trend in lower median values of all examined isotypes and subclasses in Sill KO mice. However, the difference in basal serum IgG2b and IgG1 levels between WT and KO were not significant. This came as a surprise in light of our original hypothesis that there would be a connection between basal serum Ig levels and their respective assembly pathways and presumed dependence on BiP. In fact the only isotype that showed a near significant decrease in serum levels was IgM, which assembles through $\mathrm{HL}$ intermediates that we predicted to be less BiP dependent, and therefore presumably less affected by loss of Sil1. Although IgG2b follows the same HL intermediate pathway as IgM, which we predicted to be more BiP/Sill dependent, there was a much stronger effect on IgM levels than IgG2b. Basal serum levels of IgG1, which assembles via an $\mathrm{H}_{2}$ intermediate that we presumed to be more BiP-dependent, showed a marginally lower level in $\mathrm{KO}$ serum but had a calculated $\mathrm{p}$ value that is greater than the accepted convention of significance $(\mathrm{p}=0.086)$.

Since it is clear that Sill deficient mice are capable of secreting numerous classes of immunoglobulins, we next wanted to examine the magnitude and temporal aspects of antibody secretion in response to antigen in WT an KO mice. We reasoned that the loss of Sill might result in the accumulation of unassembled antibodies, which might be expected to activate the UPR and up-regulate Grp170 expression, the other putative ER NEF as well as other ER chaperones and folding enzymes. This led us to question if there might be a delay in the secretion of immunoglobulin in response to antigen. Therefore, we devised a time course experiment that extended over 24 days whereby we could examine serum at 7 important time points during the primary and secondary humoral responses. This time course was designed to capture a snapshot of basal levels, 3 time points following initial immunization, and 3 time points following a booster immunization as shown in Figure 3-3.

Using the experimental design shown in Figure 3-3, we first chose to look at serum Ig levels with an antigen-specific ELISA by coating 96-well plates with the immunogen NP(15)-KLH rather than an anti-mouse Ig $(\mathrm{H}+\mathrm{L})$ capture antibody, which recognizes both specific and non-specific responses, as this would provide a clear picture of the ability of Sill deficient mice to generate a large volume of antigen specific immunoglobulin from a near zero starting point. Isotypes of the immune serum were determined by developing the bound antibodies with isotype- or subclass-specific reagents. Unimmunized serum was obtained from each mouse prior to intraperitoneal injection of NP(15)-KLH (100 $\mu \mathrm{g}$ at $1 \mathrm{mg} / \mathrm{mL})$ in complete Freund's adjuvant. Serum samples $(75 \mu 1$ each) were then collected by alternating retro-orbital and tail vein bleedings at five, nine, and twelve days after the primary immunization. We next administered an intraperitoneal booster immunization of the same concentration and volume of NP(15)-KLH in incomplete Freund's adjuvant fourteen days after the primary immunization. Once again, serum was obtained by the same method 18, 20, and 


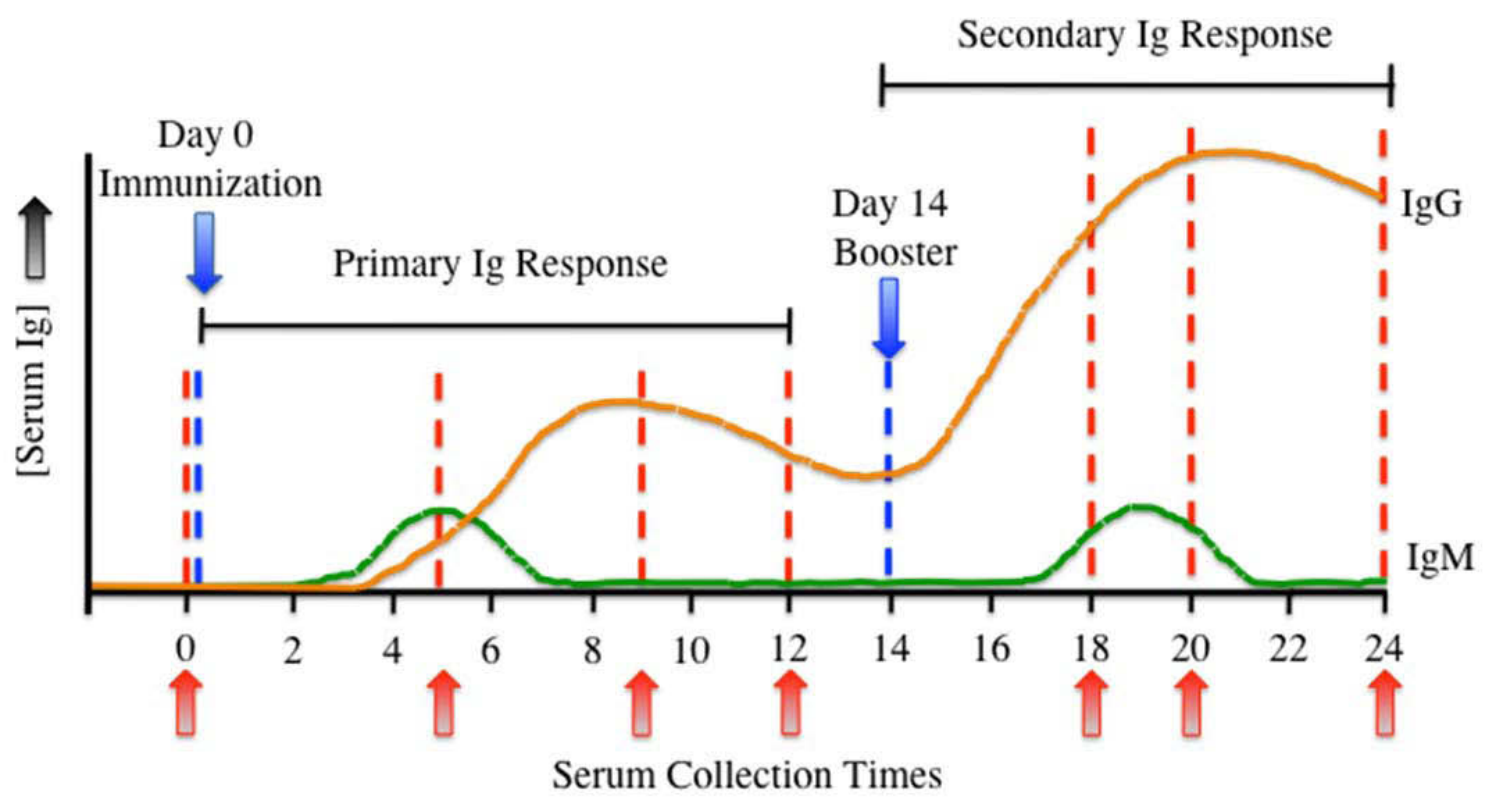

Figure 3-3. Time Course of Immunizations and Serum Collection. This schematic shows the timing of immunizations (blue arrows) and serum collection (red arrows). The predicted timing of generalized isotype responses is also indicated. IgM (green curve) is the first responding Ig subclass, whereas IgG (orange curve) appears somewhat later and predominates in the secondary Ig response. 
24 days after the original immunization. After the time course of immunizations and serum collection were complete, we analyzed the various antigen-specific isotype and subclass responses.

We observed a strong similarity in magnitude and also in kinetics of the antigenspecific serum response for all three types of Ig between WT and Sill KO mice. Figure 3-4 shows the triplicate averaged median values and interquartile range for $10 \mathrm{WT}$ and 10 $\mathrm{KO}$ mice at each time point. This result was particularly surprising in the case of IgM, where we saw no difference in an antigen specific response (Figure 3-4A). As expected, there was an undetectable amount of NP(15)-KLH specific Ig for IgM, IgG2b and IgG1 in serum on day zero (Figure 3-4A, B, C). Also as expected, we observed a quick and robust IgM response by day 5 in WT mice, which was indistinguishable in Sill KO mice (Figure 3-4A).

Antigen-specific IgG2b and IgG1 levels were examined next. We observed a very modest induction of $\operatorname{IgG} 1$ and $\operatorname{IgG} 2 \mathrm{~b}$ on day 5 , although present at concentrations $\sim 100$ fold less than IgM concentrations on the same day $(\sim 20 \mu \mathrm{g} / \mathrm{mL})$. By day 9 IgG1 increased to $\sim 100 \mu \mathrm{g} / \mathrm{mL}$ from $\sim .2 \mu \mathrm{g} / \mathrm{mL}$ on day 5 in both WT and KO mice (Figure 3-4B, C) whereas IgG2b peaked at $\sim 30 \mu \mathrm{g} / \mathrm{mL}$ on day 5 . Our observations also confirm that $\mathrm{NP}(15)-\mathrm{KLH}$ primarily produces an IgG1 response after secondary exposure since IgG2b levels did not shown an increase above $\sim 20 \mu \mathrm{g} / \mathrm{mL}$ even after a booster immunization on Day 14, whereas IgG1 concentration increased 2-fold within one week of the boost up to $\sim 200 \mu \mathrm{g} / \mathrm{mL}$ (Figure 2-4B, C).

In light of our previous observation that IgM was present at lower basal levels in Sill deficient mice, we found it surprising that there was no difference in the magnitude or kinetics of an antigen-specific response between WT and KO. To follow up on these findings we re-examined the same serum samples by a different type of ELISA. This time we coated plates with an anti-mouse $\operatorname{Ig}(\mathrm{H}+\mathrm{L})$ capture total antibody in order to observe a broader picture of total immunoglobulin serum levels after immunization, rather than specifically measuring the clonal production of antigen specific immunoglobulin.

We consistently observed a lower concentration of total IgM in serum of Sill KO mice at every time point examined (Figure 3-5A). We again noticed wider ranges of total IgM in both WT and KO compared to IgG isotypes, as was seen in our previous experiments. Longitudinal data analyses were performed to verify the significance of this apparent IgM secretion deficiency using a mixed effects model, which fits an average model to the data and then allows for additional parameters to customize this average profile to each mouse. We conclude that there is a significant difference in the average increase of IgM in KO mice after immunization over a 24 day time course $(\mathrm{p}=.045)$. Interestingly, we also note that there seems to be a decrease in the disparity between WT and $\mathrm{KO}$ as time progresses, i.e. the slope of the IgM response is higher in $\mathrm{KO}$ mice, although the $p$ value for this result is marginal $(p=.106)$. Using the same type of longitudinal data analysis but with custom models for each Ig type, we further confirmed that there is no difference in either the IgG2b or IgG1 responses between WT and Sill deficient mice. 
Figure 3-4. Antigen-Specific IgM, IgG2b, and IgG1 Production Measured over 24 Days Post Immunization.. Each point shows the median value of $10 \mathrm{WT}$ (blue) or 10 KO (red) mice. These median values were determined by triplicate-average calculated serum concentration from a single mouse analyzed by ELISA with coefficient of variation $(\mathrm{CV})<10 \%$ from each WT (blue) and $\mathrm{KO}$ (red) serum sample. As such, each graph shows the average median of the indicated days for a total of $210 \mathrm{WT}$ and $210 \mathrm{KO}$ samples at 7 time points. Error bars indicate interquartile range of values. Each plate was coated with $100 \mu \mathrm{l}$ of $2 \mu \mathrm{g} / \mathrm{mL}$ antigen and developed with isotype or subclass specific detection antibody. 
A.

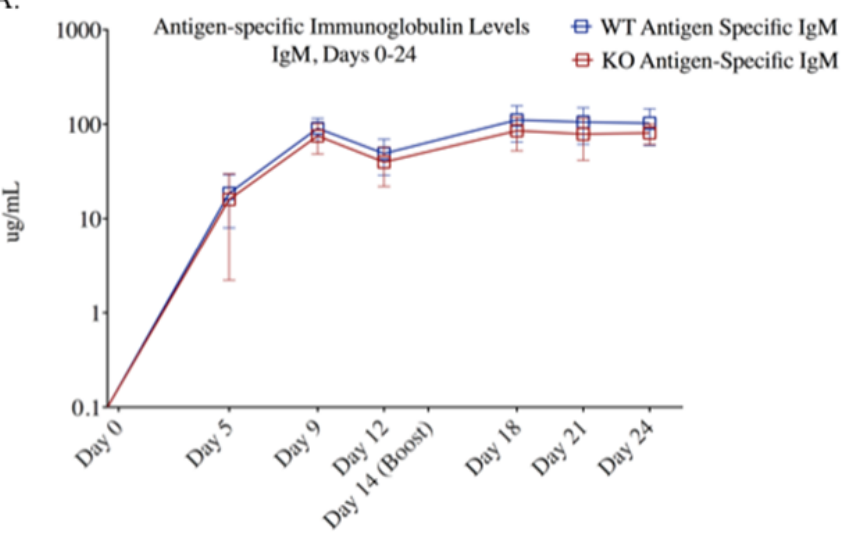

B.

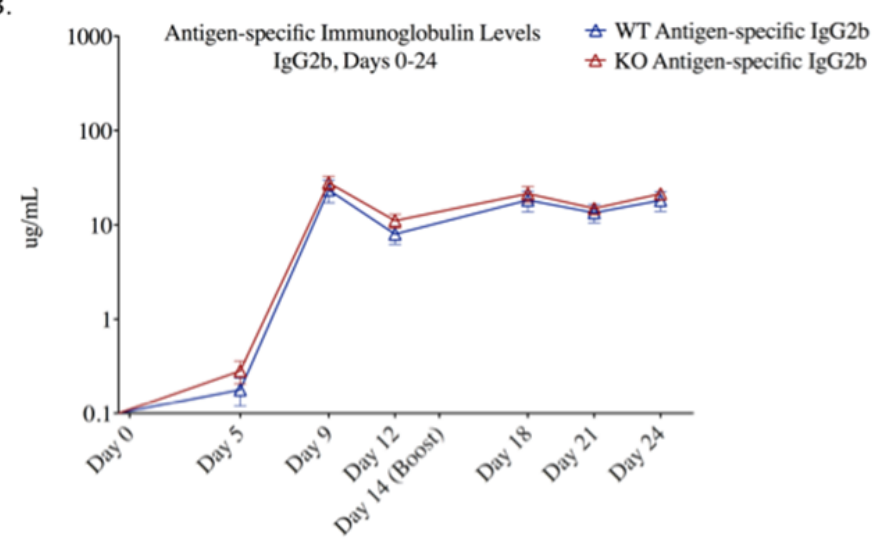

C.

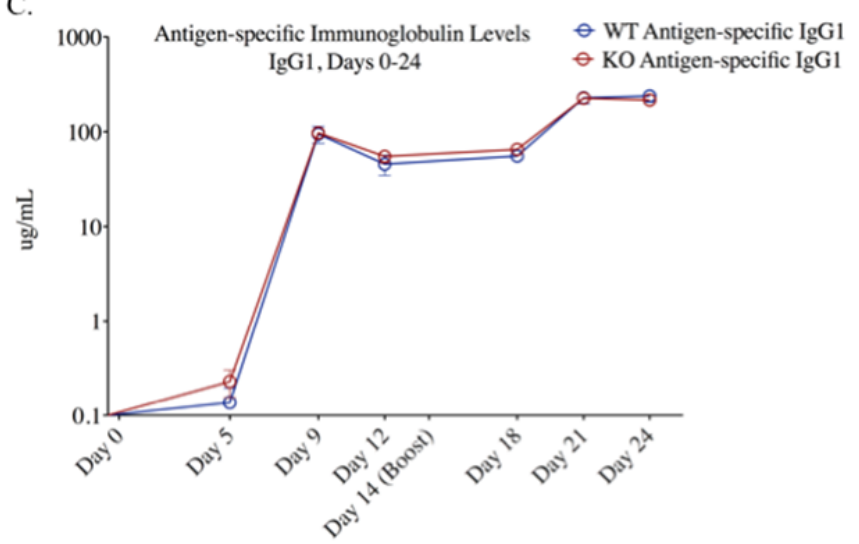

37 
Figure 3-5. Total Non-Antigen-Specific IgM, IgG2b, and IgG1 Production over 24 Days Post Immunization. Each point shows the median value of 10 WT (blue) or 10 KO (red) mice. These median values were determined by triplicate-average calculated serum concentration from a single mouse analyzed by ELISA with coefficient of variation $(\mathrm{CV})<10 \%$ from each WT (blue) and $\mathrm{KO}$ (red) serum sample. As such, each graph shows the average median of the indicated days for a total of $210 \mathrm{WT}$ and $210 \mathrm{KO}$ samples at 7 time points. Error bars indicate interquartile range of values. Each plate was coated with $100 \mu \mathrm{l}$ of $2 \mu \mathrm{g} / \mathrm{mL}$ anti-mouse Ig $(\mathrm{H}+\mathrm{L})$ and developed with isotype or subclass specific detection antibody. 

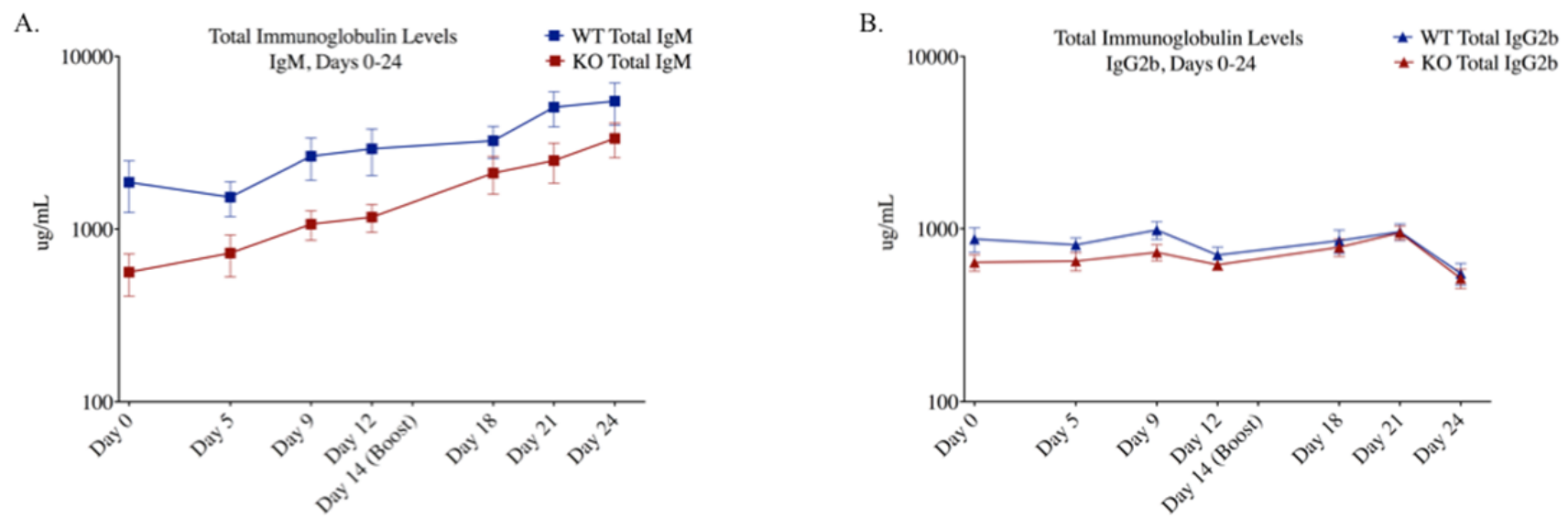

C.

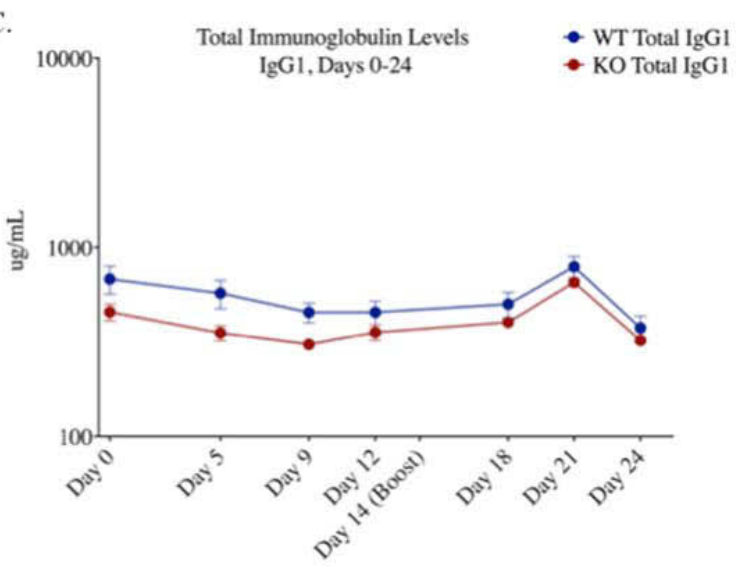

39 


\section{Conclusions}

Sill deficient mice are able to secrete immunoglobulin of all isotypes into the bloodstream. Although they had slightly lower basal levels of serum $\operatorname{IgM}(p=.056)$, which is secreted as a pentamer and is the most complex of all isotypes, they were still able to produce significant quantities compared to age matched litter controls. While there was a small trend toward lower basal serum concentrations of IgG1 and IgG2b in Sil1 KO mice, these numbers were less significant. Furthermore, we observed no correlation in the ability to secrete isotypes that are assembled via the $\mathrm{HL}$ versus the $\mathrm{H}_{2}$ intermediate pathway even though subclasses assembling through the later pathway remain bound to $\mathrm{BiP}$ much longer. In addition, we observed no difference in the production of antigenspecific IgM, IgG2b, or IgG1 in response to $\mathrm{NP}(15)-\mathrm{KLH}$ immunization at any time over a 24 day time course. Interestingly however, we saw consistently lower levels of total $\operatorname{IgM}(\mathrm{p}=.045)$, as opposed to antigen-specific IgM, in Sill deficient mice at each time point examined after immunization. Also, we found it intriguing that the extent of this difference between WT and KO IgM seemed to decrease over time, although this finding had a high $\mathrm{p}$ value $(\mathrm{p}=.106)$ and was not strictly confirmed. 


\section{CHAPTER 4. THE EFFECTS OF SIL1 LOSS ON IMMUNOGLOBULIN BIOSYNTHESIS AT THE CELLULAR LEVEL}

\section{Results}

After examining immunoglobulin secretion in an animal model, we next wanted to extract primary splenic B cells from WT and woozy mice to compare their ability to synthesize and secrete IgM antibodies in response to lipopolysaccharide (LPS) stimulation administered ex vivo. Immune responses to microbial pathogens depend on rapid and robust IgM secretion, and this response is mediated in part by B cell recognition of LPS via the Toll-Like Receptor (TLR) family of proteins and their partners. B cells that recognize LPS undergo an intense and impressive cellular transformation into terminally differentiated IgM secreting plasma cells that are capable of secreting their own mass in antibodies per day [48]. LPS stimulation induces an enormous expansion of the ER, its molecular chaperones, their cofactors and resident folding machinery. This entire process is driven by induction of a partial UPR and is mediated by BiP, as previously mentioned [49]. Ex vivo LPS stimulation of B cells is a well-established method that fit our experimental needs perfectly by allowing us to examine the secretion of IgM in a highly controlled environment. It also provides a means to measure the basal levels of the ER folding machinery when Sill is lacking and the magnitude of induction of select UPR components during the differentiation process.

The mice used in this aim were all between 4-6 months of age, which is older than the 8-12 week littermates used in Aim 1. However, the mice in Aim 2 were littermates of those used in the previous aim, only older. Since we invested a significant amount of time in quantifying all of the serum samples for antigen-specific and total antibody of each of the isotypes and subclasses we analyzed in Aim 1, the size of our breeding colony was reduced during the course of these experiments to efficiently conserve resources. We used the older mice, because around this time we began to have problems with breeding the mice, which will be discussed in the appendix.

We chose to isolate purified B cells by negatively sorting primary mouse splenocytes via Magnetic-Activated Cell Sorting (MACS), so as to not risk unintended activation of B cells by stimulating any surface receptors in a positive sort for B cell markers. Table 4-1 shows the assortment of markers used for this experiment.

B cells were cultured in LPS media and samples were remove at 24 hour time points and prepared for IgM immunostaining to identify those B cells that were activated by LPS as shown in Figure 4-1. These cells were stained after fixing and therefore indicate both surface $\operatorname{IgM}$ and intracellular $\operatorname{IgM}$. At this time, we were in the early phases of developing a staining protocol and only managed to create good slides from Day 1 samples, in the near future we plan to revisit these experiments and generate slides of unstimulated cells for comparison to each day of LPS stimulation Although this initial experiment only reflects a very small sample size of $1 \mathrm{WT}$ and $1 \mathrm{KO}$ mice (each male, 6 months old), it is notable that both WT and KO had approximately equal 
Table 4-1. Strategy for Isolating Purified Splenic B Cells.

\begin{tabular}{lcc}
\hline \multicolumn{1}{c}{$\begin{array}{c}\text { Major Cell Types } \\
\text { in Spleen }\end{array}$} & $\begin{array}{c}\text { Cell Surface } \\
\text { Marker }\end{array}$ & $\begin{array}{c}\text { Positive or } \\
\text { Negative Sort }\end{array}$ \\
\hline B cells & CD19, B220 & - \\
Erythrocytes & Ter119 & + \\
Macrophages \& Granulocytes & Mac1/Gr1 & $+/+$ \\
Cytotoxic T cells & CD8 & + \\
Helper T cells & CD4 & + \\
Natural killer cells & NK1.1 & + \\
\hline
\end{tabular}
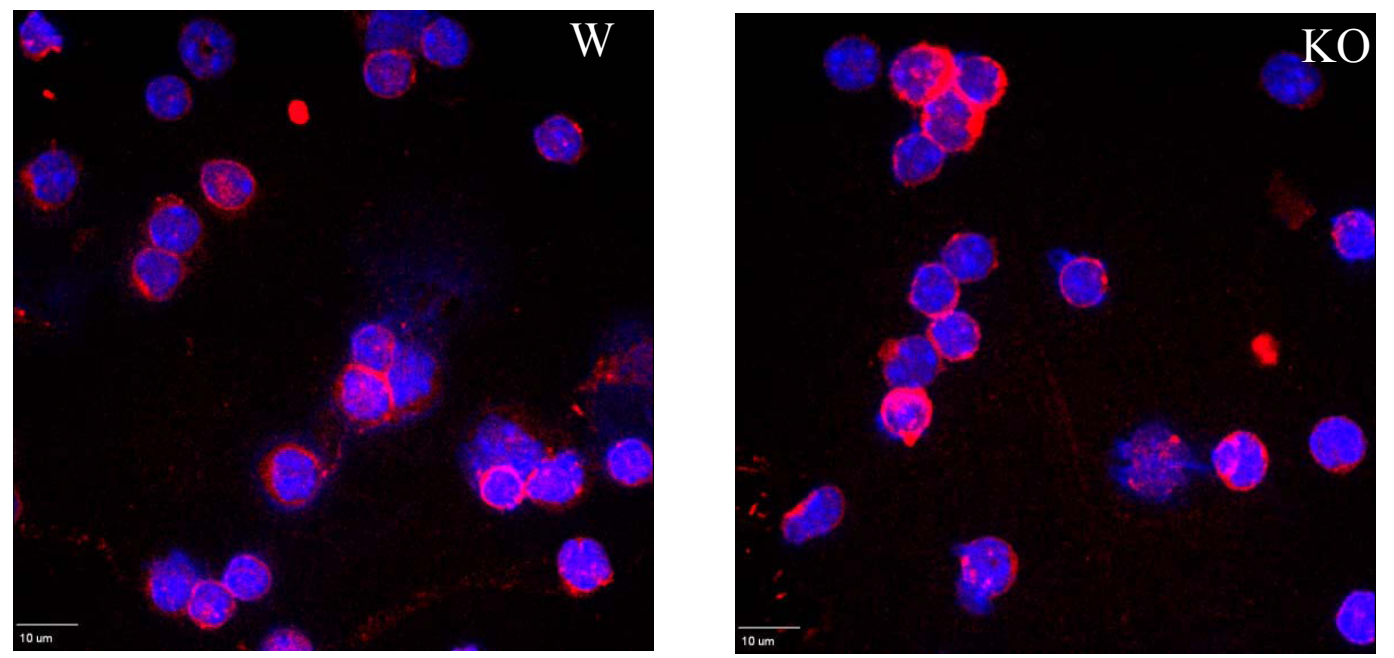

Figure 4-1. Sil1 Null Mice Respond to LPS Stimulation by Producing IgM

Positive Plasmablasts. The negatively isolated splenic B cells obtained from both WT and Sill null mice were cultured in media containing $5 \mu \mathrm{g} / \mathrm{mL}$ LPS. Cells that had been cultured for $24 \mathrm{hrs}$ were washed in 1x PBS containing 5\% FB1S and adhered to slides using a cytocentrifuge. After air-drying, slides were incubated in $95 \% \mathrm{ETOH}+5 \%$ glacial acetic acid solution for 20 minutes. 
numbers of negatively sorted B cells within similarly sized spleens and body mass, and showed no signs of susceptibility to infection, since these parameters have not been previously reported. The B cells from both animals that had been stimulated with LPS showed similar numbers of IgM positive cells with no apparent difference in morphology or staining patterns.

We next examined levels of IgM in culture media as a means of measuring the IgM secreting ability of Sill KO vs WT cells, which we were able to strictly regulate in culture. Since a report of primary cultured Sill null cells is not present in literature, it is noteworthy that we observed no differences in doubling time or macroscopic cytoarchitecture of WT or Sill KO B cells. We performed an ELISA on culture supernatant samples up to 72 hours after LPS stimulation as shown in Figure 4-2, using the same total Ig protocol as before but with optimized media dilutions. Sill null B cells secreted slightly less IgM into culture medium at 48 and 72 hours; however, this experiment was only performed on 1 mouse of each genotype and should be repeated with a larger sample sized to draw strong conclusions. During this time, both WT and KO Sil1 B cells formed characteristic proliferation foci in response to activation by LPS within 48 hours and continued proliferating at similar rates, although this observation was not quantified.

We next collected $4 \times 10^{6}$ cells from each day of LPS stimulation to analyze by western blotting (Figure 4-3). Cell pellets were lysed in 200 $\mu 1$ RIPA buffer containing complete EDTA protease inhibitor and PMSF and were run on 10\% SDS PAGE gels under reducing conditions at $3 \times 10^{5}$ cells per lane (although this required short exposure time and loading fewer cells may provide clearer resolution, for future reference). When WT and Sil KO cell lysates were compared, we saw equivalent amounts of the membrane form and secretory form of $\mu$ heavy chain, and kappa light chain at baseline (day 0 ). Furthermore, we observed no difference at any time during LPS treatment in the amount of either form of $\mu$ heavy chain or kappa light chain, suggesting that the loss of Sill did not affect the ability of IgM to be secreted from the cell. However, based on the fact that we saw a slightly reduced amount of IgM in the culture supernatant of LPS stimulated Sill KO cells, it is formally possible that unassembled heavy chains were being degraded rather than accumulating in these cells. Pulse-chase experiment performed under both reducing and non-reducing conditions will be required to determine this.

Based on data from Purkinje cells in Sill KO mice, we hypothesized that Sill null B cells might show evidence of ER stress and a compensatory upregulation of Grp170 either before LPS stimulation or during the course of plasma cell differentiation. Thus, we next examined the induction of BiP cofactors Grp170 and ERdj3 (Figure 4-4). Surprisingly, we did not observe any difference in induction of BiP HSP40 cofactor Erdj3 between WT and Sill KO cells either before or anytime after LPS stimulation, suggesting that the loss of Sill was not stressful to resting B cells or to cells that were stimulated to produce large quantities of Ig proteins in the ER. We also observed equal Grp170 levels at before and after stimulation with LPS in both WT and Sil1 KO B cells. We were surprised at this finding in light of the essential role of BiP and its cofactors during the transformation from B cell into antibody secreting plasma cells. We had hypothesized 


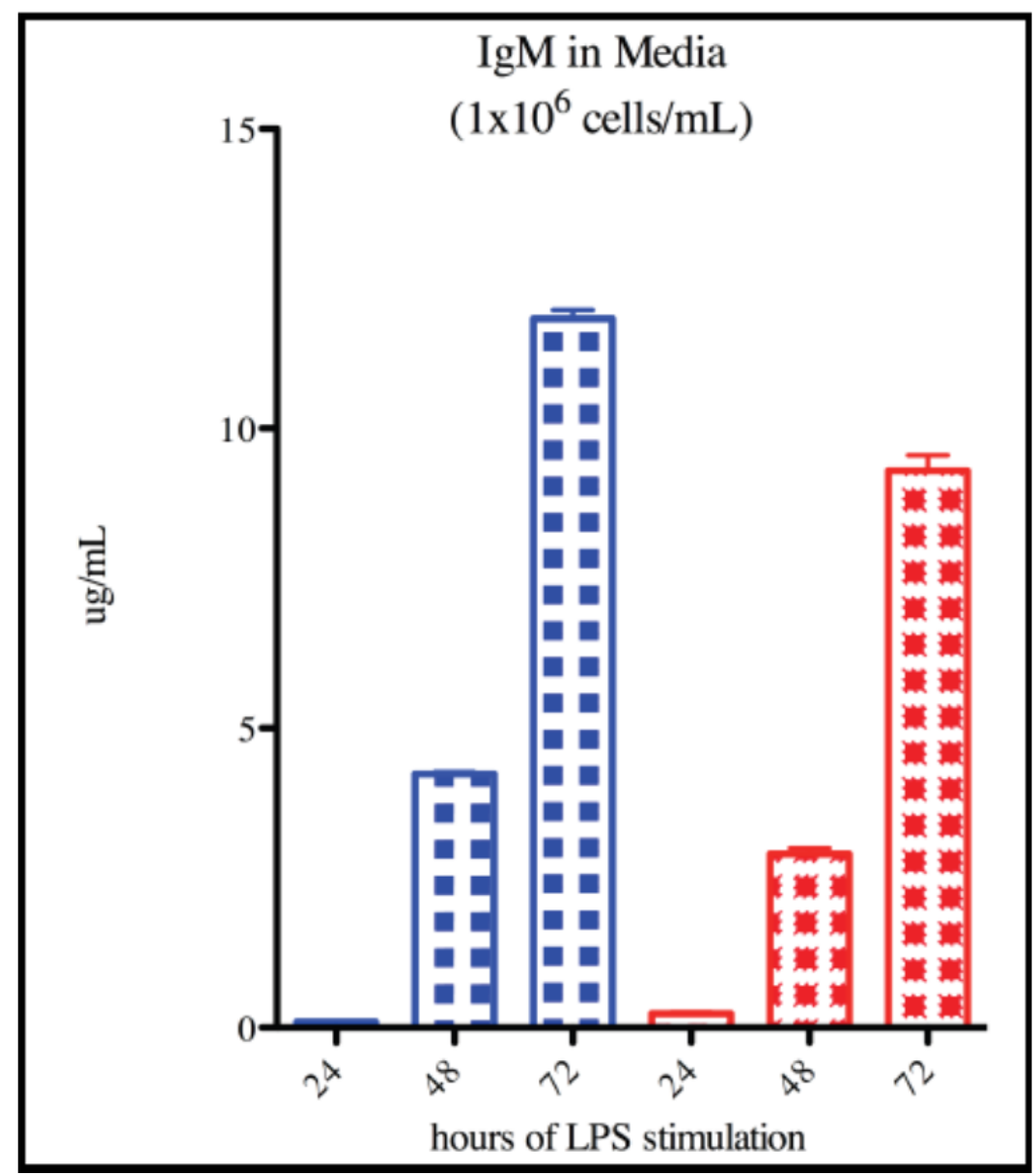

Figure 4-2. Ex Vivo IgM Secretion of Activated Plasma Cells from WT and Sil1 KO Mice in Response to LPS Stimulation. Purified primary B cells were maintained at $1 \times 10^{6}$ cells $/ \mathrm{mL}$ in the presence of LPS media for 72 hours. WT (blue) and KO (red) culture supernatant was sampled every 24 hours and analyzed for IgM secretion by ELISA. 


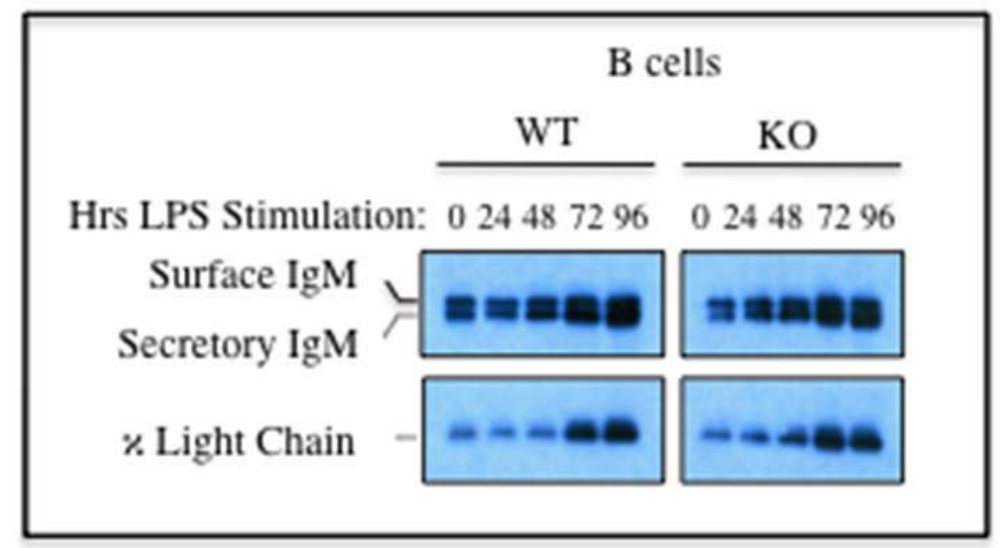

Figure 4-3. Ig Mu Heavy Chain and Kappa Light Chain Production in Response to LPS Stimulation. Purified primary B cells were grown in the presence of 5 $\mu \mathrm{g} / \mathrm{mL}$ LPS to stimulate plasma cell differentiation and examined every 24 hours for a 4 day period for IgM heavy chain and light chain levels by western blotting.

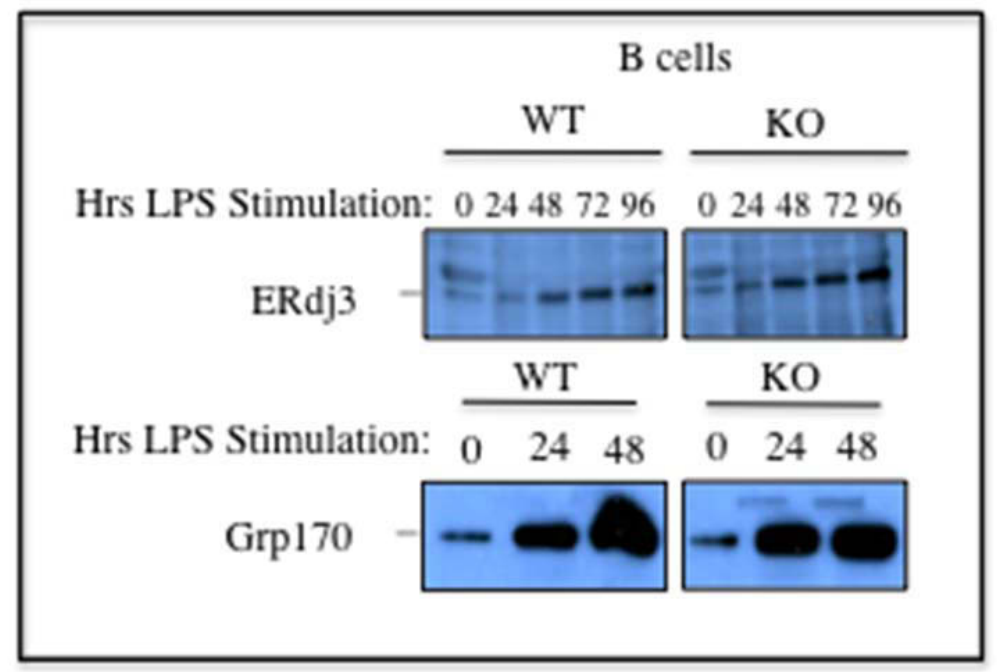

Figure 4-4. Wild Type and Sil1 Null Plasma Cells Upregulate BiP Cofactors Erdj3 and Grp170 in Response to LPS Stimulation. Purified primary B cells were stimulated to differentiate into activated antibody secreting plasma cells by exposure to 5 $\mu \mathrm{g} / \mathrm{mL}$ LPS. Levels of BiP cofactors, Erdj3 and Grp170, were examined by western blotting during this process every 24 hours. Cell lysates from $3 \times 10^{5}$ cells were obtained each day and loaded onto each lane after being lysed in RIPA buffer supplemented with complete EDTA and PMSF for 30 min. Levels of BiP cofactors, Erdj3 and Grp170, were examined by western blotting during the activation process. 
that since BiP has only two known NEFS, that loss of Sill would necessitate Grp170 upregulation to control ER stress and allow Sill deficient plasma cell survival and efficient immunoglobulin secretion. However, this was not the case. Our observation that Grp170 is not upregulated in Sill deficient B cells or activated plasma cells strongly suggests that either (1) Grp170 and Sil1 have redundant functions and that either one of these proteins is sufficient to assist $\mathrm{BiP}$ in controlling Ig assembly and secretion, (2) Grp170 is the only BiP NEF required for the assembly of immunoglobulin, or (3) that Ig light chain may be sufficient to induce BiP release from Ig heavy chain substrates, since recent in vitro studies with purified proteins reveal that Ig light chains initiate folding nuclei in the $\mathrm{CH} 1$ domain of Ig heavy chains and leading to BiP release [50].

\section{Conclusions}

We found that 4-6 months old Sill mice have similar sized spleens and contain approximate equal numbers of B cells as their WT littermates, as shown by negative isolation data from MACS. Furthermore, we observed no differences in morphology of WT vs. KO cells or in their doubling time in response to LPS stimulation in culture. ELISAs performed on culture medium from LPS stimulated cells also suggested that Sill KO plasmablasts may secrete slightly less IgM than WT mice, although our sample size was very small. Production and intracellular accumulation of the membrane-bound form of IgM, the secretory form of IgM, and kappa light chain appear identical in WT and Sill null mice as shown by western blotting, which was very reproducible, suggesting that either there is no block in secretion with Sill loss or that the unassembled precursors are rapidly degraded. We also observed similar production of the alternative BiP NEF Grp170 and the HSP40 cofactor Erdj3 during LPS stimulation at each time point examined. This was particularly interesting since we hypothesized that a compensatory mechanism would result in upregulation of Grp170 levels either at baseline or during plasma cell differentiation, but this was not the case. Based on our animal data, it is very possible that individuals affected with Marinesco-Sjögren's Syndrome will respond normally to antigens and produce normal levels of immunoglobulin. 


\section{CHAPTER 5. ADDITIONAL STUDIES ON THE PHENOTYPE OF AGED SIL1 KO MICE}

\section{Preliminary Results}

The mice used to gather the data shown in this chapter were older and varied more in age than those used in the previous aims. The youngest mice used for experiments in this section were around 9 months of age while several were well over 1 year in age. Since it required a significant amount of time to complete the experiments put forth in the previous aims, the size of our breeding colony was reduced during the course of these experiments to efficiently conserve resources, as mentioned. We began using these older mice for experiments, because when we started to expand our colony to complete more cellular experiments, we began to have problems with breeding the mice. Our hypothesis for the cause of these later onset reproductive problems will be discussed in the following.

During the negative sorting process used to purify B cells from mice that were 4-6 months old in Aim 2 we also received a sample of all non-B splenocytes, which included helper T cells, cytotoxic T cells, natural killer cells, macrophages, granulocytes and red cell precursors that represent those cell populations that were positively stained for CD4, CD8, NK1.1, Mac1/Gr1, or Ter119 respectively. This sample contained percentages of cells that directly reflected ratios of the natural populations within the spleen, including helper $\mathrm{T}$ cells, cytotoxic $\mathrm{T}$ cells, natural killer cells, macrophages and granulocytes, and any erythrocytes that managed to survive lysing. This set of samples was not originally included in our experiment outline, but we placed these cells in culture alongside the purified B cells nonetheless, which turned out to provide an interesting piece of tangential data. Although this protocol did not allow us to maintain this population very long in culture, we were able to prepare cells from both WT and Sill null cultures for western blotting and observe baseline and 24 hour time points of Grp170 expression. We had hypothesized that Grp170 levels might be upregulated at baseline or during differentiation, as in cerebellar Purkinje cells of the woozy mouse, but this was not the case (Figure 4-4). However, we did observe this exact phenomenon in the remaining unpurified splenocytes that were from the same mice used in Figure 4-4 (Figure 5-1).

On day 0 the heterogeneous population of KO splenocytes showed a higher level of Grp170 than the WT controls. After 24 hours in culture with LPS, Grp170 expression was significantly induced in the WT cells, however, the expression of Grp170 remained unchanged in the $\mathrm{KO}$ cells. The fact that we were culturing this heterogeneous population of non-B cells in media designed to maintain differentiating B cells instead of population specific media might represent a stress for them leading to the upregulation of Grp170 or some population in the mixture may be responding to LPS and increasing Grp170 as a component of their differentiation process as is seen in plasmablasts. The reason for increased basal levels of Grp170 KO cells might represent a compensation in some population as we had hypothesized might occur in B cells but did not. The inability to observe a further increase in Grp170 expression in the KO cells was even less clear. Thus 


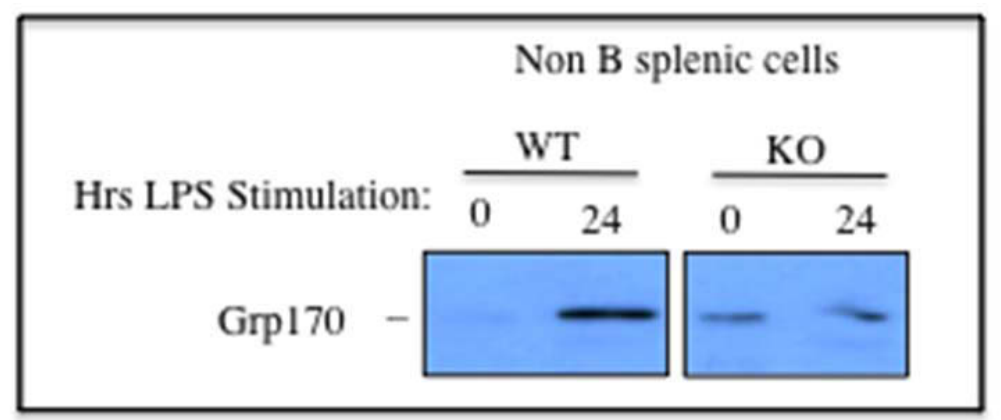

Figure 5-1. $\quad$ Sil1 Null Mice Have Higher Basal Levels of Grp170 Expression in a Heterogeneous Population of Non-B Cell Splenocytes That Is Not Further Upregulated in Culture. The remaining non B cell fraction of splenocytes from WT and Sill null mice were placed in culture under the same conditions as used for B cells. Cell lysates were prepared at day 0 and after 24 hours in culture and Grp170 expression was determined by western blotting.

further experiments are needed in which the various populations of cells are isolated and cultured with the appropriate growth factors. However, the expression of Grp170 in KO cells was non-inducible and therefore present at lower levels than WT after LPS stimulation. This heterogeneous population of cells was maintained in the same culture medium as the purified B cells and thus our result may be explained by stress induction due to nutrient deficiency of one or more of the different populations of non-B cells in the Sill KO spleen. Although these results are very interesting, they presently represent only an anecdotal story and we acknowledge that further examination of larger samples sizes is required for any strong conclusions. Regardless, this observation led us to perform an additional set of experiments.

To isolate individual spleen cell populations, we chose to positively sort cells using the same markers shown in Table 4-1 for purification, which in retrospect was not the best strategy. This experiment utilized pooled spleens from 3 WT and 3 Sill KO mice that were over 1 year of age, which was significantly older than mice used in any of our previous studies. Upon splenectomy of these aged mice, we immediately noticed that all $3 \mathrm{KO}$ mice had unusually large spleens, whereas all 3 WT mice appeared normal. Unfortunately, spleens were not weighed at this time, although Sil KO mice had spleens that were visibly 3-4 times larger than similarly aged WT mice. These spleens were pooled, a post-red cell single cell suspension was prepared and stained as indicated and samples were analyzed by FACS analysis and sorted. Figure 5-2 shows the result of this sorting experiment. On gross inspection, all expected populations of cells appeared to be present in the Sill KO spleens. Since we did not count the nucleated cells after red cell lysis, it is impossible to determine the absolute number of each of these cell types, but it appears likely that all are increased in the KO mice. Our original plan to culture each of these populations independently was prevented by the incredibly long period of time that it took to purify sufficient numbers of the individual populations which resulted in low 

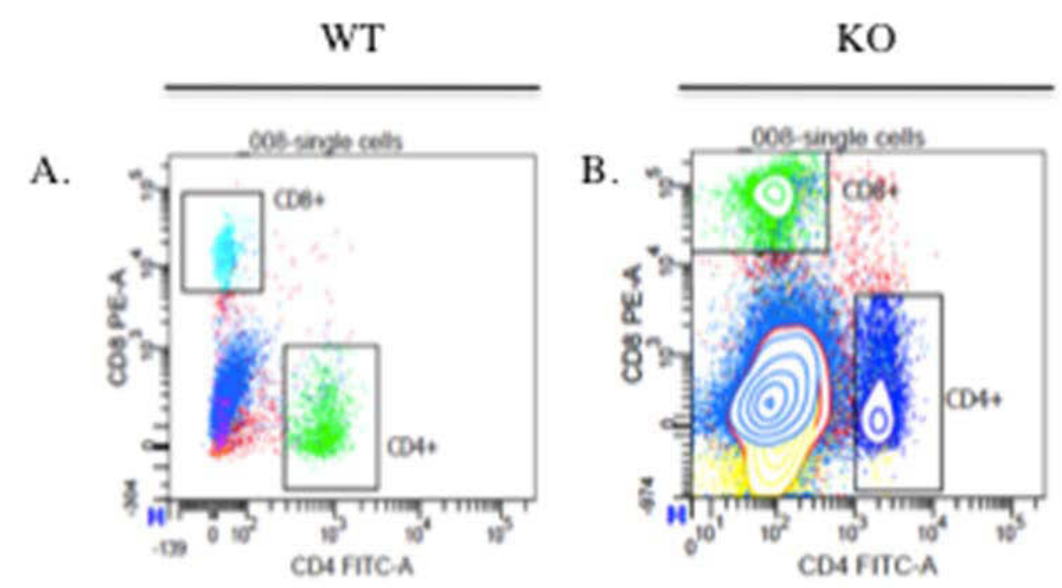

C.
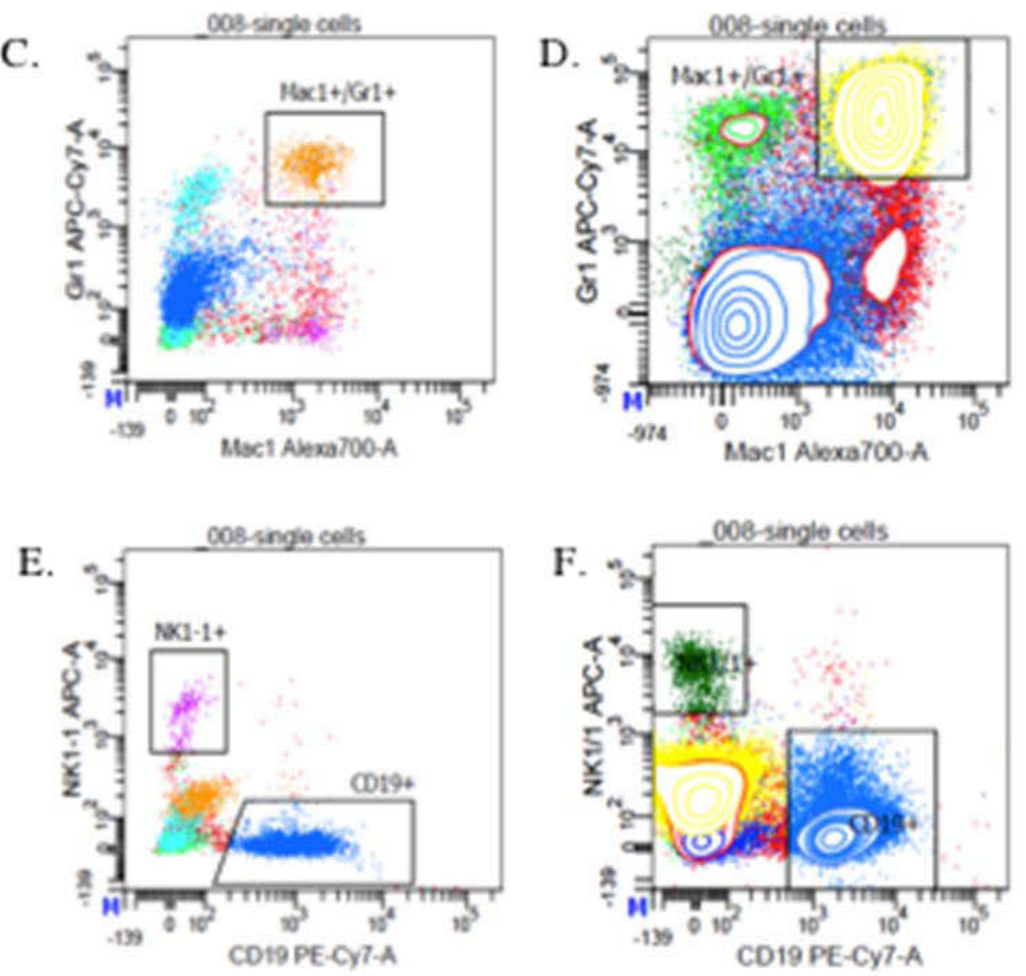

Figure 5-2. Identification of Splenic Cell Populations in Aged WT and Sil1 KO Mice. Spleens were removed from 3 WT and Sill KO mice, pooled and incubated in red cell lysis buffer and made into a single cell suspension. Cells were then stained with the indicated antibodies to identify indivual populations and subjected to FACS analysis. The $\mathrm{T}$ cell populations are indicated in panels $\mathrm{A}$ and $\mathrm{B}$, the macrophages and granulocytes in panels $\mathrm{C}$ and $\mathrm{D}$, and the NK cells in panels $\mathrm{E}$ and $\mathrm{F}$. This figure shows the analysis of $100 \times 10^{6} \mathrm{WT}$ cells and $200 \times 10^{6} \mathrm{KO}$ cells. 
viability after the stress of being sorted all day. This is a problem that can be overcome in future experiments by dividing the pooled spleen cells and performing negative sorting as was done to isolate the B cell fraction in Aim 2. This method will also have the added benefit of preventing any inadvertent stimulation of the individual populations.

Although we were unable to determine the exact count of individual populations it is very clear the ratio of cell types was highly skewed in the Sill KO spleen. We made the surprising discovery that the Mac1+/Gr1+ population accounted for $\sim 40 \%$ of total counted cells in $\mathrm{KO}$ whereas this same population only accounted for $\sim 8 \%$ of total counted cells in WT (Figure 5-3). This comparison becomes even more dramatic with the consideration that $\mathrm{KO}$ spleens were $\sim 3 \mathrm{x}$ times larger in addition to having a 5 -fold higher ratio of this population, which indicates a very large increase in total numbers of macrophage/granulocytes. Correspondingly, the relative percent of each of the other populations was decreased, although based on the increase in total spleen size it is likely that the actual numbers of these populations is also increased. B cells were still the predominate cell type in knockout spleens, and accounted for $\sim 45 \%$ of all splenocytes in these mice compared to the second-place Mac1+/Gr1+ population at $\sim 40 \%$. Helper T cells, cytotoxic $\mathrm{T}$ cells, and natural killer cells all had reduced percentages in $\mathrm{KO}$ mice at $8 \%, 7 \%$, and $1 \%$ compared to $14 \%, 12 \%$, and $2 \%$ in WT mice, respectively.

Since we were surprised by such a large shift in the proportion of Mac1+/Gr1+ cells, we reserved samples of WT and KO purified populations to examine by electron microscopy to determine if they exhibited any gross defects in cell morphology (Figure 5-4). We observed the presence of more multi-lobular nuclei that possess a higher number of dark spotted granules in the WT cells that are consistent with mature granulocytes. Although much more abundant compared to the corresponding WT population, the Sil1 KO Mac1+/Gr1+ cells showed a lower occurrence of multi-lobed nuclei and fewer granules, which suggests they represent a less differentiated precursor cell type, although an in-depth follow up study on a larger sample size will be required to conclude this.

As our mice continued to age we began to experience breeding problems with heterozygous pairs, which is normal to some degree in older mice but was earlier onset in our mice. In an attempt to increase our chances of successfully producing litters, we put more than usual breeding pairs together, including KO pairs. As a result, we had a few failed pregnancies with stillborn pups, but no successful births. This suggested to us that aged female Sill KO mice were still fertile and could become pregnant, but may have age-related complications that are problematic at some later stages of pregnancy, or possibly with the delivery process. One particular Sill null female (over 1 year of age, identification tags of older mice are often lost from chewing, fighting, or dermatitis, so only approximate age is known) was suspected to be pregnant, but was clearly overdue and well past the expected 21-day gestation period. We were advised by veterinary services to sacrifice the animal for necropsy since her health was severely compromised from this mysterious problem, which they suggested might actually be an abdominal tumor. 
CD8;

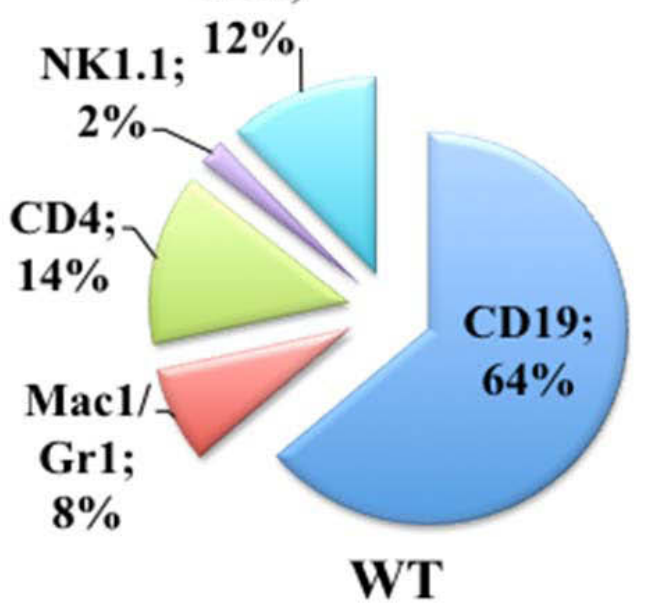

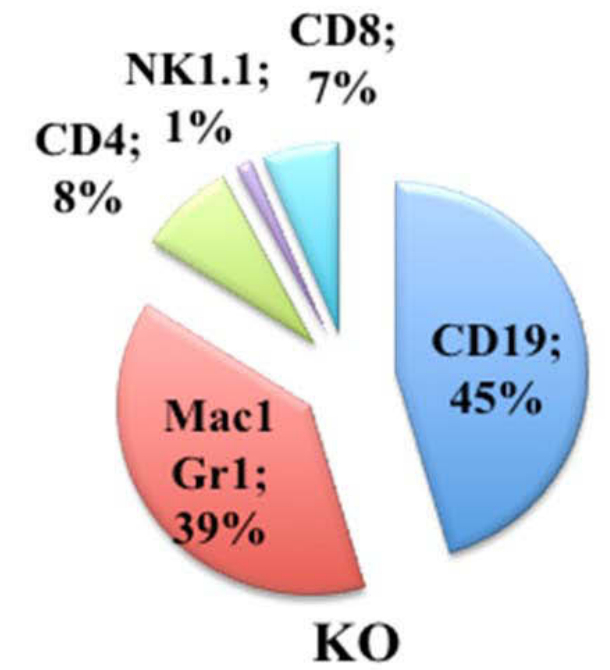

Figure 5-3. Distribution of Pooled Splenocytes from 3 WT and 3 Sil1 KO Aged Mice. Calculations based on flow cytometry analysis shown in figure 4-2 were made into pie charts to indicate the relative abundance of distinct populations within the spleen. It is important to note that even though this chart shows that percentages of some cell types are lower in the Sil1 KO (CD4, CD8, CD19, and NK1.1), the KO spleens were $\sim 3$-fold larger and so do not necessarily have few numbers of these cells even though the relative percentage of each type was lower. 
WT Macl+/Grl+

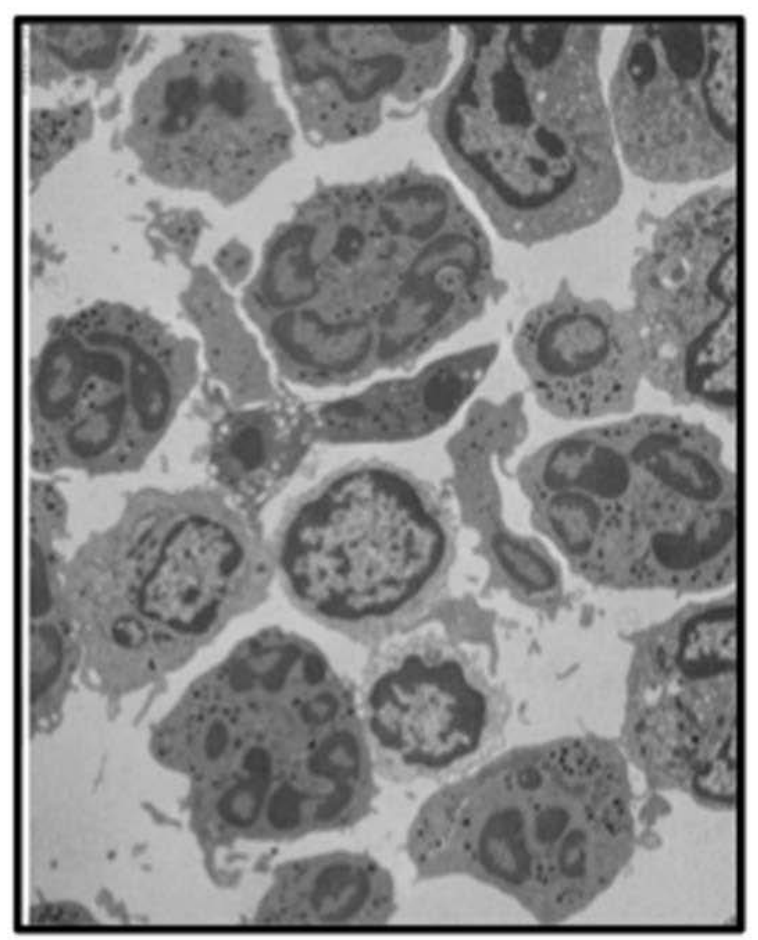

$\mathrm{KO} \mathrm{Macl}+/ \mathrm{Grl}+$

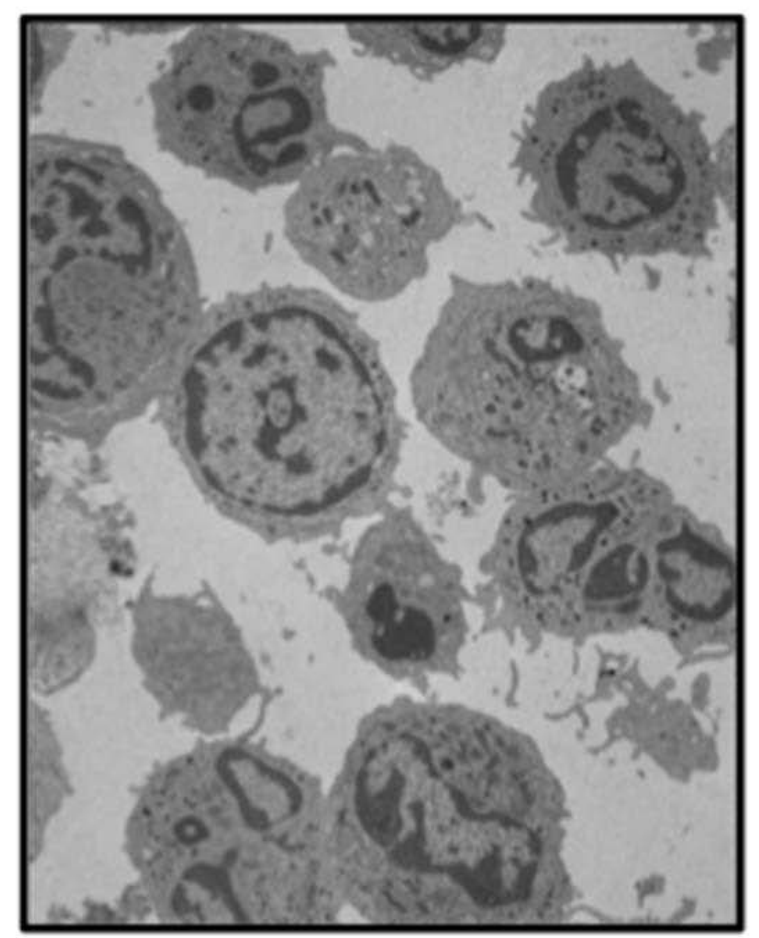

Figure 5-4. Electron Micrograph of Mac1+/Gr1+ Sorted Cells. Cells isolated by flow cytometry (Figure 4-2) were pelleted and delivered to the Cell and Tissue Imaging center at St Jude Children's Research Hospital where they were prepared for electron microscopy. 
Figure 5-5 shows the gross anatomy of this $\mathrm{KO}$ female and a similar aged WT female control. Upon necropsy, there were numerous pleiotropic pathologies in the KO female. Firstly, there were two large masses that distended each uterine horn to the point where surrounding tissues were difficult to identify. Culture analysis of these masses proved that they were not tumorogenic, but instead consisted of large infections of Pasteurella pneumotropica. Interestingly, this pathogen is known to be common in C57/B16 background mouse colonies such as ours, but infections are typically asymptomatic and rapidly dealt with in WT mice and usually only cause disease in immunodeficient mice. This particular aged KO female had an extremely large infection with symptoms that would likely have resulted in rapid death without intervention.

A complete autopsy was performed, which included a detailed review of 14 tissues, notable observations from this study are shown in Table 5-1. The autopsy revealed that this female had several retained fetuses in each uterine horn. The relationship between retained fetuses and infection is not clear at this time. This report confirmed the expected findings of cerebellar atrophy, Purkinje cell loss, and skeletal muscle pathologies expected in a Sill KO mouse, but also indicated abnormalities in the bone marrow, liver, lymph nodes, spleen and the uterus - none of which have been previously reported. It is likely that many of these lesions are directly or indirectly related to complications of the retained fetuses, but this conclusion is not clear. A possible explanation for the age-related pregnancy problems could be that progressive muscular atrophy and hypotonia may reduce the ability of aged females to successfully expel fetuses at full term, thus preventing delivery and causing them to be retained in the uterus.

There were also a number of visibly affected organs in the $\mathrm{KO}$ animal. Figure 5-6 shows examples from the spleen, thymus, and liver with their respective masses. Most notably, the spleen of this affected female was almost 10-fold larger than the WT control $(0.672 \mathrm{~g}$ vs $0.072 \mathrm{~g})$.

\section{Preliminary Conclusions and Future Direction}

In summary, studies with 3 aged Sil1 null mice revealed that they had spleens that were $\sim 3-4$ times larger than age-matched WT mice. This splenomegaly was partially due to an unusually large number of cells of the Mac1+/Gr1+ lineage. An in-depth necropsy was also performed on an additional aged female $\mathrm{KO}$ mouse, which at first appeared to be pregnant. Instead, this animal was found have a wildly out-of-control infection by a pathogen that is easily controlled by normal immune responses of WT mice and is known to be symptomatic primarily in immunodeficient animals. In addition to the previously discussed splenomegaly, severe infection, mummified fetuses, and apparent reproductive defect, this female also exhibited a number of other pleiotropic defects that have not been reported in a range of Sill KO tissues. Our pathology report shows additional abnormalities in bone marrow, liver, lymph nodes, and pancreas. We also have another preliminary pathology report that supports the aforementioned pleiotropic observations (Table 5-2) and also shows new findings that solicit further investigation. Although it is 

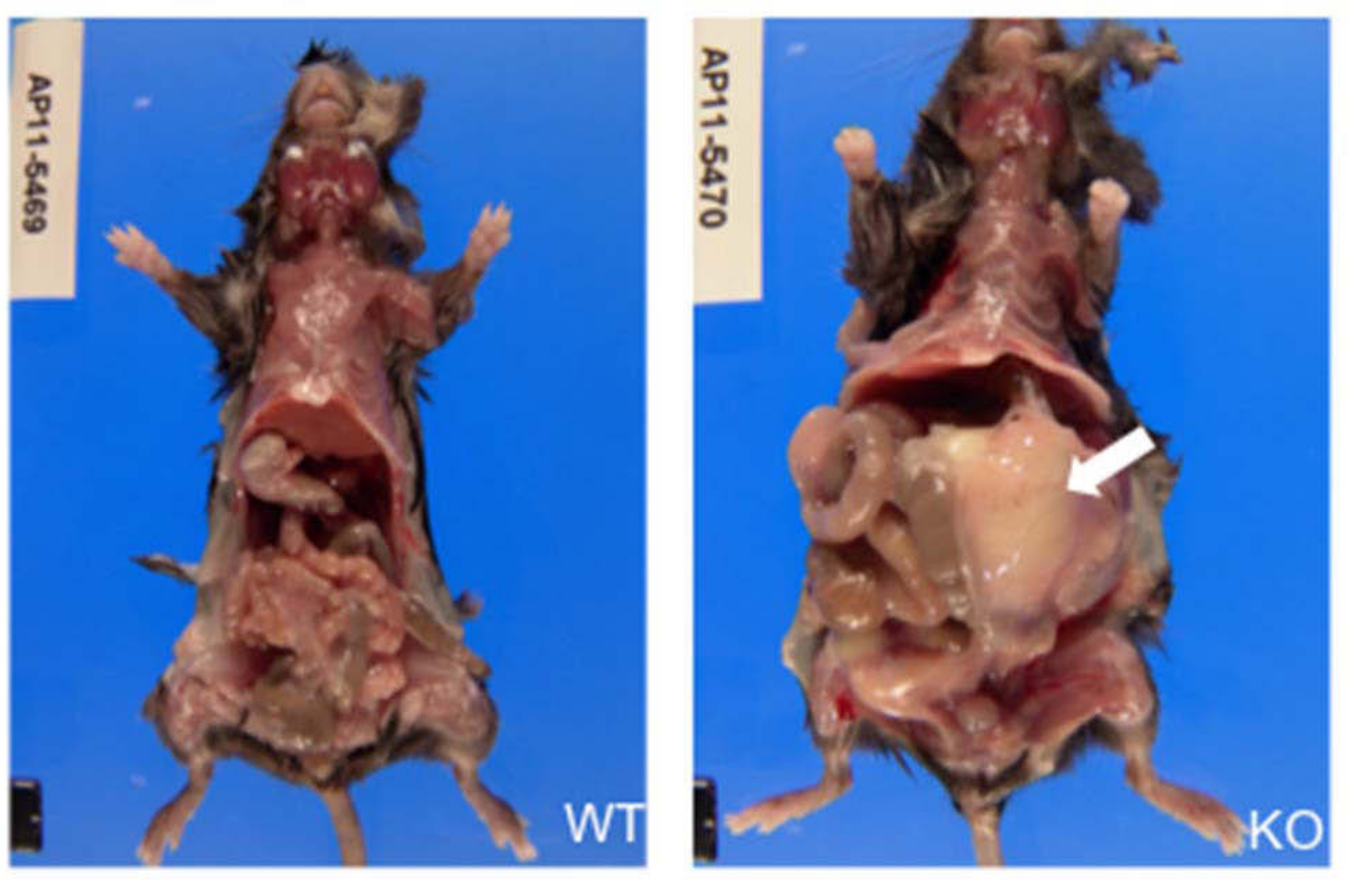

Figure 5-5. Gross Anatomical Comparison of Aged WT Female vs. Sil1 KO Female with Retained Mummified Fetuses and Large Pasteurella pneumotropica Infection. The KO mouse on the right was observed pregnant but sacrificed for animal welfare concerns after carrying past term for an indefinite period of time. This animal was then immediately submitted for necropsy with an age-matched WT control. Although only one mass is visible in this photo (white arrow) there was also a similarly sized mass in the corresponding contralateral uterine horn. 
Table 5-1. Pleiotropic Effects in Sil1 KO.

\begin{tabular}{lll}
\hline Tissue Type & \multicolumn{1}{c}{ Findings } & Extent \\
\hline Bone Marrow & Hyperplasia, granulocytosis, diffuse & Severe \\
Cerebellum & Hypoplasia, Purkinje cell loss, diffuse & Severe \\
Liver & Granulocytopoiesis, multifocal & Moderate \\
Liver (capsule) & Inflammation, chronic-active, diffuse & Mild \\
Lymph nodes & Plasmacytosis, diffuse & Moderate \\
Pancreas & Inflammation, peritoneal, chronic, diffuse & Marked \\
Skeletal muscle & Atrophy, diffuse & Moderate \\
Spleen & Granulocytopoiesis, plasmacytopoiesis, diffuse & Marked \\
Uterus & Mummified fetuses, bilateral, necrosis, abscess & Severe \\
\hline
\end{tabular}

Organ Size
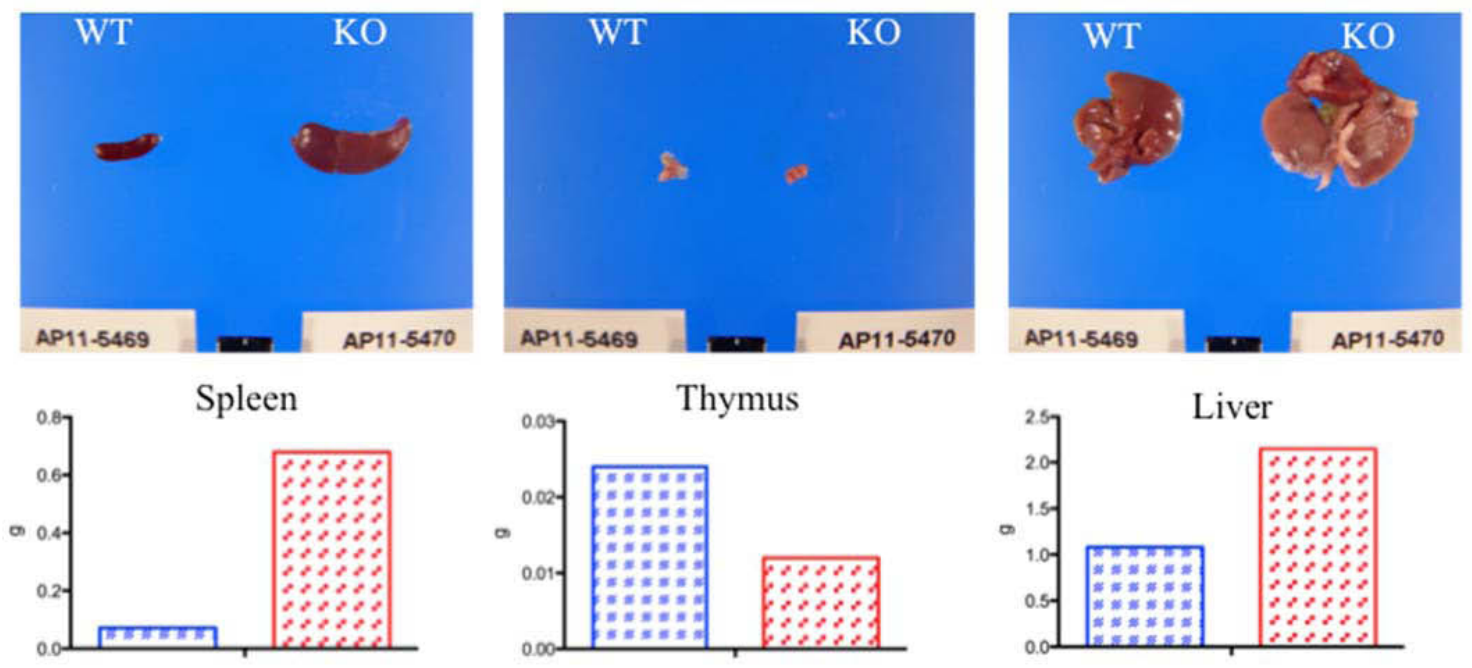

Figure 5-6. Size Comparison of Organs in WT vs. Sil1 Null Mouse with Mummified Fetuses and Pasteurella pneumotropica Infection. Images were taken immediately post mortem during necropsy. Graphs below show the mass of WT (blue) vs. KO (red) indicated organs. 
Table 5-2. Additional Phenotypes of Aged Wil1 KO Mice.

\begin{tabular}{|c|c|c|c|c|c|c|c|}
\hline $\begin{array}{c}\text { Mouse } \\
\text { ID }\end{array}$ & $\begin{array}{c}\text { Stomach } \\
\text { and Colon }\end{array}$ & $\begin{array}{l}\text { Pancreas Islets } \\
\text { of Langerhans }\end{array}$ & Cerebellum & $\begin{array}{c}\text { Skeletal } \\
\text { Muscle }\end{array}$ & Bone Marrow & Blood & $\begin{array}{c}\text { Adipose } \\
\text { Tissue }\end{array}$ \\
\hline $\begin{array}{l}\text { KO } \\
466\end{array}$ & $\begin{array}{l}\text { Edema, } \\
\text { submucosal, } \\
\text { diffuse, } \\
\text { moderate }\end{array}$ & $\begin{array}{l}\text { Vaculization, } \\
\text { perinuclear, } \\
\text { diffuse, } \\
\text { moderate }\end{array}$ & $\begin{array}{l}\text { Hypoplasia w/ } \\
\text { Purkinje cell } \\
\text { loss, diffuse, } \\
\text { severe }\end{array}$ & $\begin{array}{l}\text { Nuclear } \\
\text { centralization } \\
\text { and atrophy, } \\
\text { multifocal, } \\
\text { mild to } \\
\text { moderate }\end{array}$ & $\begin{array}{l}\text { Granulocytosis } \\
\text { (eosinophils), } \\
\text { diffuse, } \\
\text { moserate }\end{array}$ & $\begin{array}{l}\text { Reticulocytosis } \\
\text { mild }\end{array}$ & N/A \\
\hline $\begin{array}{l}\mathrm{KO} \\
514\end{array}$ & As above & As above & As above & As above & As above & As above & $\mathrm{N} / \mathrm{A}$ \\
\hline $\begin{array}{l}\mathrm{KO} \\
515\end{array}$ & As above & As above & As above & As above & As above & As above & $\begin{array}{l}\text { Fibrosis, } \\
\text { nodular, } \\
\text { multifocal, } \\
\text { moderate with } \\
\text { chronic } \\
\text { lymphogranul } \\
\text { o-matous } \\
\text { inflammation } \\
\text { and large } \\
\text { unilocular } \\
\text { lipid depots }\end{array}$ \\
\hline
\end{tabular}


possible that many of the lesions observed in the aged female $\mathrm{KO}$ mouse were directly or indirectly related to complications of the retained fetuses, our data from the 3 aged KO mice with splenomegaly suggest that broad systemic defects in the woozy mouse are likely the result of Sill loss. None of these phenotypes have been investigated in the Sill KO model before; however, our observations are not entirely surprising in light of the spectrum of reported pathologies of patients with Marinesco Sjögren's Syndrome and the fact that the only detailed studies of Sill KO mice have focused primarily on their striking neurodegenerative phenotype. Furthermore, considering the huge repertoire of $\mathrm{BiP}$ substrates, it is reasonable to hypothesize that a protein maturation deficiency resulting from loss of a nucleotide exchange factor could be a major problem in a wide range of tissues. Additional studies on Grp170 will also be helpful in understanding these phenomena, it will be particularly interesting to see if those tissues most affected by Sill loss in Marinesco Sjögren's Syndrome, and now in the woozy mouse, are those with lower Grp170 levels. We are currently taking steps to investigate this possibility by northern blotting.

In addition, we also ordered a blood pathology report from each of these mice to identify any differences in cell type, numbers, and percentages as shown in Figures 5-7 and 5-8. We observed a 4-fold higher number of total white blood cells in the KO animal (elevated numbers are to be expected during infection). Interestingly, the percentage of neutrophils and lymphocytes was switched in the two animals at approximately 80/20\% in $\mathrm{KO}$ and $20 / 80 \%$ in WT. Furthermore, there were only small differences in red blood cells, hemoglobin levels, and hematocrit percentage in these animals as shown in Figure 5-7B.

In the future, we are particularly interested to investigate the possibility that Sill null mice may become immunodeficient with age, for several reasons. Firstly, because we did not notice observe any problems in young Sill KO mice (other than slightly decreased levels of total IgM in serum), secondly because of the Pasteurella infection in the female with retained mummified fetuses (which generally only occurs in immune compromised mice), and lastly because the 3 aged $\mathrm{KO}$ mice we identified with splenomegaly were maintained in separate cages. Together, these observations suggest that our findings were not the result of single random events but in fact, due to Sill loss. We plan to begin a set of experiments to challenge these mice with pathogen to investigate their immunocompetence and simultaneously monitor long-term splenic growth by high-frequency ultrasound. We also plan to investigate aggregation tendencies and degradation processes in Sil1 KO cells from these animals, since it should be expected that any Sill related pathologies are related to decreased levels of free BiP or problems with substrate maturation and protein misfolding. This could lead to increasing levels of aggregate formation over time and thus result in presentation of symptoms upon aging. Currently, we are beginning a set of immunohistochemistry experiments to look at the ubiquitin staining patterns of various tissues from the $\mathrm{KO}$ mice referenced in Tables 5-1 and 5-2 that will provide some insight into this hypothesis. 
White blood cells, Neutrophils, Lymphocytes Monocytes, Eosinophils, Basophils
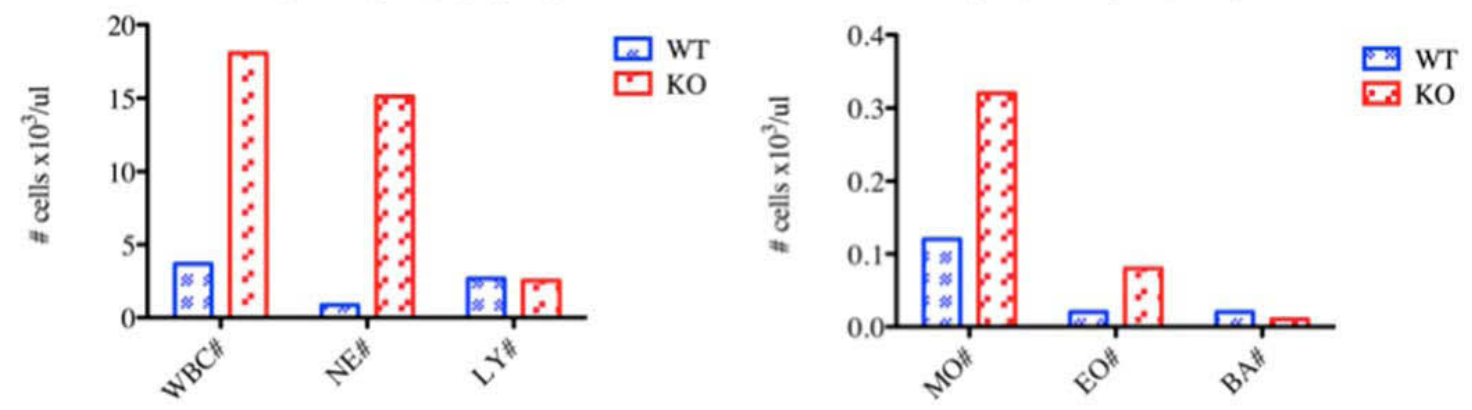

White blood cells, Neutrophils, Lymphocytes Monocytes, Eosinophils, Basophils
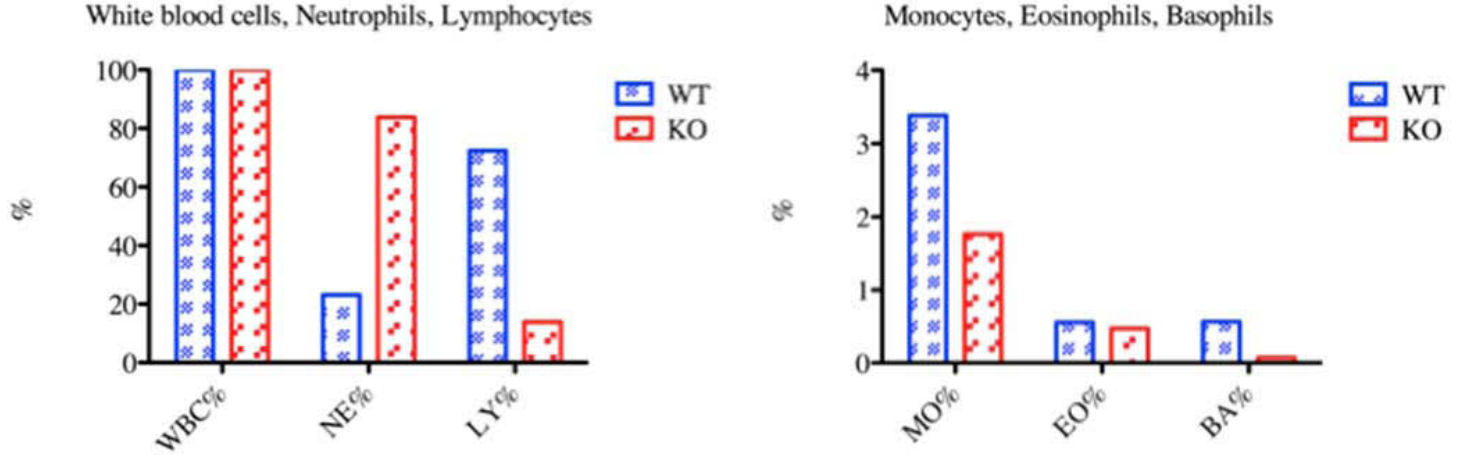

Figure 5-7. Number and Relative Percentages of Non-Red Cells Present in Blood of Aged Matched WT Control and Sil1 KO Female with Retained Mummified Fetuses and Large Pasteurella pneumotropica Infection. Whole blood samples from mice shown in Figure 5-5 were submitted to the veterinary pathology department of St Jude Children's Research Hospital for analysis immediately post-mortem as part of a complete autopsy to quantify total numbers (top) and relative percentages (bottom) of white blood cells (WBC), neutrophils (NE), lymphocytes (LY), monocytes (MO), eosinophils (EO), and basophils (BA). (Note: each graph has a distinct scale on the Y-axis). 

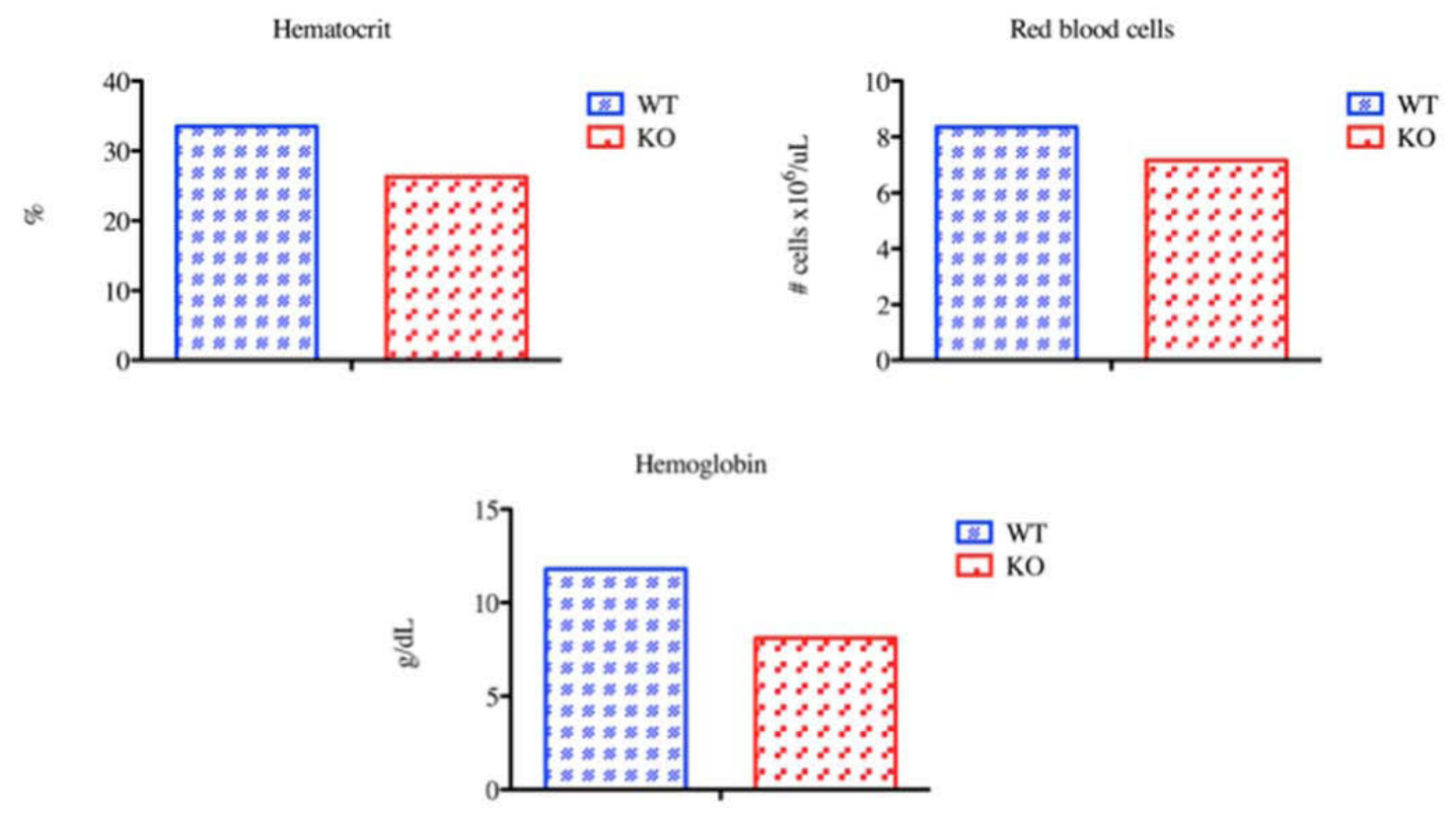

Figure 5-8. Quantitation of Hematocrit, Red Blood Cells, and Hemoglobin in Blood of Aged Matched WT Control and Sil1 KO Female with Retained Mummified Fetuses and Large Pasteurella pneumotropica Infection. Whole blood samples from mice shown in Figure 5-5 were submitted to the veterinary pathology department of St Jude Children's Research Hospital for analysis immediately post-mortem as part of a complete autopsy to quantify hematocrit $\%$, number of red blood cells, and hemoglobin concentration. 


\section{LIST OF REFERENCES}

1. Groombridge, B. and M. Jenkins, World atlas of biodiversity : earth's living resources in the 21st century2002, Berkeley, Calif. London: University of California Press. xii, $340 \mathrm{p}$.

2. Anfinsen, C.B., Principles that govern the folding of protein chains. Science, 1973. 181(4096): p. 223-30.

3. Brocchieri, L. and S. Karlin, Protein length in eukaryotic and prokaryotic proteomes. Nucleic Acids Res, 2005. 33(10): p. 3390-400.

4. Laskey, R.A., et al., Nucleosomes are assembled by an acidic protein which binds histones and transfers them to DNA. Nature, 1978. 275(5679): p. 416-20.

5. Hartl, F.U., A. Bracher, and M. Hayer-Hartl, Molecular chaperones in protein folding and proteostasis. Nature, 2011. 475(7356): p. 324-32.

6. Ritossa, F., Discovery of the heat shock response. Cell Stress Chaperones, 1996. 1(2): p. 97-8.

7. Morimoto, R.I., Cells in stress: transcriptional activation of heat shock genes. Science, 1993. 259(5100): p. 1409-10.

8. Kéri, G.r. and I.n. Tóth, Molecular pathomechanisms and new trends in drug research2003, London; New York: Taylor \& Francis. xiv, 635 p.

9. Kampinga, H.H., et al., Guidelines for the nomenclature of the human heat shock proteins. Cell Stress Chaperones, 2009. 14(1): p. 105-11.

10. Gupta, R.S., Evolution of the chaperonin families (Hsp60, Hsp10 and Tcp-1) of proteins and the origin of eukaryotic cells. Mol Microbiol, 1995. 15(1): p. 1-11.

11. Reissmann, S., et al., Essential function of the built-in lid in the allosteric regulation of eukaryotic and archaeal chaperonins. Nat Struct Mol Biol, 2007. 14(5): p. 432-40.

12. Hartl, F.U. and M. Hayer-Hartl, Converging concepts of protein folding in vitro and in vivo. Nat Struct Mol Biol, 2009. 16(6): p. 574-81.

13. Tanaka, N. and H. Nakamoto, HtpG is essential for the thermal stress management in cyanobacteria. FEBS Lett, 1999. 458(2): p. 117-23.

14. Echeverria, P.C., et al., An interaction network predicted from public data as a discovery tool: application to the Hsp90 molecular chaperone machine. PLoS One, 2011. 6(10): p. e26044.

15. Wandinger, S.K., K. Richter, and J. Buchner, The Hsp90 chaperone machinery. J Biol Chem, 2008. 283(27): p. 18473-7.

16. Kampinga, H.H. and E.A. Craig, The HSP70 chaperone machinery: J proteins as drivers of functional specificity. Nat Rev Mol Cell Biol, 2010. 11(8): p. 579-92.

17. Haas, I.G. and M. Wabl, Immunoglobulin heavy chain binding protein. Nature, 1983. 306(5941): p. 387-9.

18. Ellgaard, L. and A. Helenius, Quality control in the endoplasmic reticulum. Nat Rev Mol Cell Biol, 2003. 4(3): p. 181-91.

19. Hibi, T. and H.M. Dosch, Limiting dilution analysis of the $B$ cell compartment in human bone marrow. Eur J Immunol, 1986. 16(2): p. 139-45. 
20. Bole, D.G., L.M. Hendershot, and J.F. Kearney, Posttranslational association of immunoglobulin heavy chain binding protein with nascent heavy chains in nonsecreting and secreting hybridomas. J Cell Biol, 1986. 102(5): p. 1558-66.

21. Kitao, Y., et al., Expression of the endoplasmic reticulum molecular chaperone (ORP150) rescues hippocampal neurons from glutamate toxicity. J Clin Invest, 2001. 108(10): p. 1439-50.

22. Wei, J. and L.M. Hendershot, Characterization of the nucleotide binding properties and ATPase activity of recombinant hamster BiP purified from bacteria. J Biol Chem, 1995. 270(44): p. 26670-6.

23. Wei, J., J.R. Gaut, and L.M. Hendershot, In vitro dissociation of BiP-peptide complexes requires a conformational change in BiP after ATP binding but does not require ATP hydrolysis. J Biol Chem, 1995. 270(44): p. 26677-82.

24. Liberek, K., et al., Escherichia coli DnaJ and GrpE heat shock proteins jointly stimulate ATPase activity of DnaK. Proc Natl Acad Sci U S A, 1991. 88(7): p. 2874-8.

25. Henics, T., et al., Mammalian Hsp70 and Hsp110 proteins bind to RNA motifs involved in mRNA stability. J Biol Chem, 1999. 274(24): p. 17318-24.

26. Dragovic, Z., et al., Molecular chaperones of the Hspl10 family act as nucleotide exchange factors of Hsp70s. EMBO J, 2006. 25(11): p. 2519-28.

27. de Keyzer, J., et al., Nucleotide binding by Lhs1p is essential for its nucleotide exchange activity and for function in vivo. J Biol Chem, 2009. 284(46): p. 3156471.

28. Easton, D.P., Y. Kaneko, and J.R. Subjeck, The hsp110 and Grp1 70 stress proteins: newly recognized relatives of the Hsp70s. Cell Stress Chaperones, 2000. 5(4): p. 276-90.

29. Gao, P., et al., Secretion of stress protein grp170 promotes immune-mediated inhibition of murine prostate tumor. Cancer Immunol Immunother, 2009. 58(8): p. 1319-28.

30. Saito, H., Y. Nakamura, and H. Uchida, A transducing lambda phage carrying grpE, a bacterial gene necessary for lambda DNA replication, and two ribosomal protein genes, rpsP (S16) and rplS (L19). Mol Gen Genet, 1978. 165(3): p. 24756.

31. Kabani, M., J.M. Beckerich, and C. Gaillardin, Sls1p stimulates Sec63p-mediated activation of Kar2p in a conformation-dependent manner in the yeast endoplasmic reticulum. Mol Cell Biol, 2000. 20(18): p. 6923-34.

32. Tyson, J.R. and C.J. Stirling, LHS1 and SIL1 provide a lumenal function that is essential for protein translocation into the endoplasmic reticulum. EMBO J, 2000. 19(23): p. 6440-52.

33. Chung, K.T., Y. Shen, and L.M. Hendershot, BAP, a mammalian BiP-associated protein, is a nucleotide exchange factor that regulates the ATPase activity of BiP. J Biol Chem, 2002. 277(49): p. 47557-63.

34. Craven, R.A., M. Egerton, and C.J. Stirling, A novel Hsp70 of the yeast ER lumen is required for the efficient translocation of a number of protein precursors. EMBO J, 1996. 15(11): p. 2640-50. 
35. Lin, H.Y., et al., The 170-kDa glucose-regulated stress protein is an endoplasmic reticulum protein that binds immunoglobulin. Mol Biol Cell, 1993. 4(11): p. 1109-19.

36. Steel, G.J., et al., Coordinated activation of Hsp 70 chaperones. Science, 2004. 303(5654): p. 98-101.

37. Brocchieri, L., E. Conway de Macario, and A.J. Macario, hsp70 genes in the human genome: Conservation and differentiation patterns predict a wide array of overlapping and specialized functions. BMC Evol Biol, 2008. 8: p. 19.

38. Kitao, Y., et al., ORP150/HSP12A regulates Purkinje cell survival: a role for endoplasmic reticulum stress in cerebellar development. J Neurosci, 2004. 24(6): p. 1486-96.

39. Andreasson, C., et al., The endoplasmic reticulum Grp170 acts as a nucleotide exchange factor of Hsp70 via a mechanism similar to that of the cytosolic Hsp110. J Biol Chem, 2010. 285(16): p. 12445-53.

40. Howes, J., et al., C-terminal Mutations Destabilize SIL1/BAP and Can Cause Marinesco-Sjogren Syndrome. J Biol Chem, 2012. 287(11): p. 8552-60.

41. Anttonen, A.K., et al., The gene disrupted in Marinesco-Sjogren syndrome encodes SIL1, an HSPA5 cochaperone. Nat Genet, 2005. 37(12): p. 1309-11.

42. Yan, M., J. Li, and B. Sha, Structural analysis of the Sill-Bip complex reveals the mechanism for Sill to function as a nucleotide-exchange factor. Biochem J, 2011. 438(3): p. 447-55.

43. Anttonen, A.K. and A.E. Lehesjoki, Marinesco-Sjogren Syndrome, in GeneReviews, R.A. Pagon, et al., Editors. 1993: Seattle (WA).

44. Senderek, J., et al., Mutations in SIL1 cause Marinesco-Sjogren syndrome, a cerebellar ataxia with cataract and myopathy. Nat Genet, 2005. 37(12): p. 13124.

45. Lagier-Tourenne, C., et al., Homozygosity mapping of Marinesco-Sjogren syndrome to 5q31. Eur J Hum Genet, 2003. 11(10): p. 770-8.

46. Zhao, L., et al., Protein accumulation and neurodegeneration in the woozy mutant mouse is caused by disruption of SIL1, a cochaperone of BiP. Nat Genet, 2005. 37(9): p. 974-9.

47. Anttonen, Anna-Kaisa "The Molecular Basis of Marinesco-Sjogren Syndrome." Academic Dissertation, Helsinki Biomedical Graduate School, 2008

48. van Anken, E., et al., Efficient IgM assembly and secretion require the plasma cell induced endoplasmic reticulum protein $p E R p 1$. Proc Natl Acad Sci U S A, 2009. 106(40): p. 17019-24.

49. Ma, Y., et al., Plasma cell differentiation initiates a limited ER stress response by specifically suppressing the PERK-dependent branch of the unfolded protein response. Cell Stress Chaperones, 2010. 15(3): p. 281-93.

50. Feige, M.J., et al., An unfolded CH1 domain controls the assembly and secretion of IgG antibodies. Mol Cell, 2009. 34(5): p. 569-79. 


\section{VITA}

Tyler Sanford was born in Jessieville, Arkansas in 1985. He graduated from Jessieville High School in 2003 and went on to earn a Bachelor of Science degree in biology, chemistry and Christian studies from Ouachita Baptist University in 2008. In 2012 he completed his Master of Science degree in cancer and developmental biology at the University of Tennessee Health Science Center. The research for his thesis was done in Dr. Linda Hendershot's lab as part of the tumor cell biology department at St. Jude Children's Research Hospital in Memphis, TN. 